\title{
ECAR-5067 Computational Evaluation on Effect of Edge-rounding in Circular to Annular Flow Transitions within a Hexagonal Duct
}

\author{
SuJong Yoon \\ December 2020
}

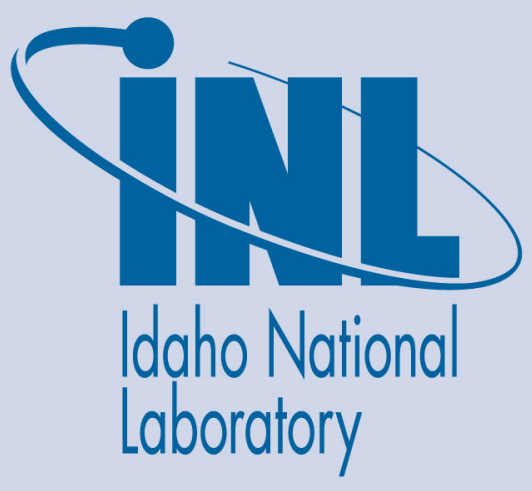

The INL is a U.S. Department of Energy National Laboratory operated by Battelle Energy Alliance 


\title{
ECAR-5067 Computational Evaluation on Effect of Edge-rounding in Circular to Annular Flow Transitions within a Hexagonal Duct
}

\author{
SuJong Yoon
}

December 2020

Idaho National Laboratory Idaho Falls, Idaho 83415

http://www.inl.gov

Prepared for the U.S. Department of Energy National Nuclear Security Administration Under DOE Idaho Operations Office Contract DE-AC07-05ID14517 
Computational Evaluation on Effect of Edge-rounding in Circular to Annular Flow

Title: $\quad$ Transitions within a Hexagonal Duct

$\begin{array}{lllll}\text { ECAR No.: } 5067 & \text { Rev. No.: } & 0 & \text { Project No.: } 32833 & \text { Date: } T B D\end{array}$

1. VTR Consequence Level [VTR CL DESIGNATION; [3]

2. Objective/Purpose:

The pressure loss of the fuel rod bundle is an important parameter that can directly affect the primary pump specification, the flow distribution and the safety behavior of the core. The pressure loss of the fuel rod bundle mainly occurs at the inlet module and the fuel region. There are several empirical correlations for the wire-wrapped fuel region whereas the inlet module still remains to be studied. Since the local pressure loss is dominant in the inlet module, the effect of internal structures in the inlet module on the pressure loss needs to be investigated. For instance, the edge rounding-off of internal geometry could reduce the form loss in the inlet module effectively. The computational fluid dynamics (CFD) analysis of the internal flow with varying cross-section from circle to annulus was carried out focusing on the effect of edge-rounding of the internal structure.

3. If revision, please state the reason and list sections and/or pages being affected: Initial Release

4. Conclusions/Recommendations (Note: Clearly state any actions or additional reviews that were identified within the body of the report):

In this ECAR, the computational fluid dynamics (CFD) simulation of the duct with a crosssection varying from circle to annulus was performed to evaluate the effect of edge-rounding of the internal edges. The edge of circular channel and the edge of inner annular channel were rounded with the radius of curvature ranged from $0 \mathrm{~mm}$ to $20 \mathrm{~mm}$. The CFD results show that the pressure loss of the duct can be reduced by increasing the radius of the rounded edge. Case-A results showed that the pressure drop can be significantly reduced by the edge-rounding, e.g., the pressure drop was reduced approximately $56 \%$ by the radius of curvature of $5.0 \mathrm{~mm}$, and reduced $70 \%$ by the radius of curvature of $20.0 \mathrm{~mm}$ although its effectiveness would be attenuated as the radius of curvature of edge increases. Results from Case-B showed the impact of rounding the inlet edge was practically negligible compared to the outlet edge. This ECAR could provide a guideline to determine the optimum inlet module design of the VTR fuel rod bundle. 


\section{Computational Evaluation on Effect of Edge-rounding in Circular to Annular Flow}

Title: $\quad$ Transitions within a Hexagonal Duct

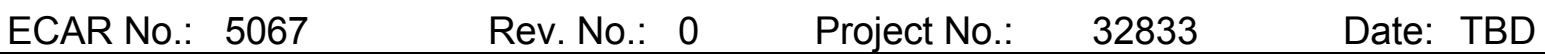

\section{CONTENTS}

ECAR Approvals

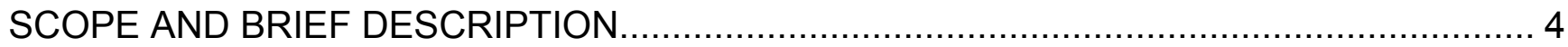

DESIGN OR TECHNICAL PARAMETER INPUT AND SOURCES.................................... 4

RESULTS OF LITERATURE SEARCHES AND OTHER BACKGROUND DATA $\ldots \ldots \ldots \ldots \ldots \ldots . . . . . . . .4$

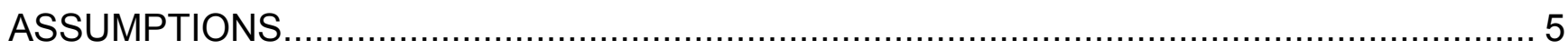

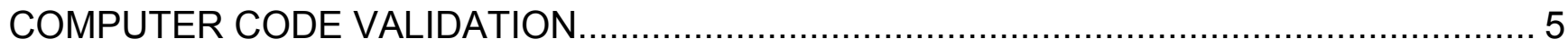

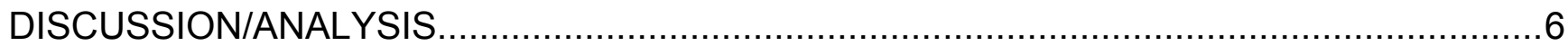

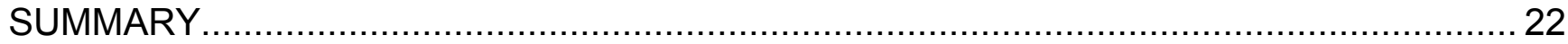

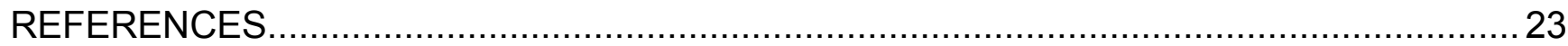

\section{APPENDIXES}

Appendix A. MESH STRUCTURE OF STAR-CCM+ MODEL Appendix B. THE STAR-CCM+ PRESSURE DROP RESULTS Appendix C. NEK5000 AVERAGED VELOCITY AND PRESSURE DISTRIBUTIONS 


\section{Computational Evaluation on Effect of Edge-rounding in Circular to Annular Flow}

Title: $\quad$ Transitions within a Hexagonal Duct

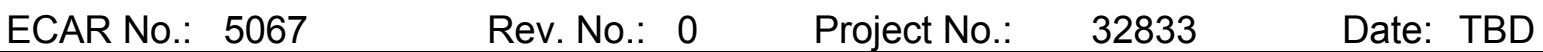

\section{ECAR Approvals}

\begin{tabular}{|c|c|c|c|}
\hline Project Role & Name (Printed) & Signature & Date \\
\hline Performer & S. Yoon, D. Shaver & & \\
\hline Checker $^{a}$ & F. Heidet & & \\
\hline Independent Reviewer ${ }^{b}$ & $\mathrm{~N} / \mathrm{A}$ & $\mathrm{N} / \mathrm{A}$ & - \\
\hline VTR Nuclear Safetyc & J. Andrus & & \\
\hline CUI Reviewer & TBD & & \\
\hline $\begin{array}{l}\text { VTR Integration } \\
\text { Principale }\end{array}$ & J. Roglans-Ribas & & \\
\hline VTR Program Manager ${ }^{f}$ & Adrian Collins & & \\
\hline VTR Exec Director ${ }^{9}$ & K. Pasamehmetoglu & $\mathrm{N} / \mathrm{A}$ & - \\
\hline
\end{tabular}

\section{Responsibilities}

The program manager has the ultimate responsibility and authority to determine required reviews and approvals in this section and may deviate from the guidance in the Responsibilities section. In most cases the following guidance will be used to determine required reviews and approvals, and scope of the review.

a. Required for VTR Consequence Levels 1, 2, and 3: Confirmation of completeness, references used, compliance to engineering inputs, appropriateness of assumptions, mathematical accuracy, correctness of calculated data employing, as appropriate, different or independent analytical methods from the ones used to produce the original engineering deliverable, and validity of conclusions and recommendations. Must not check own work.

b. Required for VTR Consequence Levels 1 and 2: Concurrence of method or approach, validity of assumptions, and compliance to input requirements of both performer and checker output. Must not check own work.

c. Required for all VTR consequence levels: Concurrence with VTR Nuclear Safety approach, and that the content is consistent with all applicable safety bases. Contributing to ECAR that is reviewed is acceptable.

d. Required for all VTR consequence levels: Concurrence with the document's markings in accordance with LWP-11202.

e. Required for all VTR consequence levels: Concurrence indicates that competent individuals performed and checked the ECAR and that this ECAR represents the appropriate inputs, methods, and approach, that outputs and recommendations are clear and understandable and represent the appropriate outcome for the program including compliance with design basis. Contributing to ECAR that is reviewed is acceptable.

f. Required for all VTR consequence levels: Owner concurrence indicates that the document content is appropriate for program use, that appropriate reviews have been completed; signature accepts the document for program use UNLESS VTR executive director signature is not NA'ed.

g. Required as determined by VTR program manager for when deliverable has potential significant impact to the VTR Program or is of external interest: Executive director concurrence indicates the document content is appropriate and accepts the document for program use.

NOTE: VTR Consequence Levels are found in SP-60.2.1.1, "VTR Program Documents," Appendix A. 
Computational Evaluation on Effect of Edge-rounding in Circular to Annular Flow

Title: $\quad$ Transitions within a Hexagonal Duct

$\begin{array}{llllll}\text { ECAR No.: } 5067 & \text { Rev. No.: } & 0 & \text { Project No.: } & 32833 & \text { Date: } T B D\end{array}$

\section{SCOPE AND BRIEF DESCRIPTION}

The pressure loss of the fuel rod bundle is an important parameter that can directly affects the primary pump specification, the flow distribution and the safety behavior of the core. The pressure loss of the fuel rod bundle mainly occurs at the inlet module and the fuel region. There are several empirical correlations ( [1], [2], [3] [4] and [5]) for the wire-wrapped fuel region, but the inlet module still remains to be studied. Since the form loss is dominant in the inlet module, the effect of internal geometries in the inlet module on the pressure loss needs to be investigated. For instance, the edge rounding-off of internal geometry could reduce the form loss in the inlet module effectively. Since the form loss in the inlet module is geometry-dependent and difficult to be evaluated by simple methods using hydraulic (equivalent) diameter, the experiment or computational method is required.

This ECAR aims at evaluating the effect of edge-rounding in the duct with cross-section varying from circle to annulus on the pressure loss to provide a useful guideline for design optimization of the VTR fuel rod bundle.

\section{DESIGN OR TECHNICAL PARAMETER INPUT AND SOURCES}

Relevant information is provided throughout the discussion and analysis section of this document.

\section{RESULTS OF LITERATURE SEARCHES AND OTHER BACKGROUND DATA}

Ref. [6] provides the formulas for the abrupt expansion and contraction pressure losses derived by processing the experimental results. The total resistance coefficient $(\zeta)$ through abrupt expansion

downstream of circular tube with uniform velocity distribution $\left(\geq 3.3 \times 10^{3}\right)$ is given as follows: 
Title: $\quad$ Transitions within a Hexagonal Duct

ECAR No.: 5067

Rev. No.: 0

Project No::

32833

Date: TBD

where is the local resistance coefficient, is the friction coefficient, $\lambda$ is the frictional resistance coefficient,

$\Delta p$ is the pressure drop through the channel $(\mathrm{Pa}), \rho$ is the fluid density $\left(\mathrm{kg} / \mathrm{m}^{3}\right), n_{\text {ar }}$ is the cross-sectional area ratio $\left(=F_{2} / F_{0}\right), w_{0}$ is the upstream velocity $(\mathrm{m} / \mathrm{s}), w_{2}$ is the downstream velocity $(\mathrm{m} / \mathrm{s}), F_{0}$ is the crosssectional area of upstream channel $\left(\mathrm{m}^{2}\right), F_{2}$ is the cross-sectional area of downstream channel $\left(\mathrm{m}^{2}\right)$.

The local resistance coefficient $\zeta_{\text {loc }}$ is tabulated in Table 1 [6].

Table 1 Local resistance coefficient through abrupt expansion downstream of circular tube with uniform velocity distribution $\left(\operatorname{Re}_{0} \geq 3.3 \times 10^{3}\right)$

\begin{tabular}{|l|c|c|c|c|c|c|c|c|c|c|}
\hline & 0.0 & 0.1 & 0.2 & 0.3 & 0.4 & 0.5 & 0.6 & 0.7 & 0.8 & 1.0 \\
\hline & 1.0 & 0.81 & 0.64 & 0.5 & 0.36 & 0.25 & 0.16 & 0.09 & 0.04 & 0 \\
\hline
\end{tabular}

The coefficient of local resistance to an abrupt contraction at large Reynolds number greater than $10^{4}$ can be approximately determined by following formula [6]:

where $F_{0}$ is the downstream cross-sectional area $\left(\mathrm{m}^{2}\right)$ and $F_{1}$ is the upstream cross-sectional area $\left(\mathrm{m}^{2}\right)$.

Although Ref. [6] provides a vast amount of data for the hydraulic resistances of various geometries, the data for specific geometries of interest in this ECAR are not available. The local resistance of the complex geometry can only be determined by either the experiment or the computational fluid dynamics. In this ECAR, the computational fluid dynamics (CFD) was adopted to determine the pressure loss of interested geometries.

\section{ASSUMPTIONS}

1. Three-dimensional, steady-state, isothermal, incompressible and turbulent flow of liquid sodium

2. Constant sodium density, dynamic viscosity were assumed to be $860 \mathrm{~kg} / \mathrm{m}^{3}$ and $3.0 \times 10^{-4} \mathrm{~Pa} \cdot \mathrm{s}$, respectively.

3. Uniform inlet velocity distribution 
Computational Evaluation on Effect of Edge-rounding in Circular to Annular Flow

Title: $\quad$ Transitions within a Hexagonal Duct

$\begin{array}{lllll}\text { ECAR No.: } 5067 & \text { Rev. No.: } & 0 & \text { Project No.: } 32833 & \text { Date: } T B D\end{array}$

\section{COMPUTER CODE VALIDATION - Star-CCM+}
A. Computer type: INL LEMHI cluster
B. Operating System and Version: CentOS 7.6 operating system
C. Computer program name and revision: STARCCM+13.06.012-R8
D. Inputs (may refer to an appendix): Relevant information is provided throughout the discussion and analysis section of this document.

E. Outputs (may refer to an appendix): Relevant information is provided throughout the discussion and analysis section of this document.

F. Evidence of, or reference to, computer program validation: Siemens's STAR$\mathrm{CCM}+$,The commercial multiphysics computational fluid dynamics (CFD) software, has achieved ASME Nuclear Quality Assurance-1 compliance. The addition of NQA-1 compliance in rigorous ASME QA certification program ensures the code meets industrystandard requirements for nuclear industry customers in support of safe-related application.

G. Bases supporting application of the computer program to the specific physical problem: Calculation of flow velocity and pressure gradient calculations performed herein have been acceptably performed and are common analysis types for which the identified program, STARCCM+ is designed to be used and has been acceptably demonstrated through commercial use and application. The identified software package is well suited for the calculations documented by this report to the quality level indicated on the title page.

\section{COMPUTER CODE VALIDATION - Nek5000}

A. $\quad$ Computer type: ANL - "Bebop": Intel Xeon E5-2695v4 Broadwell CPUs, INL "Sawtooth": Intel Xeon 8268 Cascade Lake CPUs

B. Operating System and Version: Bebop: CentOS 7 operating system, Sawtooth: CentOS 7.7 operating system

C. Computer program name and revision: Nek5000 v19.0

D. Inputs (may refer to an appendix): Relevant information is provided throughout the discussion and analysis section of this document.

E. Outputs (may refer to an appendix): Relevant information is provided throughout the discussion and analysis section of this document.

F. Evidence of, or reference to, computer program validation: Nek5000 is an open source 
Computational Evaluation on Effect of Edge-rounding in Circular to Annular Flow

Title: $\quad$ Transitions within a Hexagonal Duct

$\begin{array}{llllll}\text { ECAR No.: } 5067 & \text { Rev. No.: } & 0 & \text { Project No.: } & 32833 & \text { Date: } T B D\end{array}$

CFD code, maintained and developed as part of the DOE NEAMS program. It has been in use for $30+$ years as a high-fidelity CFD tool. It has been extensively validated through participation in international blind benchmarks.

G. Bases supporting application of the computer program to the specific physical problem: Calculation of flow velocity and pressure gradient calculations performed herein have been acceptably performed and are common analysis types for which the identified program, Nek5000 is designed to be used and has been acceptably demonstrated through research, academic, and industry use and application. The identified software package is well suited for the calculations documented by this report to the quality level indicated on the title page.

\section{DISCUSSION/ANALYSIS}

\section{A. GEOMETRY DESCRIPTION}

Figure 1 shows the schematic of the test geometry. The inlet of the duct is a circular channel with an inner diameter $\left(D_{C}\right)$ of $60.0 \mathrm{~mm}$ and a length of $300.0 \mathrm{~mm}$. There is $40.0 \mathrm{~mm}$-long transition region between the circular and annular channels. The inner diameter $\left(D_{A, \text { in }}\right)$ and outer diameter $\left(D_{A, \text { out }}\right)$ of annulus are $80.0 \mathrm{~mm}$ and $100.0 \mathrm{~mm}$, respectively. The length of annular channel is $300.0 \mathrm{~mm}$. In Case$A$, only the inner edge of the annulus was rounded off from $0.0 \mathrm{~mm}$ to $20.0 \mathrm{~mm}$. In Case-B, the radius of curvature of inner edge of the annulus $\left(R_{A, \text { Curr }}\right)$ was fixed at $5.0 \mathrm{~mm}$, and the radius of curvature of the circular channel $\left(R_{c, \text { Curv }}\right)$ was varied from $0.0 \mathrm{~mm}$ to $20.0 \mathrm{~mm}$. Test matrix is summarized in Table 2.

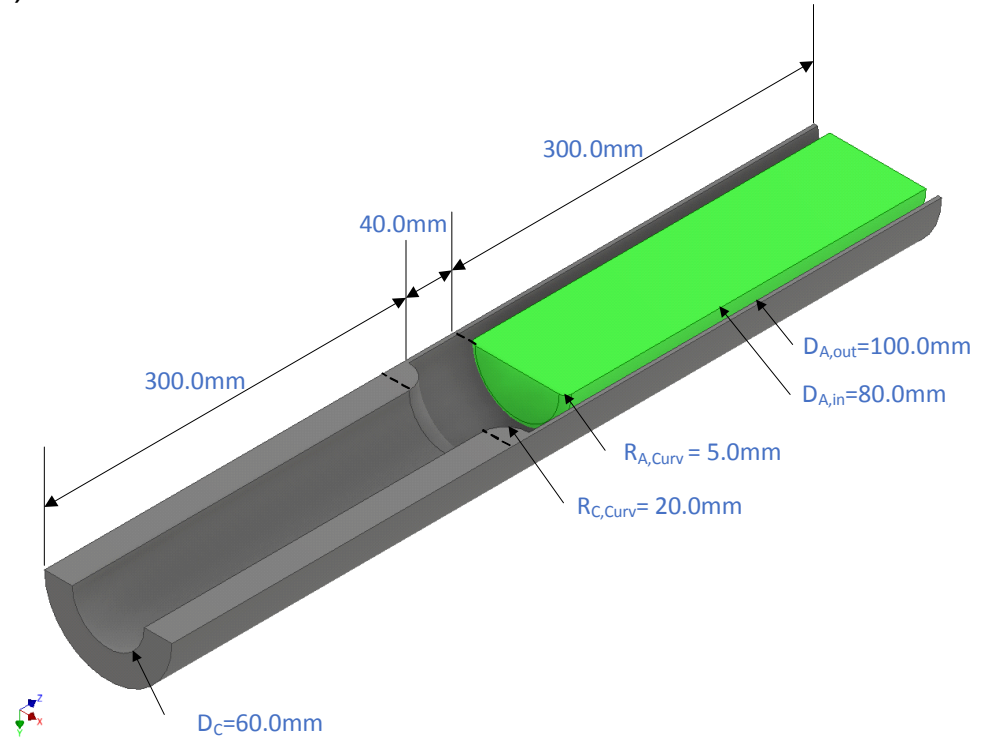

Figure 1. Schematic of the geometry sample $\left(R_{\mathrm{C}, \mathrm{Curv}}=20.0 \mathrm{~mm}, R_{\mathrm{A}, \mathrm{Curv}}=5.0 \mathrm{~mm}\right)$ 
Rev. 1

Computational Evaluation on Effect of Edge-rounding in Circular to Annular Flow

Title: $\quad$ Transitions within a Hexagonal Duct

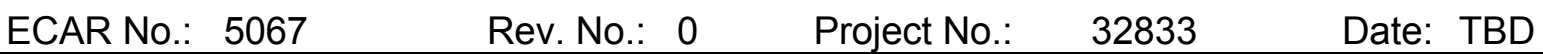

\begin{tabular}{|c|c|c|}
\hline Test Case & $\mathrm{R}_{\mathrm{C}, \text { Curv }}(\mathrm{mm})$ & $\mathrm{R}_{\mathrm{A}, \text { Curv }}(\mathrm{mm})$ \\
\hline Case-A & 0.0 (fixed) & $0.0,1.0,2.0,5.0,10.0,20.0$ \\
\hline Case-B & $0.0,1.0,2.0,5.0,10.0,20.0$ & 5.0 (fixed) \\
\hline
\end{tabular}

\section{B. STAR-CCM+ MODEL DESCRIPTION}

A commercially-available CFD software, STAR-CCM+ version 13.06.012-R8 [7] was adopted as a numerical solver. Three-dimensional, steady-state, incompressible, Reynolds-Averaged Navier-Stokes (RANS) equation-based simulation was solved by adopting the segregated flow, segregated isothermal, and Shear Stress Transport (SST) k- $\omega$ turbulence model with all y+ wall treatment model. $2^{\text {nd }}$ order convection schemes for the momentum and turbulence solver were adopted. Constant fluid properties were used in this analysis. The density and dynamic viscosity of sodium were specified by $860.0 \mathrm{~kg} / \mathrm{m}^{3}$ and $3.0 \times 10^{-3} \mathrm{~Pa} \cdot \mathrm{s}$, respectively. Inlet velocity and pressure outlet boundary conditions were specified to the inlet and outlet of the duct. Turbulent intensity of 0.01 and turbulent viscosity of 10.0 were employed to specify the turbulent parameters at the inlet boundary.

Figure 2 shows the typical mesh structure of computational domain. The polyhedral mesh with boundary prism layers was adopted for generating the computational mesh. The mesh structures of all CFD models are provided in Appendix A. The base size mesh of the CFD model was $1.0 \mathrm{~mm}$. Target and minimum surface size were specified by $100 \%$ and $10 \%$ of the base size, respectively. The number of prism boundary layers was 8 . Total thickness of the boundary prism layer was specified by $33.33 \%$ of the base size. The prism layer stretching ratio was specified by 1.2. The surface averaged wall $y+$ value was less than 1 . The radiuses of curvature of $1 \mathrm{~mm}$ and $2 \mathrm{~mm}$ resulted in larger number of cells than other cases. The mesh statistics are summarized in Table 3. 
Computational Evaluation on Effect of Edge-rounding in Circular to Annular Flow Transitions within a Hexagonal Duct

ECAR No.: 5067 $\begin{array}{lll}\text { Rev. No.: } 0 & \text { Project No.: } \quad 32833\end{array}$

Date: TBD

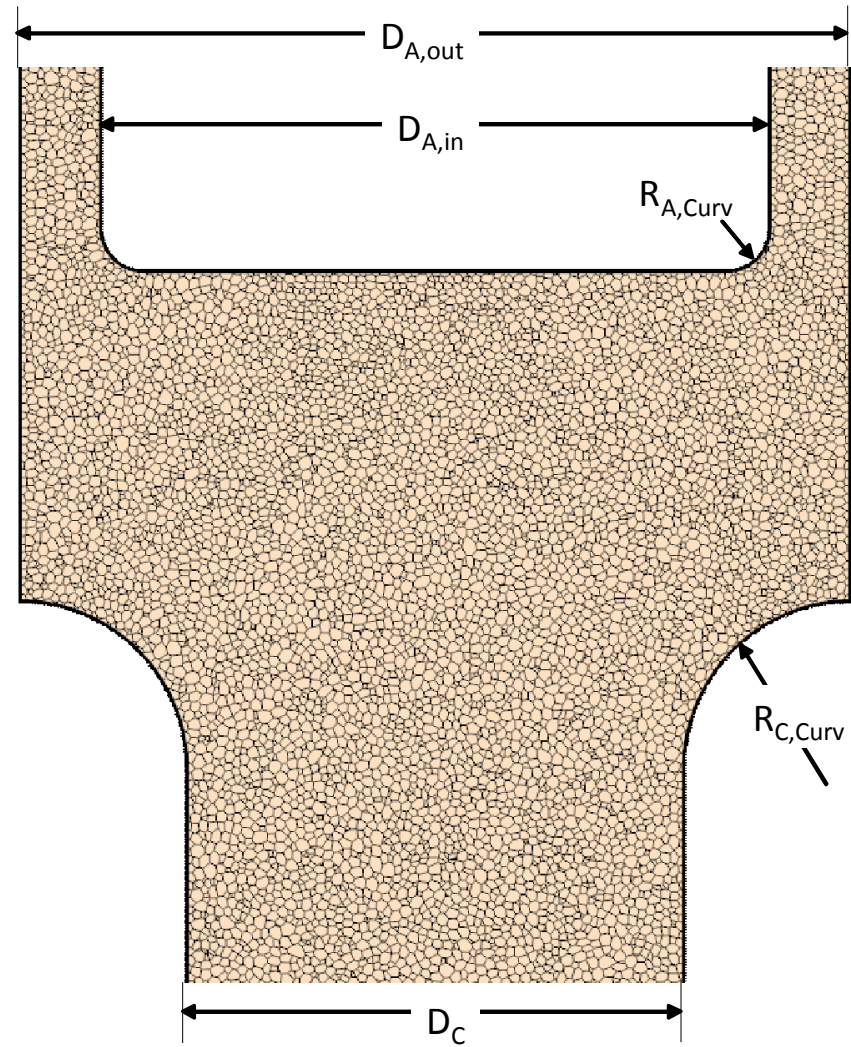

Figure 2. Mesh structure of STAR-CCM+CFD Model $\left(R_{A, \text { Curv }}=5 \mathrm{~mm}, R_{c, \text { Curv }}=20 \mathrm{~mm}\right)$

Table 3. Mesh Statistics of the Star-CCM+ model

\begin{tabular}{|c|c|c|c|c|}
\hline Test Case & $\begin{array}{l}R_{c, \text { Curv }} \\
(\mathrm{mm})\end{array}$ & $\begin{array}{l}R_{A, \text { Curv }} \\
(\mathrm{mm})\end{array}$ & $\begin{array}{l}\text { Number of cells } \\
\text { (Million) }\end{array}$ & $\begin{array}{c}\text { Surface averaged Wall y+ } \\
\left(\operatorname{Re}=1 \times 10^{5}\right)\end{array}$ \\
\hline \multirow[t]{6}{*}{ Case-A } & \multirow{6}{*}{0.0 (fixed) } & 0.0 & 3.58 & 0.84 \\
\hline & & 1.0 & 4.15 & 0.83 \\
\hline & & 2.0 & 3.98 & 0.81 \\
\hline & & 5.0 & 3.69 & 0.77 \\
\hline & & 10.0 & 3.53 & 0.75 \\
\hline & & 20.0 & 3.59 & 0.74 \\
\hline \multirow[t]{4}{*}{ Case-B } & 1.0 & \multirow[t]{4}{*}{5.0 (fixed) } & 4.81 & 0.77 \\
\hline & 2.0 & & 4.02 & 0.77 \\
\hline & 5.0 & & 3.94 & 0.77 \\
\hline & 10.0 & & 3.78 & 0.76 \\
\hline
\end{tabular}


Computational Evaluation on Effect of Edge-rounding in Circular to Annular Flow

Title: $\quad$ Transitions within a Hexagonal Duct

$\begin{array}{lllll}\text { ECAR No.: } 5067 & \text { Rev. No.: } & 0 & \text { Project No.: } 32833 & \text { Date: } T B D\end{array}$

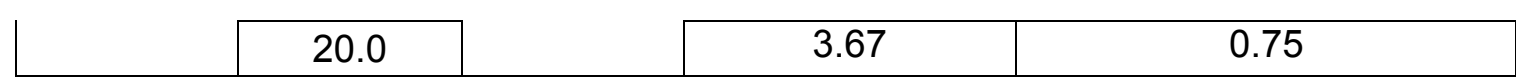

\section{STAR-CCM+ Results}

Figure 3 shows the velocity distribution on the mid-plane of the Case-A geometry for Reynolds numbers of $2 \times 10^{4}$. Figure 4 shows the pressure distribution on the mid-plane of the Case-A geometry for Reynolds numbers of $2 \times 10^{4}$. The re-circulation region was observed at the corner of transition region. Flow separation and reattachment at the entrance of annulus were observed where the radius of curvature of internal structure was less than $10 \mathrm{~mm}$. The peak velocity at the entrance of annulus was linearly proportional to the Reynolds number. Sudden contraction of flow area at the entrance of annulus resulted in Vena Contracta flow with the flow separation occurred only on one side. The peak velocity of Vena Contracta flow decreased as the radius of curvature increased.

The CFD results show that the pressure drop can be significantly reduced by the edge-rounding, e.g., the pressure drop was reduced approximately $56 \%$ by the radius of curvature of $5.0 \mathrm{~mm}$, and reduced $70 \%$ by the radius of curvature of $20.0 \mathrm{~mm}$. The pressure drop of Case-A geometry as an inlet Reynolds number was shown in Figure 5. The pressure drop is proportional to the square of inlet Reynolds number. The second order polynomial fitting curves agreed with the CFD result. R-squared values of fitting curves were very close to unity. The pressure drop of Case-A geometry as a function of Radius of curvature was shown in Figure 6. The pressure drop of tested geometry decreased with increasing radius of curvature. For a large radius of curvature (e.g. in this test, greater than $10 \mathrm{~mm}$ ), increasing the radius of curvature would not yield a reduced pressure drop as much as small radius of curvature.

The flow separation occurred at the exit of circular channel and the recirculation region at the corners of transition region formed by the impinging jet flow from the circular channel. The minor pressure loss due to this flow separation and recirculation can be reduced by adding the curved edge at the exit of circular channel. To evaluate the effect of edge smoothing at the exit of circular channel, the CFD simulations of Case-B geometries were carried out. Figure 7 shows the velocity distribution on the mid-plant of Case$B$ geometry for three Reynolds number of $2 \times 10^{4}$. Figure 8 shows the pressure distribution on the midplane of the Case-B geometry for Reynolds number of $2 \times 10^{4}$. The effect of radius of curvature at the exit of circular channel, i.e., the entrance of transition region, was relatively less than that of inner radius which faces the flow. As show in Figure 9, a large radius of curvature at the exit of circular channel is needed to get the pressure loss reduction greater than $10 \%$. Hence, it can be concluded that the benefit of edge rounding of exit of flow channel is not significant.

In summary, if there is no other geometrical restriction, the radius of curvature of $10.0 \mathrm{~mm}$ for both sides of edge would be applicable to reduce the local pressure loss in the channel which has sudden expansion and contraction in the flow area. In this ECAR, the ratio of channel diameters and the radius of curvature was not investigated. A further parametric study on the design parameters is necessary to provide a general guideline for the design optimization. The velocity distributions and pressure distributions by other Reynolds numbers are provided in Appendix B and Appendix C, respectively. All pressure drop results are summarized in Appendix D. 
Computational Evaluation on Effect of Edge-rounding in Circular to Annular Flow

Title: $\quad$ Transitions within a Hexagonal Duct

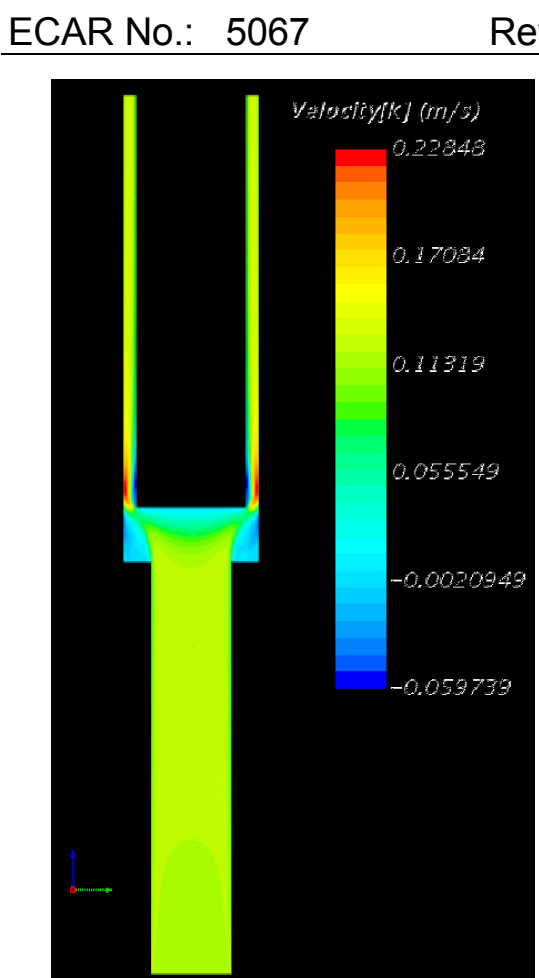

(a) $\mathrm{R}_{\mathrm{A}, \mathrm{Curv}}=0 \mathrm{~mm}$

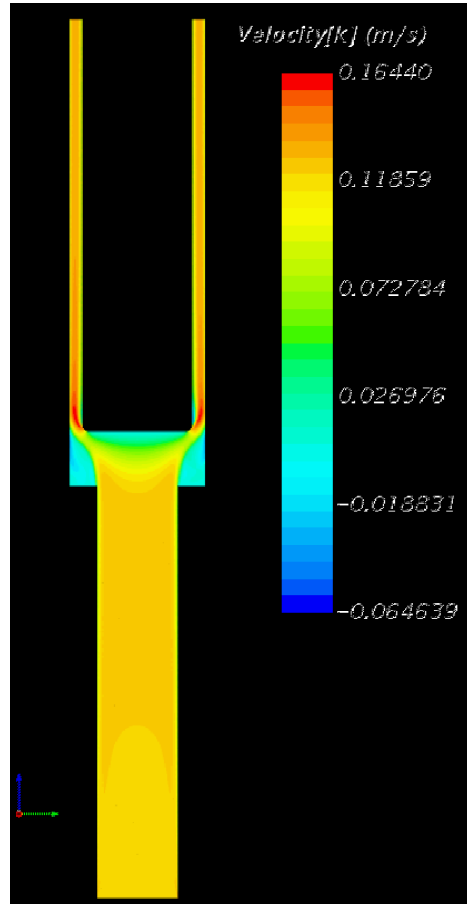

(d) $R_{A, \text { Curv }}=5 \mathrm{~mm}$

Rev. No: 0

Project No: :

32833

Date: TBD

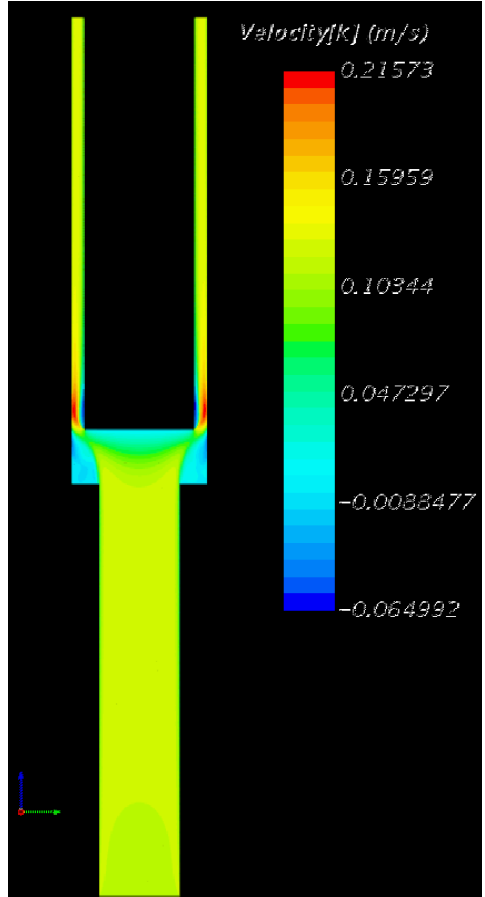

(b) $R_{A, \text { Curv }}=1 \mathrm{~mm}$

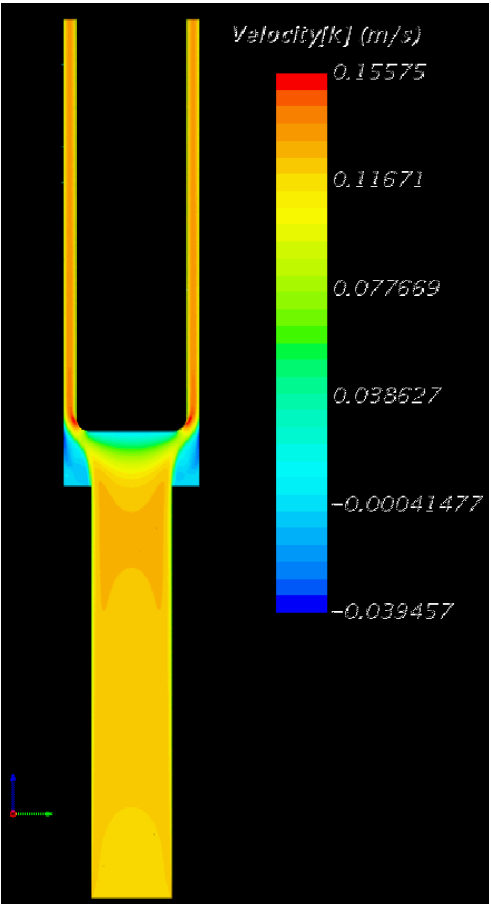

(e) $R_{A, \text { Curv }}=10 \mathrm{~mm}$

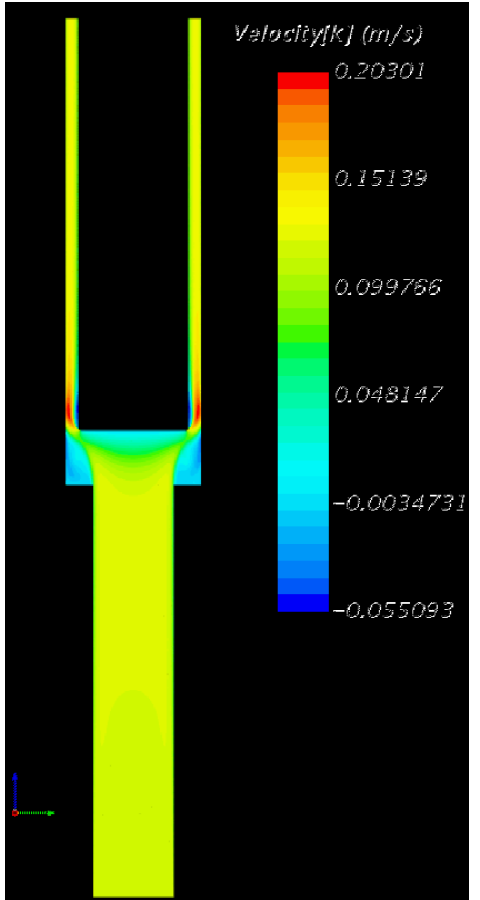

(C) $\mathrm{R}_{\mathrm{A}, \text { Curv }}=2 \mathrm{~mm}$

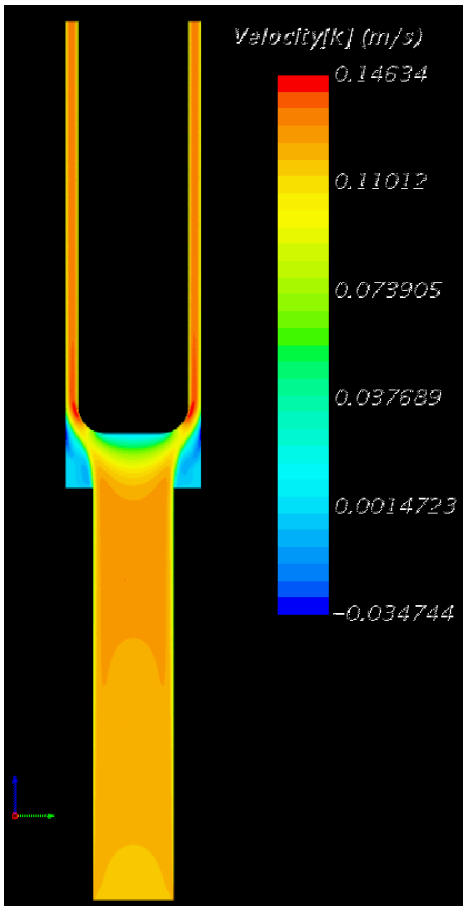

(f) $R_{A, C u r v}=20 \mathrm{~mm}$

Figure 3 Velocity profiles on the mid-plane of the channel (Case-A, $R e_{D}=2 \times 10^{4}$ ) 
Computational Evaluation on Effect of Edge-rounding in Circular to Annular Flow

Title: $\quad$ Transitions within a Hexagonal Duct

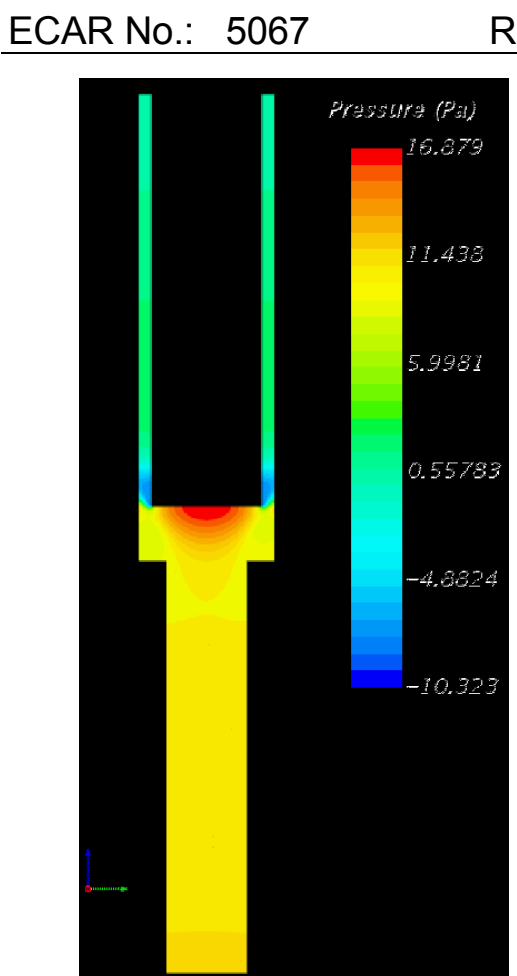

(a) $\mathrm{R}_{\mathrm{A}, \mathrm{Curv}}=0 \mathrm{~mm}$

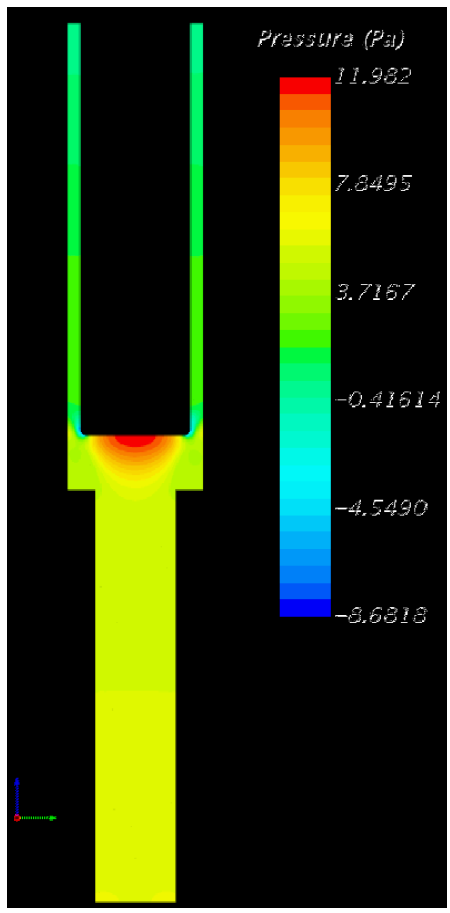

(d) $R_{A, C u r v}=5 \mathrm{~mm}$

Rev. No:: 0

Project No::

32833

Date: TBD

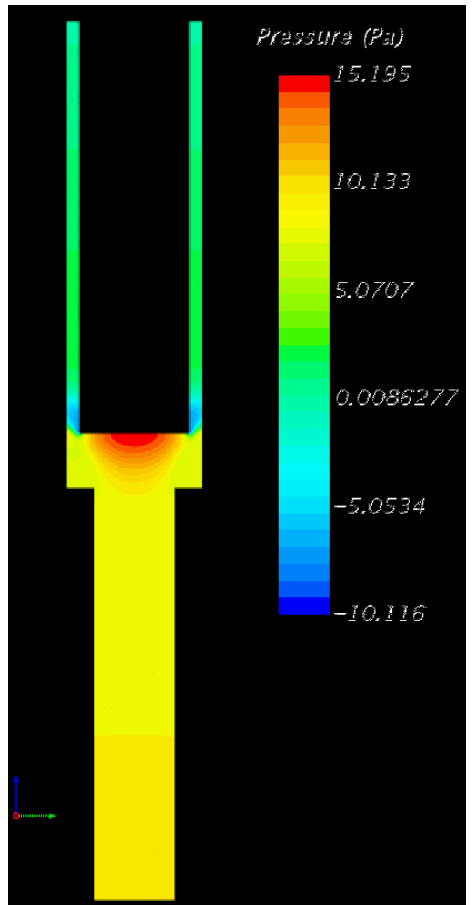

(b) $R_{A, \text { Curv }}=1 \mathrm{~mm}$

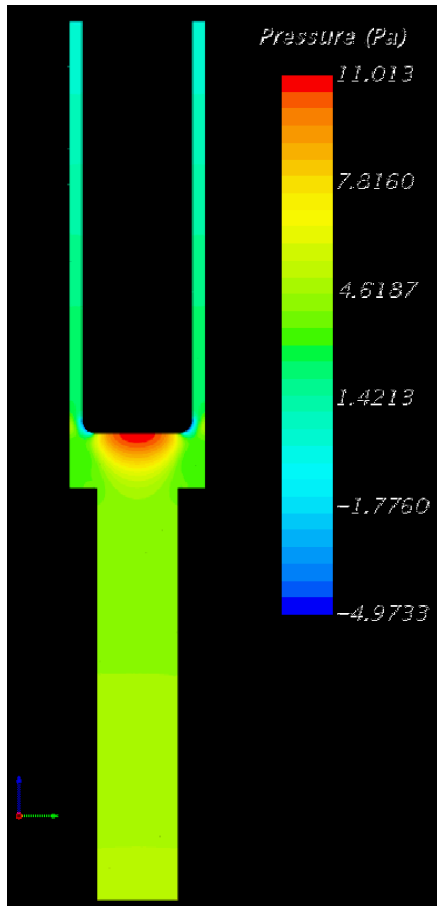

(e) $R_{\mathrm{A}, \text { Curv }}=10 \mathrm{~mm}$

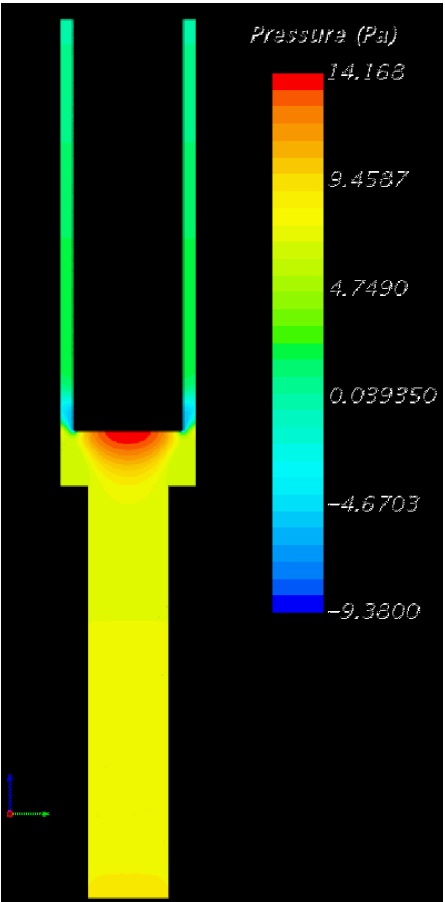

(C) $\mathrm{R}_{\mathrm{A}, \text { Curv }}=2 \mathrm{~mm}$

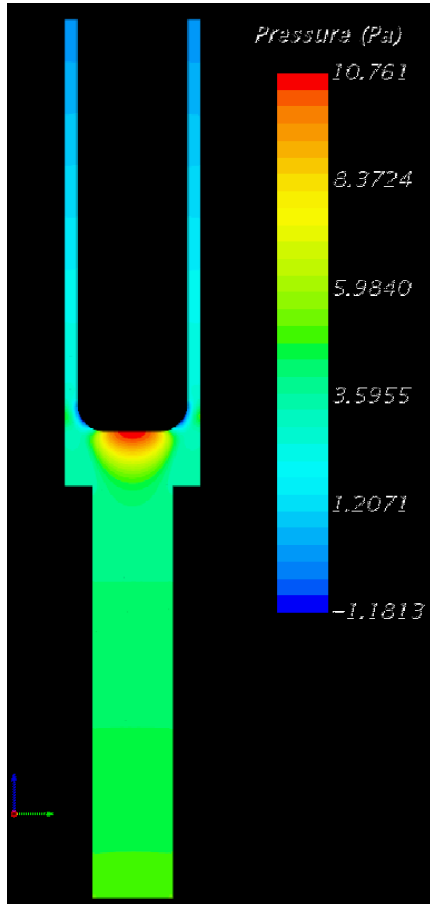

(f) $R_{A, C u r v}=20 \mathrm{~mm}$

Figure 4 Pressure distributions on the mid-plane of the channel (Case-A, $\operatorname{Re}_{D}=2 \times 10^{4}$ ) 
TEM-326

$01 / 07 / 19$

Rev. 1

Computational Evaluation on Effect of Edge-rounding in Circular to Annular Flow

Title: $\quad$ Transitions within a Hexagonal Duct

ECAR No.: 5067

Rev. No.: $0 \quad$ Project No.: 32833

Date: TBD

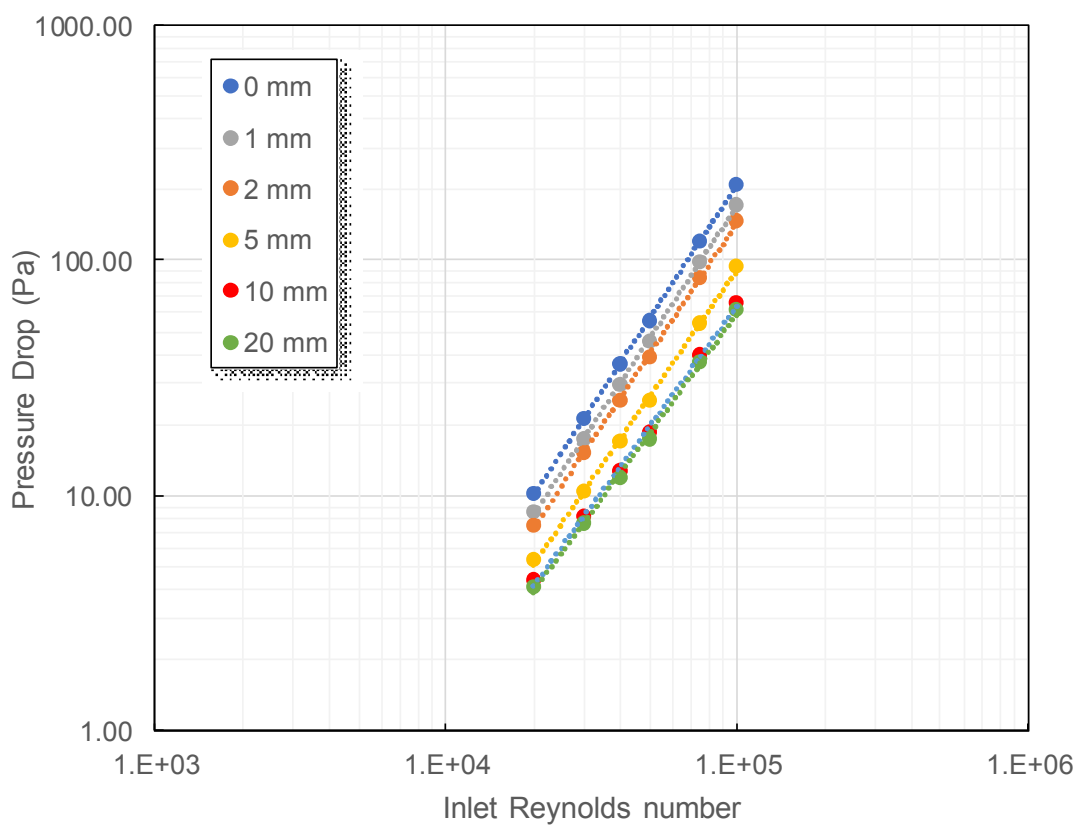

Figure 5 Pressure drop of Case-A geometry plotted as a function of Inlet Reynolds number

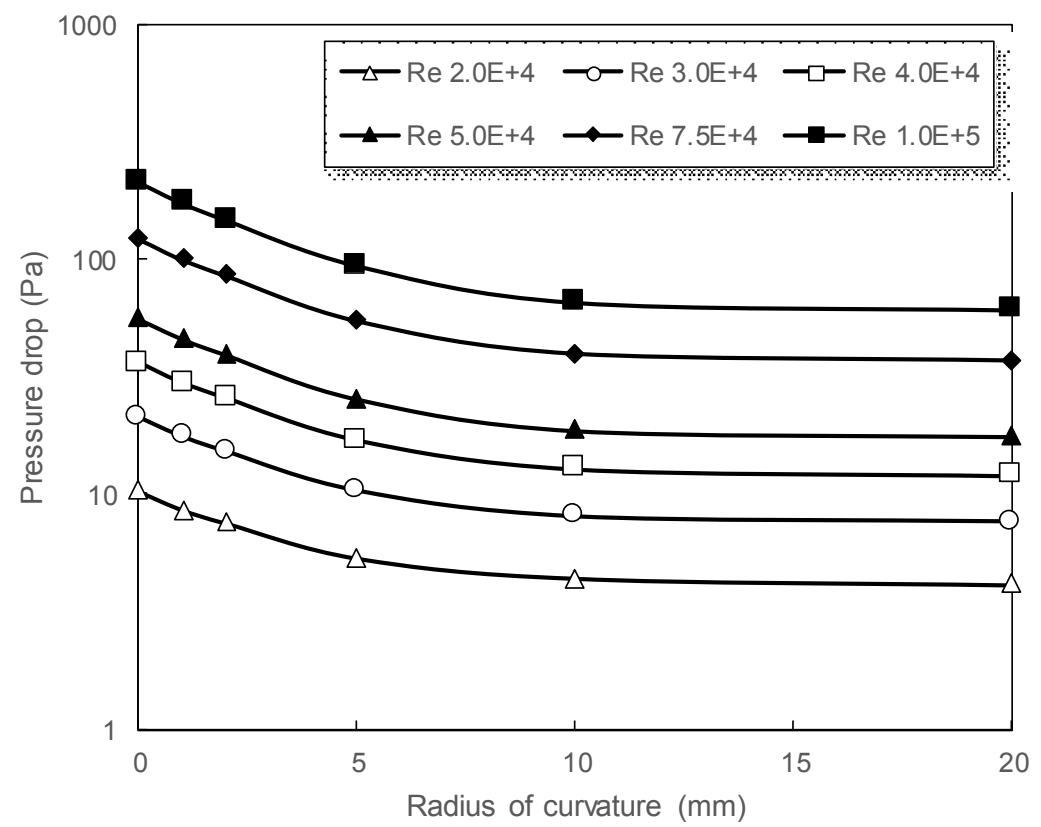

Figure 6 Pressure drop of Case-A geometry plotted as a function of radius of curvature 
Computational Evaluation on Effect of Edge-rounding in Circular to Annular Flow

Title: $\quad$ Transitions within a Hexagonal Duct

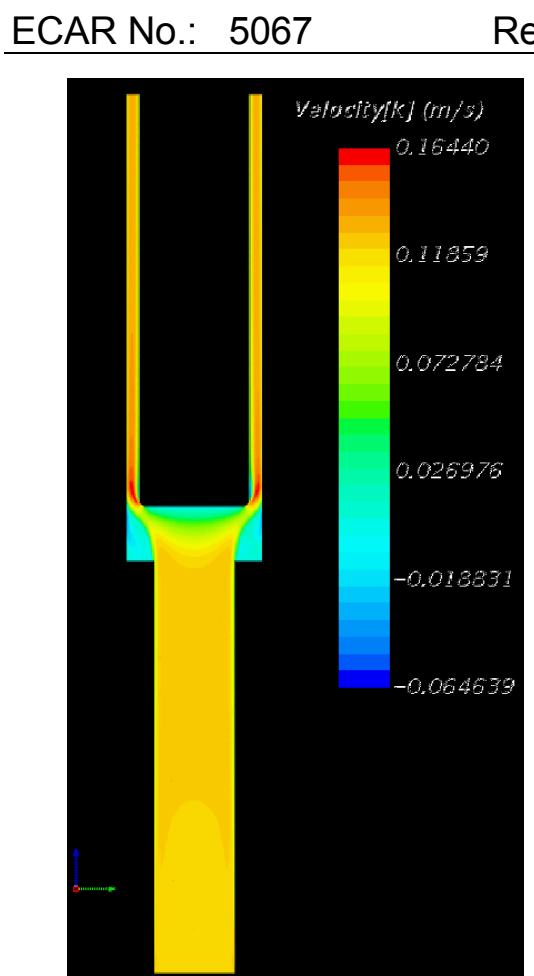

(a) $R_{c, \text { Curv }}=0 m m($ Case-A)

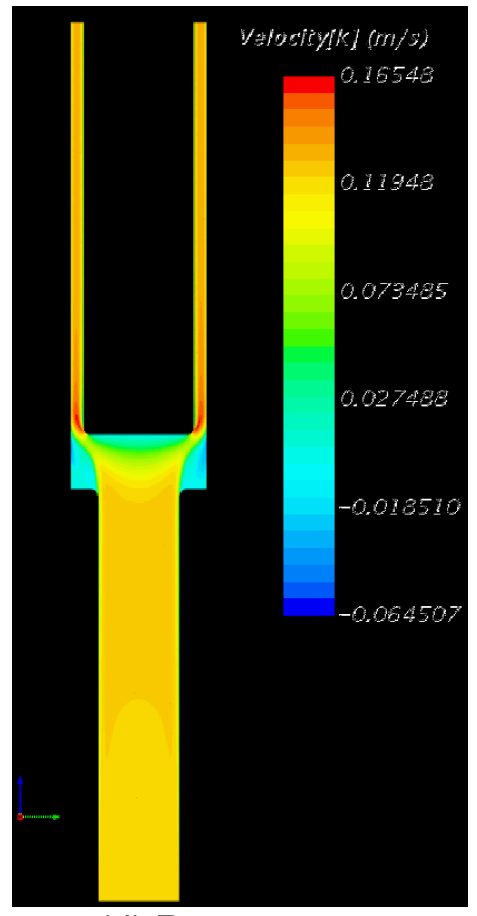

(d) $\mathrm{R}_{\mathrm{C}, \text { Curv }}=5 \mathrm{~mm}$

Rev. No: : 0

Project No.:

32833

Date: TBD

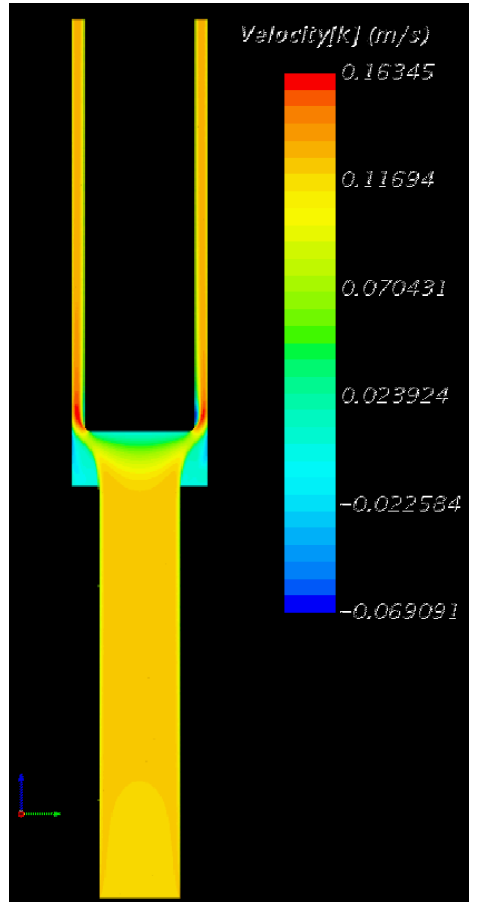

(b) $R_{\mathrm{C}, \text { Curv }}=1 \mathrm{~mm}$

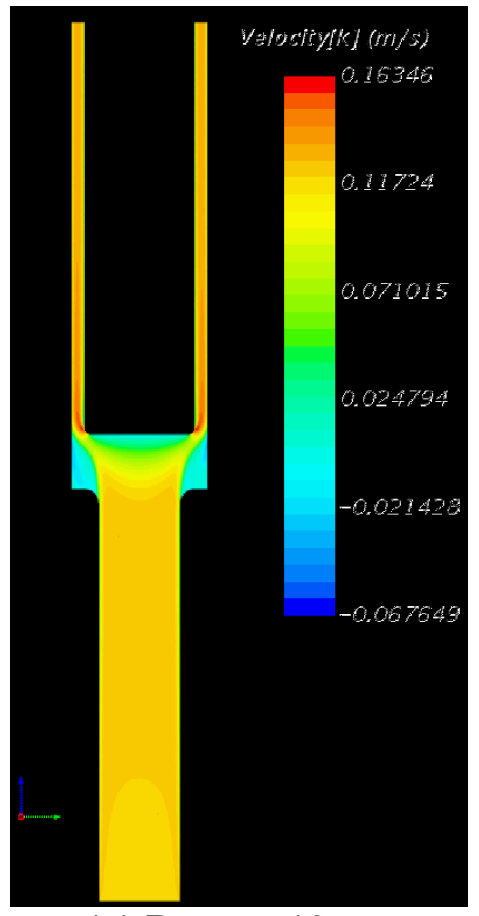

(e) $R_{\mathrm{C}, \text { Curv }}=10 \mathrm{~mm}$

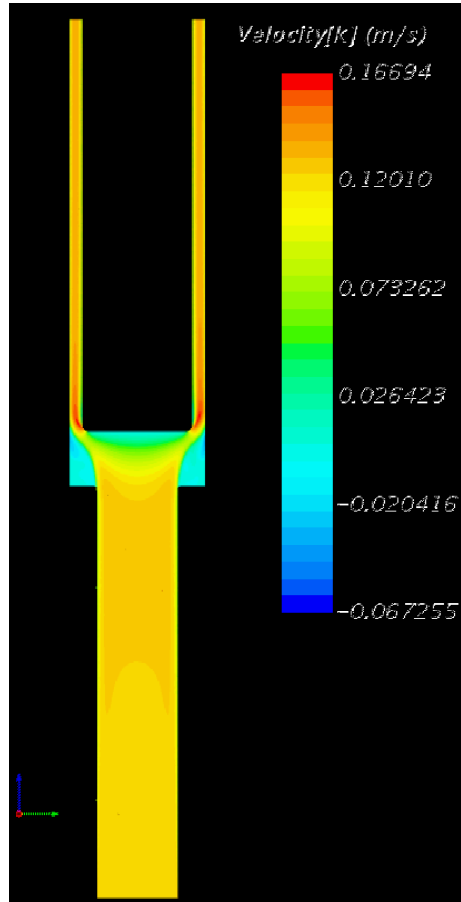

(c) $R_{C, \text { Curv }}=2 \mathrm{~mm}$

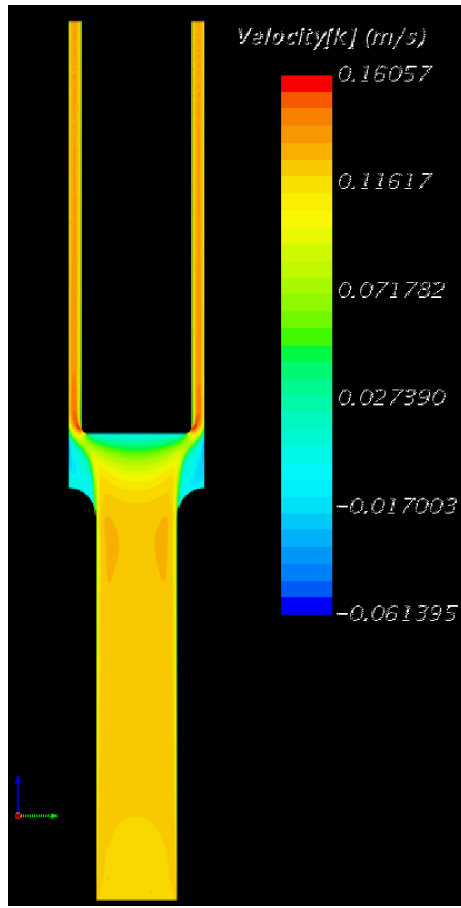

(f) $R_{\mathrm{C}, \text { Curv }}=20 \mathrm{~mm}$

Figure 7 Velocity distributions on the mid-plane of the channel (Case-B, $R e_{D}=2 \times 10^{4}$ ) 
Computational Evaluation on Effect of Edge-rounding in Circular to Annular Flow

Title: $\quad$ Transitions within a Hexagonal Duct

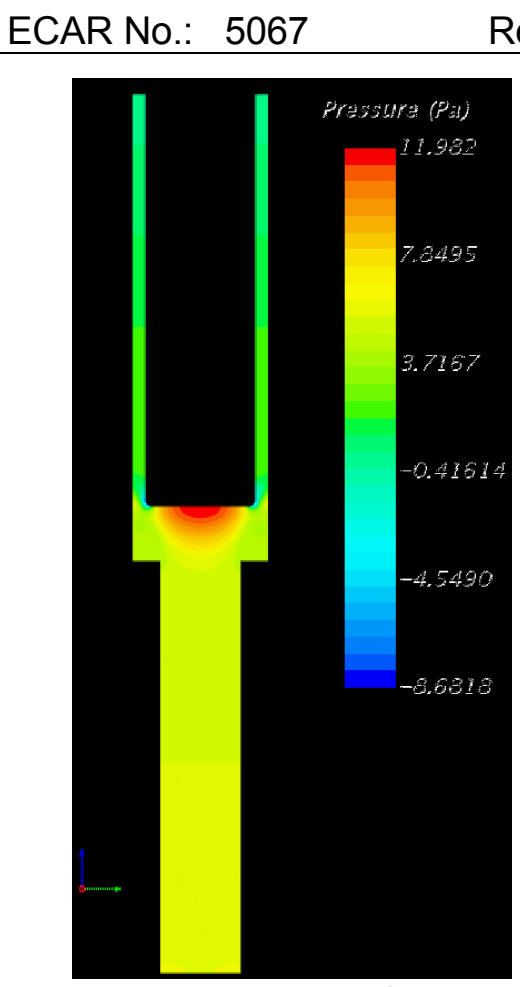

(a) $\mathrm{R}_{\mathrm{c}, \text { Curv }}=0 \mathrm{~mm}$ (Case-A)

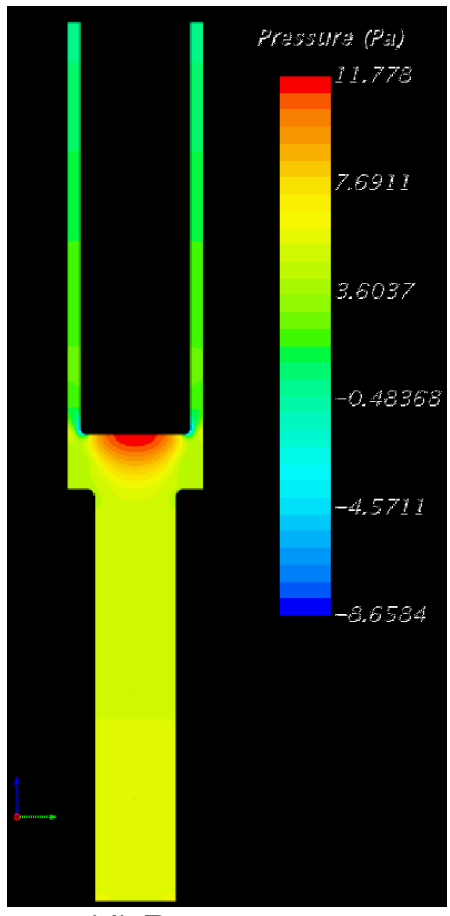

(d) $\mathrm{R}_{\mathrm{C}, \text { Curv }}=5 \mathrm{~mm}$

Rev. No.: 0

Project No::

32833

Date: TBD

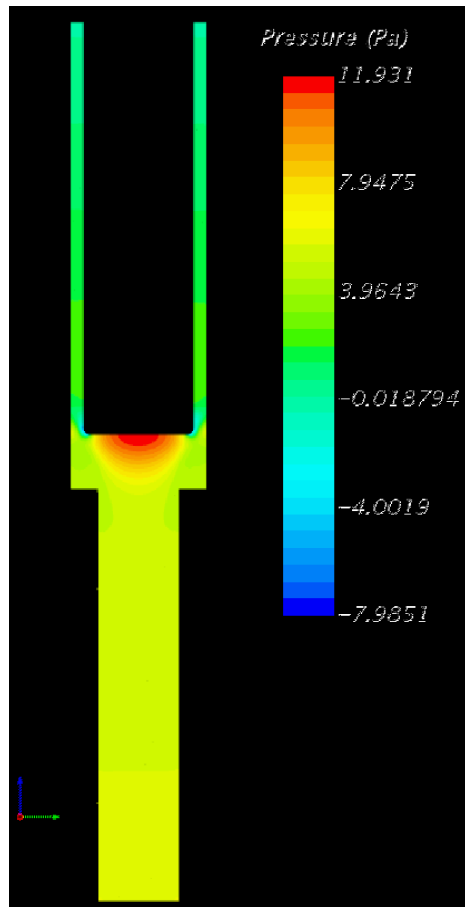

(b) $R_{\mathrm{C}, \text { Curv }}=1 \mathrm{~mm}$

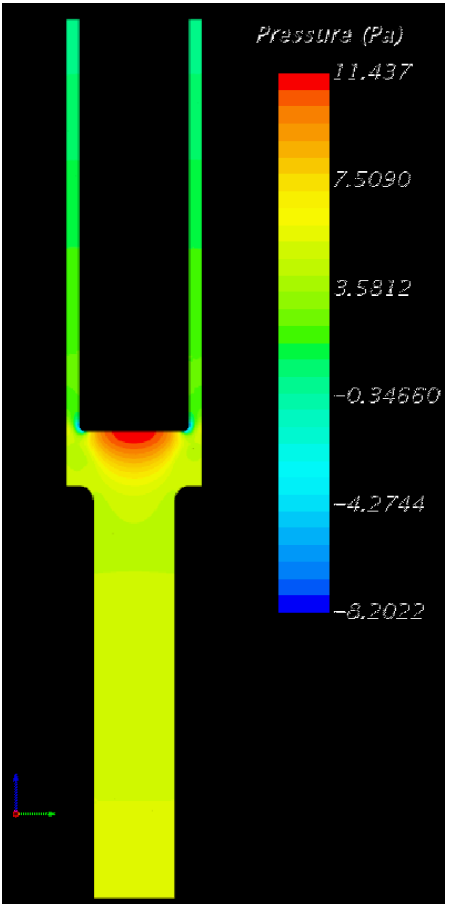

(e) $R_{\mathrm{c}, \text { Curv }}=10 \mathrm{~mm}$

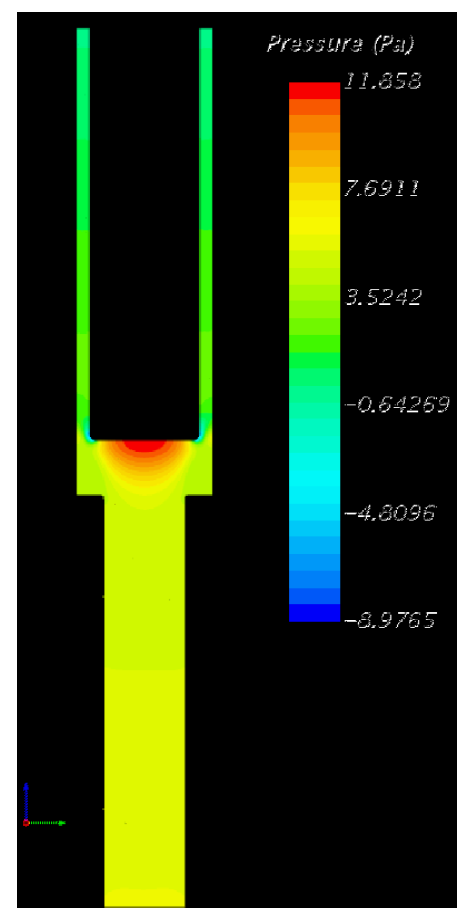

(c) $R_{C, \text { Curv }}=2 \mathrm{~mm}$

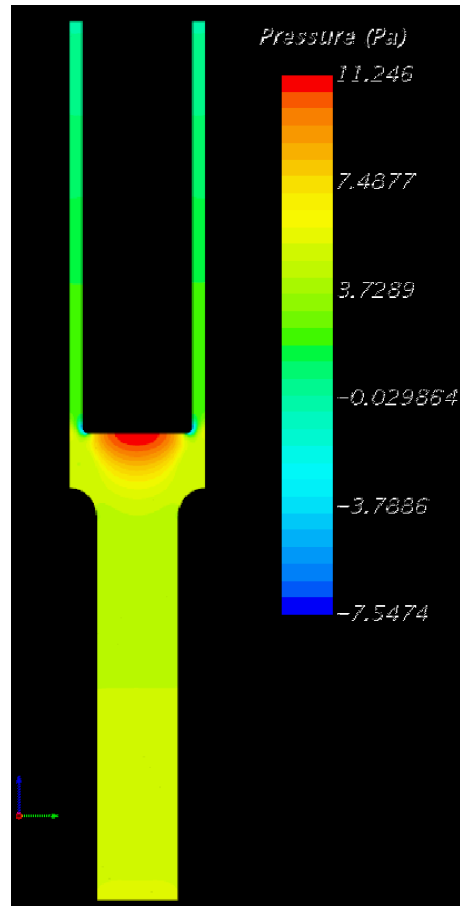

(f) $R_{\mathrm{C}, \text { Curv }}=20 \mathrm{~mm}$

Figure 8 Pressure distributions on the mid-plane of the channel (Case- $B, \operatorname{Re}_{D}=2 \times 10^{4}$ ) 
Computational Evaluation on Effect of Edge-rounding in Circular to Annular Flow

Title: $\quad$ Transitions within a Hexagonal Duct

$\begin{array}{llllll}\text { ECAR No.: } 5067 & \text { Rev. No.: } & 0 & \text { Project No.: } & 32833 & \text { Date: } T B D\end{array}$

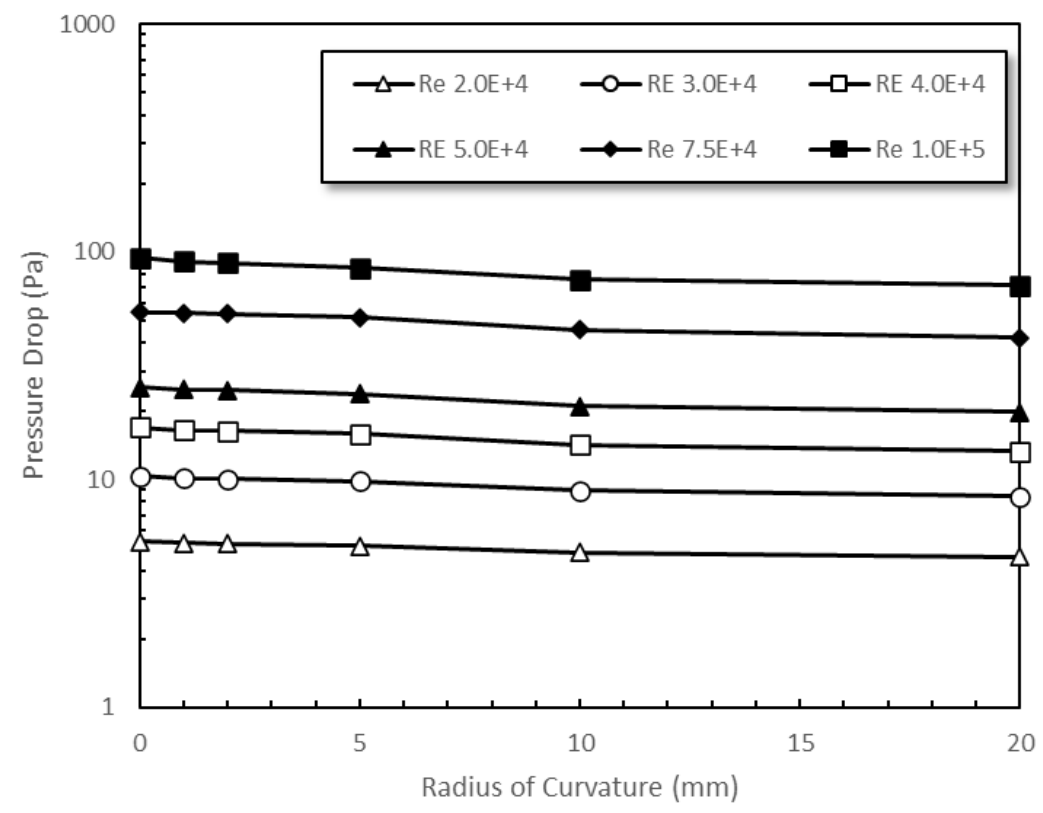

Figure 9 Pressure drop of Case-B geometry plotted as a function of radius of curvature

\section{NEK5000 MODEL DESCRIPTION}

In Nek5000, the dimensionless, incompressible, constant-viscosity forms of the conservation of mass and momentum equations where solved. These are given by

Where the inlet diameter and inlet mean velocity were used as reference values for length and velocity, respectively. This leads to the definition of the Reynolds number as 
Title: $\quad$ Transitions within a Hexagonal Duct

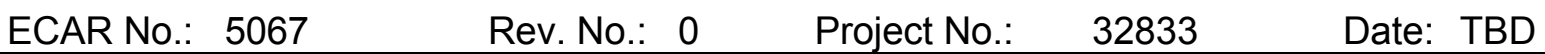

Which is consistent with the definition used in the Star-CCM+ analysis. It is important to note that the only non-trivial input parameter for each Nek5000 simulation is the Reynolds number. This encompasses the effects of fluid density, viscosity, and flow rate. Turbulence was modeled using an LES approach, which captures all but the smallest scale structures in the flow. The model is implemented using a filtering approach, where the velocity is filtered after every time step, adding dissipation at the smallest scales.

A recycling boundary condition was used in the Nek5000 simulations for the inlet. The velocity profile from 4.5 diameters downstream of the inlet was interpolated back onto the inlet and appropriately scaled to ensure a consistent mass flux. Recycling the boundary condition in this way ensures that turbulence is well characterized at the inlet boundary.

Nek5000 requires a mesh consisting entirely of hexahedral elements. As an inherent part of the spectral element method, the element mesh is further subdivided into Gauss-Lobatto-Legendre (GLL) quadrature points where the number of GLL points is based on the spatial approximation order. In this work a consistent blocking structure was used which could accommodate the investigated edge radii. Cross sections of two of the meshes used, one for the sharp-edged and one for the case with both fillets set to $5 \mathrm{~mm}$, are shown in Figure 10 with the overlaid GLL points at $7^{\text {th }}$ order accuracy.

Mesh-independence was confirmed for the sharp-edged case by gathering statistical pressure drop data at $5^{\text {th }}, 7^{\text {th }}, 9^{\text {th }}$, and $11^{\text {th }}$ spatial approximation orders. Each subsequent increase in the approximation order represents a geometric increase in spatial resolution. This sort of mesh independence study is known as p-type study. The pressure drop data is plotted in Figure 11, with the average values and percent differences compared to the $11^{\text {th }}$ order data given in Table 4 . The difference between $5^{\text {th }}$ and $11^{\text {th }}$ order was demonstrated to be only $2 \%$, which is quite reasonable. The average next-to-wall $y+$ value is also shown for each mesh. Typically a value of less than 1 is recommended for a wall-resolved method, however consistent results are obtained at an average value of 1.21 , it is therefore concluded that a $7^{\text {th }}$ order mesh is well resolved. It is expected that this case will have the highest resolution requirements due to the nature of flow around sharp edges and that a $7^{\text {th }}$ order mesh will be sufficient for the remaining cases. The mesh statistics for all LES cases are shown in Table 5. 
Rev. 1

Computational Evaluation on Effect of Edge-rounding in Circular to Annular Flow

Title: $\quad$ Transitions within a Hexagonal Duct

$\begin{array}{lllll}\text { ECAR No.: } 5067 \quad \text { Rev. No.: } & 0 & \text { Project No.: } & 32833 & \text { Date: TBD }\end{array}$

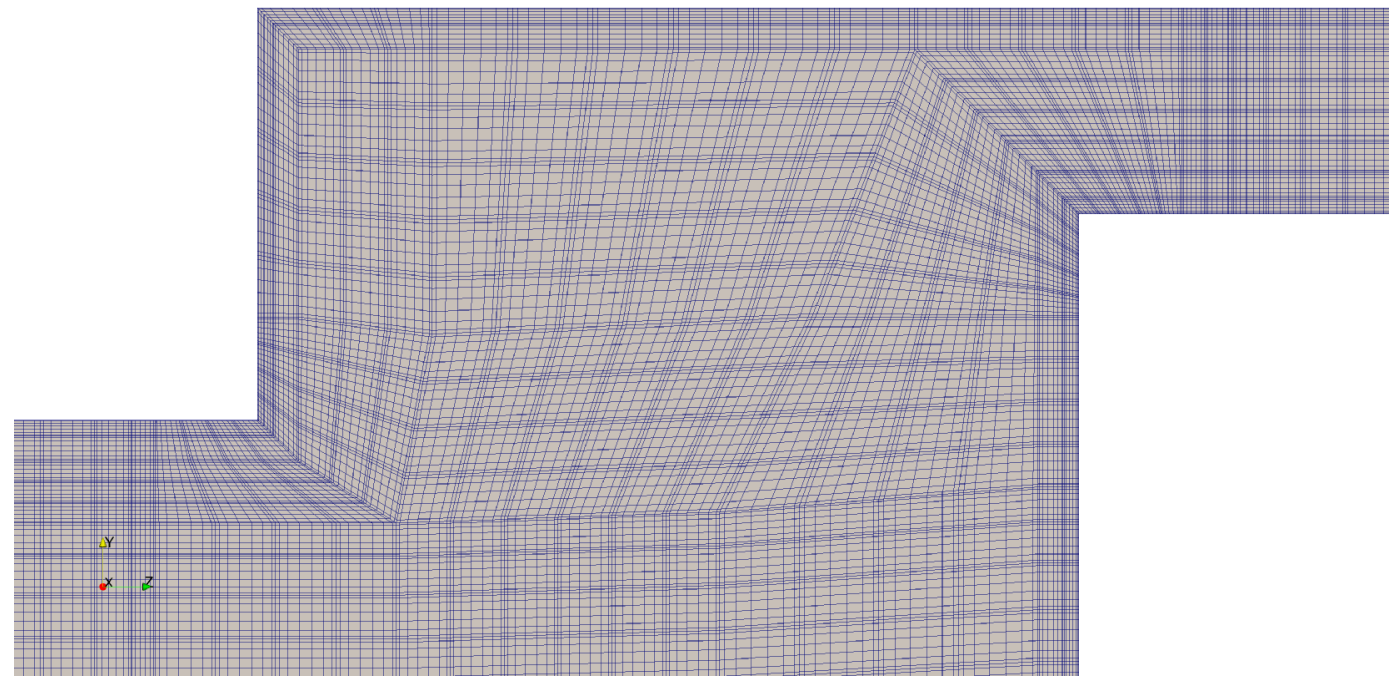

(a) sharp-edged case

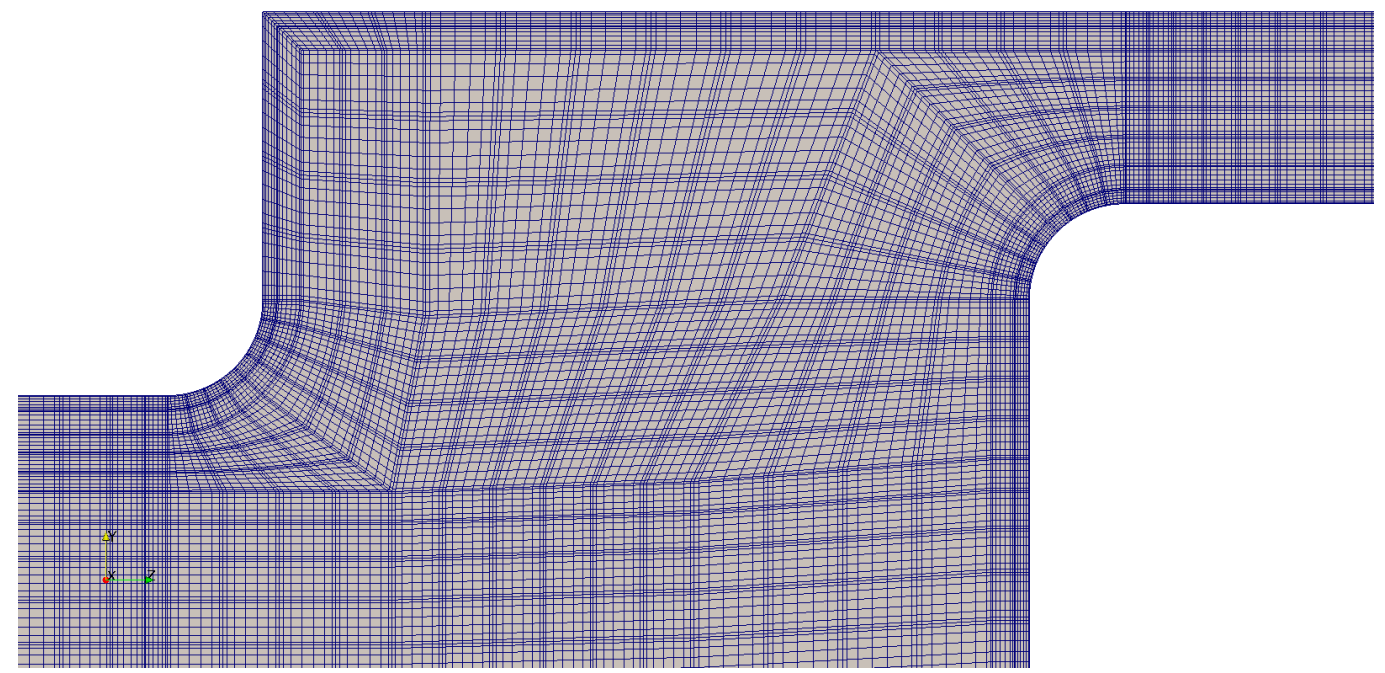

(b) $5 \mathrm{~mm}$ fillets on inlet and annulus edges

Figure 10 Cross section of the $7^{\text {th }}$ order Nek5000 meshes for (a) the sharp-edged case and (b) a rounded edge case. 
Computational Evaluation on Effect of Edge-rounding in Circular to Annular Flow

Title: $\quad$ Transitions within a Hexagonal Duct

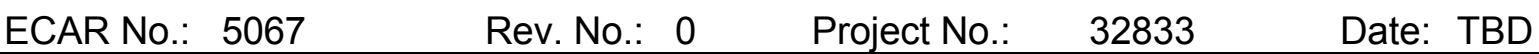

Transient pressure data

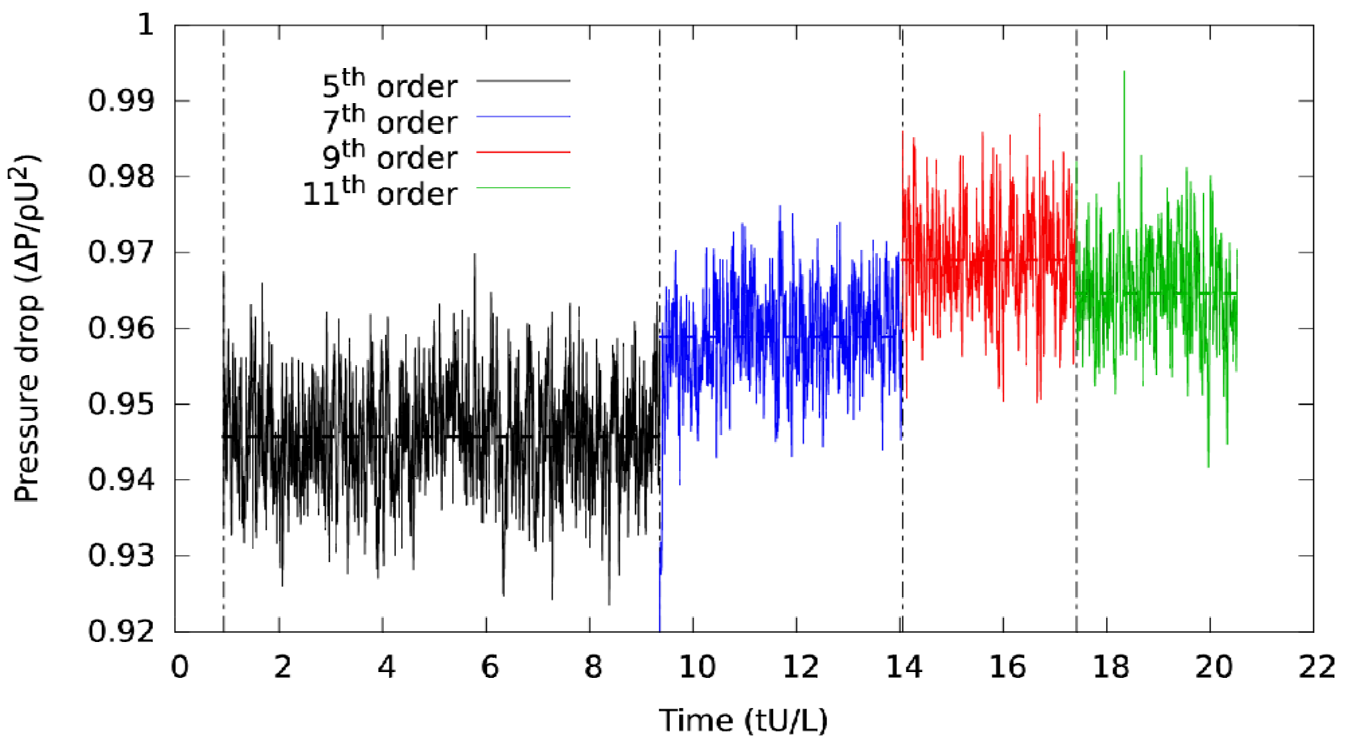

Figure 11 Transient pressure drop data for the sharp-edged case at varying spatial approximation orders, the dashed lines indicate averaged values.

Table 4 Pressure drop and percent differences for the sharp-edged case at varying spatial approximation order

\begin{tabular}{|c|c|c|c|}
\hline Order & $\begin{array}{c}\text { Average } y+\text { of the first GLL } \\
\text { point }\end{array}$ & Average pressure drop & Percent difference \\
\hline 5 & 2.15 & 0.946 & 1.98 \\
\hline 7 & 1.21 & 0.959 & 0.598 \\
\hline 9 & 0.77 & 0.969 & 0.452 \\
\hline 11 & 0.53 & 0.965 & -- \\
\hline
\end{tabular}

Table 5 Meshing statistics for the Nek5000 analysis

\begin{tabular}{|c|c|c|c|c|c|}
\hline Test Case & $\begin{array}{c}\mathrm{R}_{\mathrm{c}, \text { Curv }} \\
(\mathrm{mm})\end{array}$ & $\begin{array}{c}\mathrm{R}_{\mathrm{A}, \mathrm{Cur}} \\
(\mathrm{mm})\end{array}$ & $\begin{array}{c}\text { Number of } \\
\text { elements }\end{array}$ & $\begin{array}{c}\text { Number of } \\
\text { degrees of } \\
\text { freedom (millions) }\end{array}$ & Average $\mathrm{y}+$ \\
\hline Case-A & \multirow{2}{*}{0.0 (fixed) } & 0.0 & 81,040 & 27.5 & 1.21 \\
\cline { 5 - 6 } & & 2.0 & 77,040 & 26.1 & 1.18 \\
\cline { 5 - 6 } & & 5.0 & 79,040 & 26.8 & 1.15 \\
\cline { 5 - 6 } & & 10.0 & 83,040 & 28.1 & 1.13 \\
\hline Case-B & 2.0 & 5.0 (fixed) & 74,720 & 25.3 & 1.14 \\
\cline { 5 - 6 } & 5.0 & & 79,040 & 26.8 & 1.15 \\
\cline { 5 - 6 } & 10.0 & & 83,360 & 28.3 & 1.14 \\
\hline
\end{tabular}


Title: $\quad$ Transitions within a Hexagonal Duct

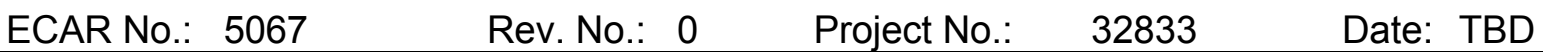

\section{E. NEK5000 RESULTS}

LES cases were run with Nek5000 for an inlet Reynolds number of 20,000 . For a flow of liquid sodium with a density of $860 \mathrm{~kg} / \mathrm{m}^{3}$ and viscosity of $0.0003 \mathrm{~kg} / \mathrm{m}$-s, this corresponds to an inlet velocity of 0.12 $\mathrm{m} / \mathrm{s}$. A Reynolds number of 20,000 was chosen as higher values proved to be too expensive computationally. All simulations were run until the recycling inlet condition reached a statistically fully developed state and an additional duration to allow the full domain to reach a statistically steady state. This corresponded to approximately 20 flow-through times $(t=20 \mathrm{~L} / \mathrm{U})$. The instantaneous pressure drop was then recorded at every time step for an additional 10-20 flow-through times and timeaveraged to reduce statistical uncertainty.

The overall loss coefficients and the corresponding pressure drop in Pa are provided in Table 6 and the lost coefficients predicted by LES in Nek5000 are compared to those predicted with RANS in Star$\mathrm{CCM}+$ in Figure 12 for the varying outlet radius and Figure 13 for the varying inlet radius. The LES data was curve fit using an exponential function and uncertainty bands of $+/-5 \%$ and $+/-20 \%$ are shown for reference. It can be seen that the RANS model in Star-CCM+ consistently predicts about a $20 \%$ lower pressure drop compared to the LES model in Nek5000. It is likely that the LES results are more accurate due to the higher-fidelity nature of the model and the significant recirculation zones present in the flow, which RANS models are known to have difficulty in predicting accurately.

Table 6 Pressure drop results for the LES cases

\begin{tabular}{|c|c|c|c|c|}
\hline Test Case & $\begin{array}{l}R_{\mathrm{c}, \text { Curv }} \\
(\mathrm{mm})\end{array}$ & $\begin{array}{l}R_{A, \text { Curv }} \\
(\mathrm{mm})\end{array}$ & $\begin{array}{c}\text { Loss } \\
\text { coefficient }\end{array}$ & $\begin{array}{l}\text { Pressure drop } \\
\quad(\mathrm{Pa})\end{array}$ \\
\hline \multirow[t]{4}{*}{ Case-A } & \multirow[t]{4}{*}{0.0 (fixed) } & 0.0 & 1.93 & 11.2 \\
\hline & & 2.0 & 1.49 & 8.6 \\
\hline & & 5.0 & 1.15 & 6.7 \\
\hline & & 10.0 & 0.924 & 5.4 \\
\hline \multirow[t]{3}{*}{ Case-B } & 2.0 & \multirow[t]{3}{*}{5.0 (fixed) } & 1.14 & 6.6 \\
\hline & 5.0 & & 1.12 & 6.5 \\
\hline & 10.0 & & 1.10 & 6.4 \\
\hline
\end{tabular}


Title: $\quad$ Computational Evaluation on Effect

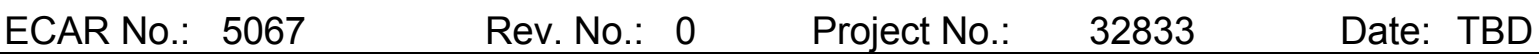

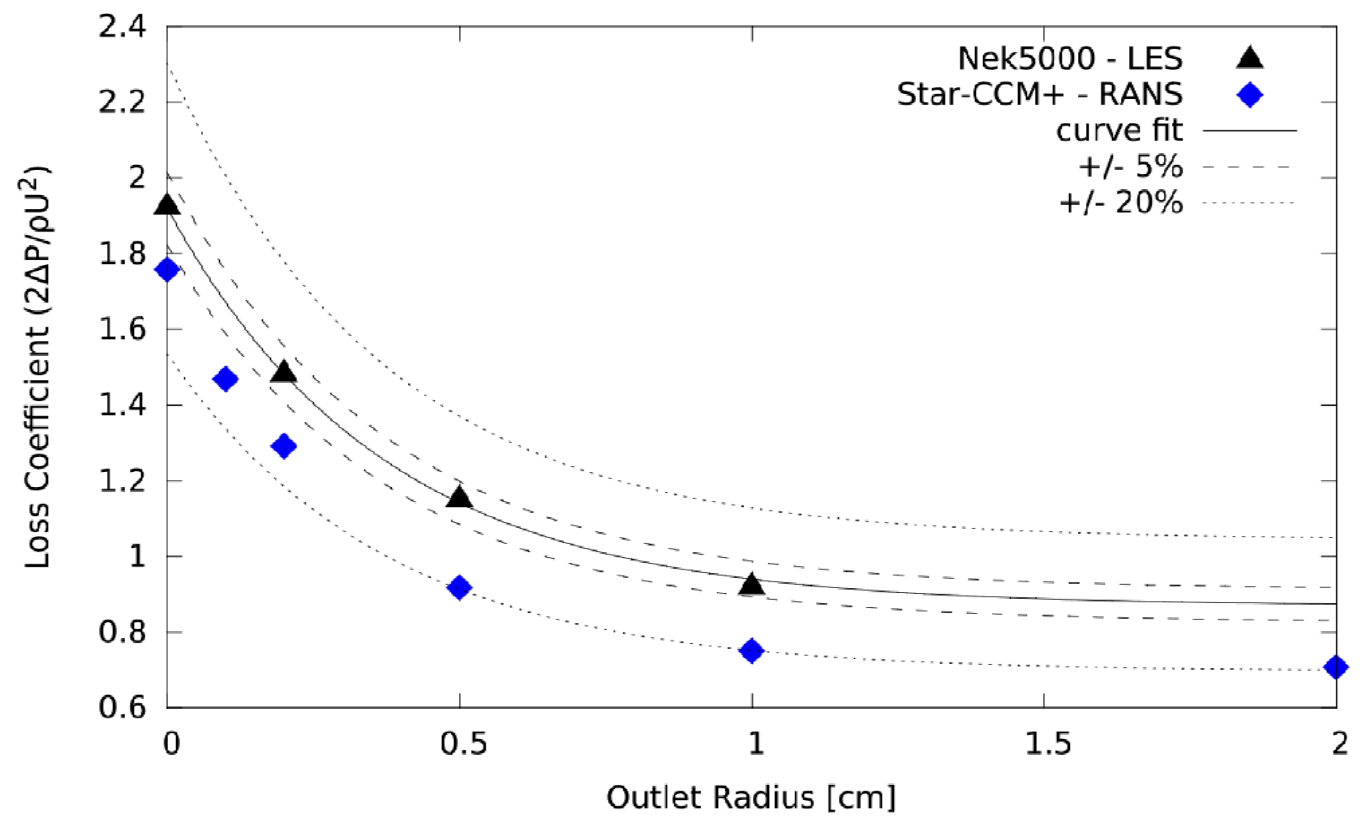

Figure 12 Variation in the overall loss coefficient for variable outlet edge roundedness

Colormaps showing profiles of the instantaneous and average velocity distributions on a midplane slice across the transition region for the sharp-edged case are shown in Figure 14 with the pressure profiles shown in Figure 15 with the colormaps of the time-averaged distributions for the remainder of the cases presented in Appendix E. From the results presented in Figures 12 \& 13, both models predict very similar trends in behavior. It can then reasonably be concluded that the effect of increasing the edge radius on the outlet has by far the more significant effect on the overall pressure drop. This is likely due to the presence of the vena contract, which can be seen in the velocity colormaps just after the transition to the annulus. As the outlet radius is increased, the effect of the vena contracta can be observed to decrease in magnitude. 
Computational Evaluation on Effect of Edge-rounding in Circular to Annular Flow

Title: $\quad$ Transitions within a Hexagonal Duct

ECAR No.: 5067

Rev. No.: 0

Project No:

32833

Date: TBD

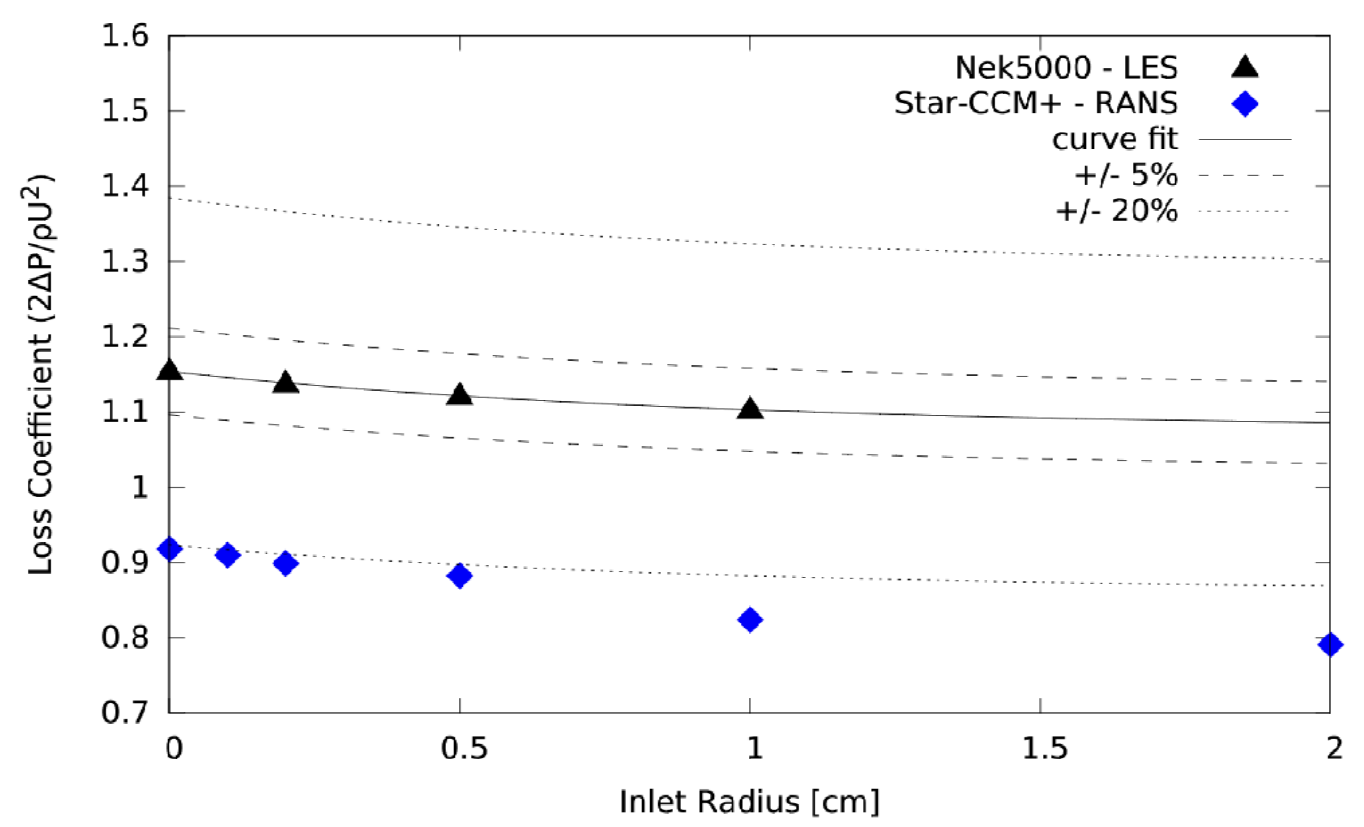

Figure 13 Variation in the overall loss coefficient for variable inlet edge roundedness
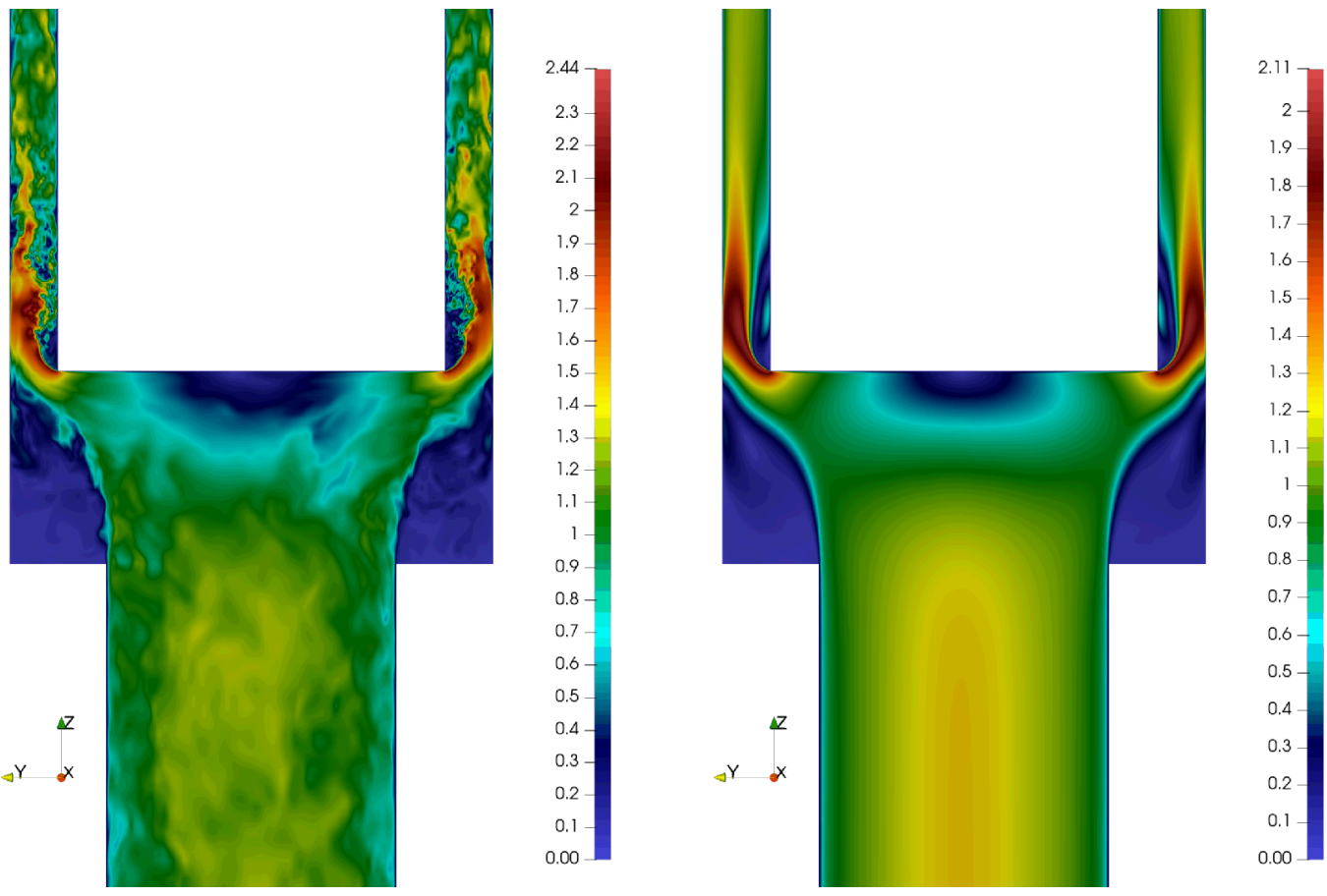

Figure 14 Velocity ( $\mathrm{u} / \mathrm{U})$ predicted by Nek5000 for the sharp-edged case showing both (left) instantaneous and (right) time-averaged profiles. 


\section{Title: $\quad$ Transitions within a Hexagonal Duct}

$\begin{array}{llllll}\text { ECAR No.: } 5067 & \text { Rev. No.: } & 0 & \text { Project No.: } & 32833 & \text { Date: }\end{array}$
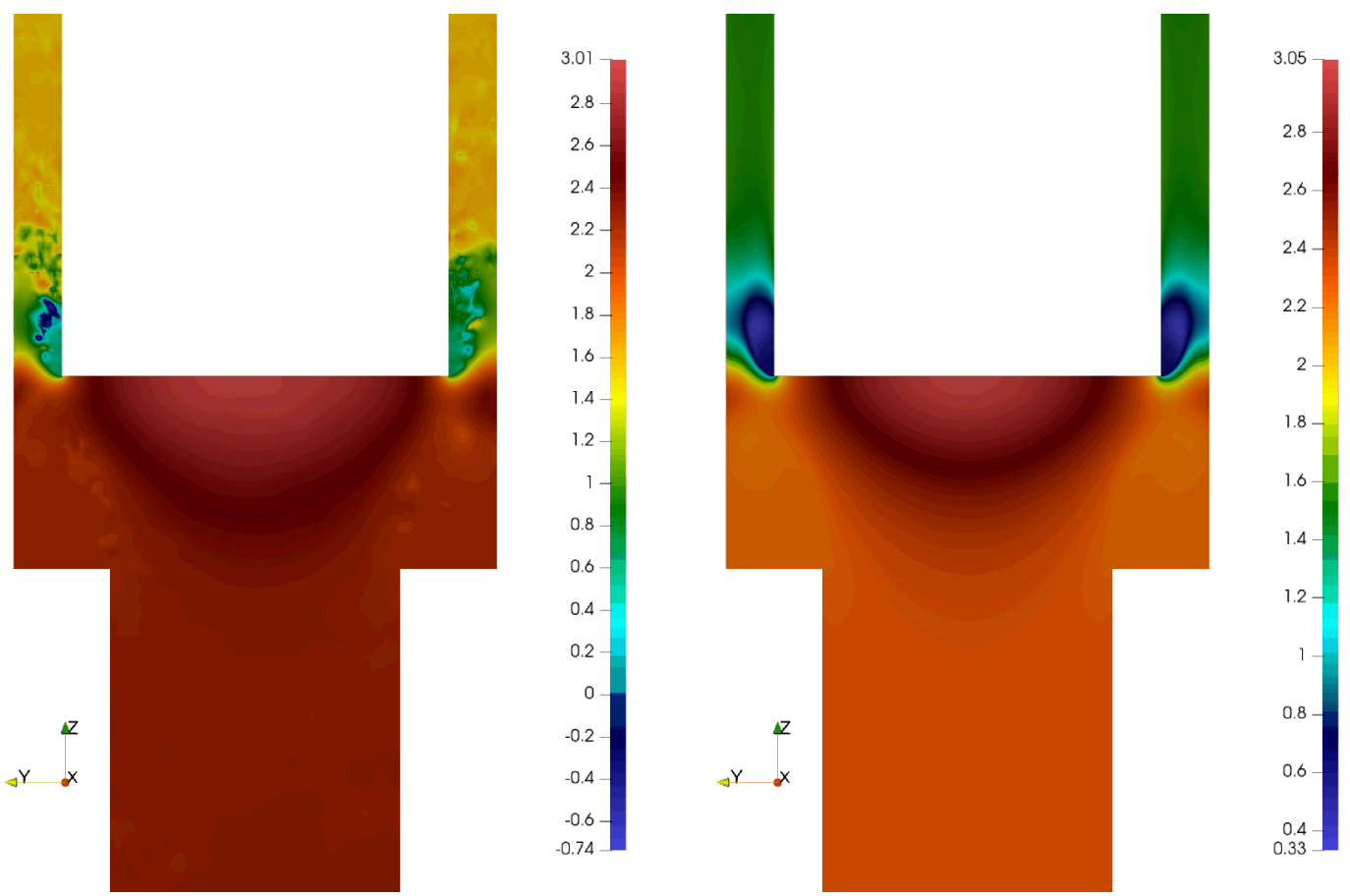

Figure 15 Pressure $\left(\mathrm{P} / \mathrm{pU}^{2}\right)$ predicted by Nek5000 for the sharp-edged case showing both (left) instantaneous and (right) time-averaged profiles.

\section{SUMMARY}

In this ECAR, the computational fluid dynamics (CFD) simulation of the duct with a cross-section varying from circle to annulus was performed to evaluate the effect of edge-rounding of the internal edges. The edge of circular channel and the edge of inner annular channel were rounded with the radius of curvature ranged from $0 \mathrm{~mm}$ to $20 \mathrm{~mm}$. The CFD results show that the pressure loss of the duct can be reduced by increasing the radius of the rounded edge. Case-A results showed that the pressure drop can be significantly reduced by the edge-rounding, e.g., the pressure drop was reduced approximately $56 \%$ by the radius of curvature of $5.0 \mathrm{~mm}$, and reduced $70 \%$ by the radius of curvature of $20.0 \mathrm{~mm}$ although its effectiveness would be attenuated as the radius of curvature of edge increases. Results from Case-B showed the impact of rounding the inlet edge was practically negligible compared to the outlet edge. This ECAR could provide a guideline to determine the optimum inlet module design of the VTR fuel rod bundle. 
Computational Evaluation on Effect of Edge-rounding in Circular to Annular Flow

Title: $\quad$ Transitions within a Hexagonal Duct

$\begin{array}{llllll}\text { ECAR No.: } 5067 & \text { Rev. No.: } & 0 & \text { Project No.: } & 32833 & \text { Date: } T B D\end{array}$

\section{REFERENCES}

[1] S. Cheng and N. Todreas, "Hydrodynamic models and correlations for bare and wire-wrapped hexagonal rod bundles - Bundle friction factors, subchannel friction factors and mixing parameters," Nuclear Engineering and Design, vol. 92, no. 2, pp. 227-251, 1986.

[2] E. Novendstern, "Turbulent Flow Pressure Drop Model for Fuel Rod Assemblies Utilizing a Helical Wire-wrap Sapcer System," Nulcear Engineering and Design, vol. 22, pp. 19-27, 1972.

[3] K. Rehme, "Pressure Drop Correlations for Fuel Element Spacers," Nuclear Technology, vol. 17, pp. 15-23, 1973.

[4] F. Engel, R. Markley and A. Bishop, "Laminar, Transition, and Turbulent Parallel Flow Pressure Drop Across Wire-Wrap-Spaced Rod Bundles," Nuclear Science and Engineering, vol. 69, no. 2, pp. 290-296, 1979.

[5] C. Baxi and M. Dalle Donne, Heat Transfer and Fluid Flow in Nuclear Systems, Pergamon Press Inc., 1981, pp. 410-462.

[6] I. Idelchik, Handbook of Hydraulic resistance, 3rd Edition, New York: Begell House, 2001.

[7] Simens PLM Software, "STAR-CCM+ Documentation," 2019. 
Rev. 1

Title:

Computational Evaluation on Effect of Edge-rounding in Duct with Cross-section varying from Circle to Annulus

ECAR No.:

5067

Rev. No.: 0

Project No.:

32833

Date: TBD

\section{Appendix A. MESH STRUCTURE OF STAR-CCM+ MODEL}

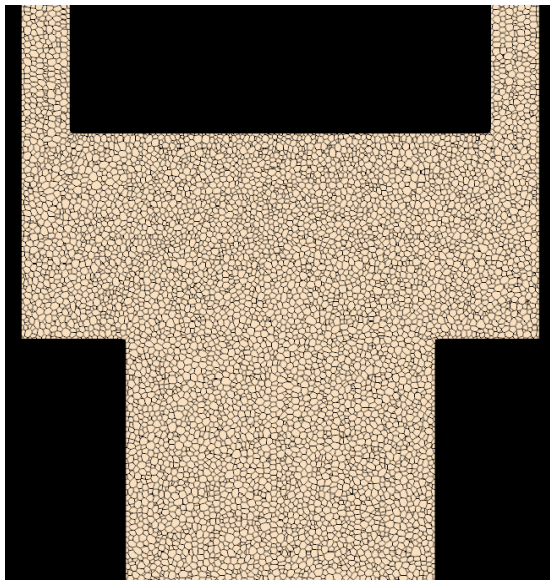

(a) $\mathrm{R}_{\mathrm{A}, \text { Curv }}=0 \mathrm{~mm}$

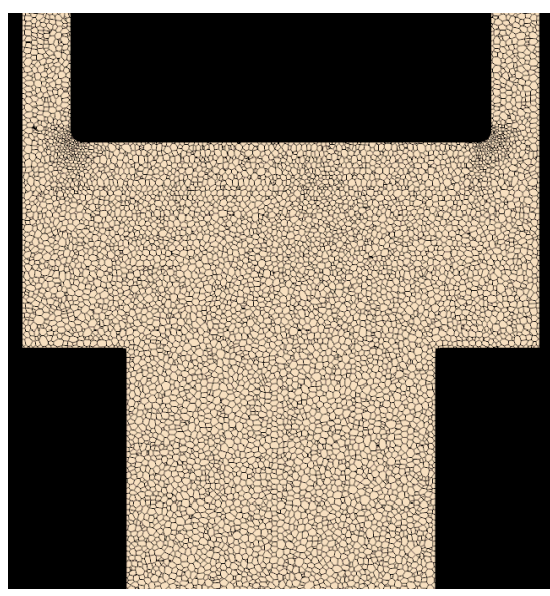

(c) $\mathrm{R}_{\mathrm{A}, \mathrm{Curv}}=2 \mathrm{~mm}$

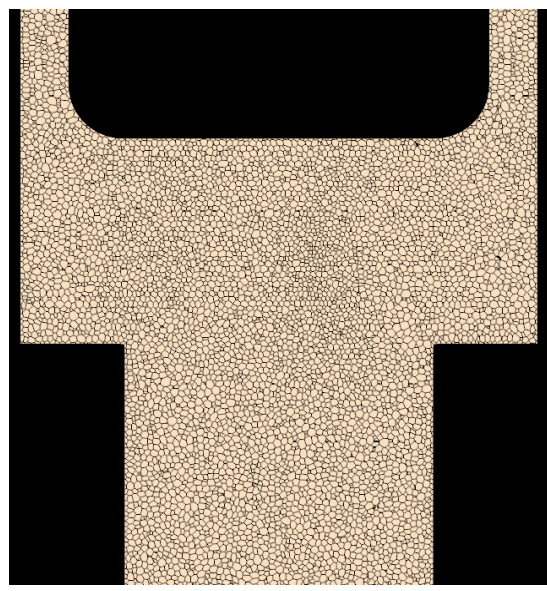

(e) $R_{A, C u r v}=10 \mathrm{~mm}$

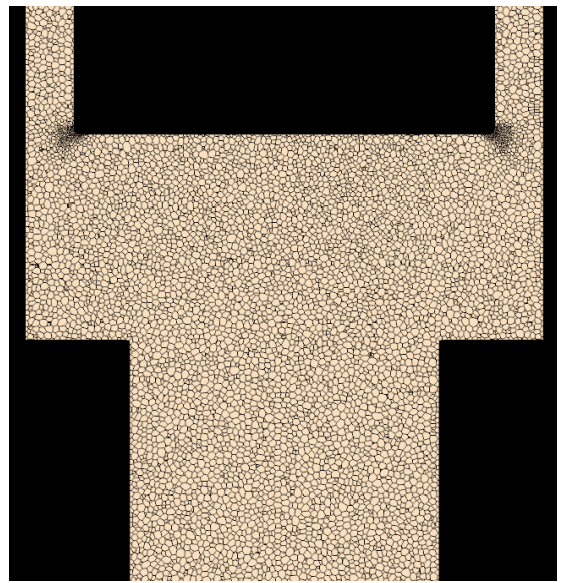

(b) $\mathrm{R}_{\mathrm{A}, \text { Curv }}=1 \mathrm{~mm}$

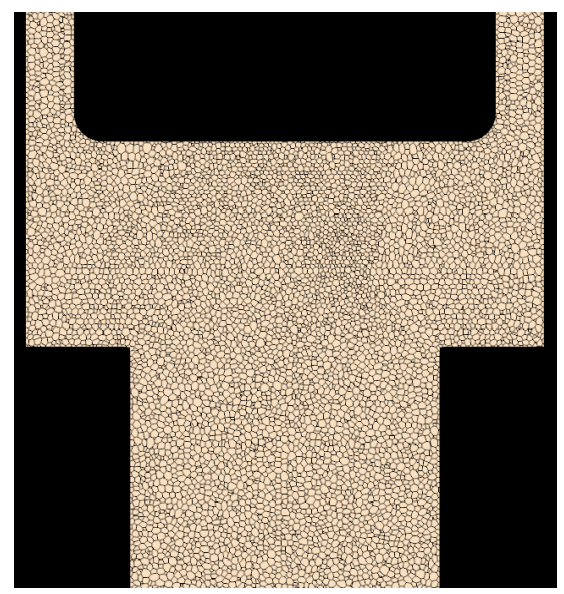

(d) $R_{\text {A,Curv }}=5 \mathrm{~mm}$

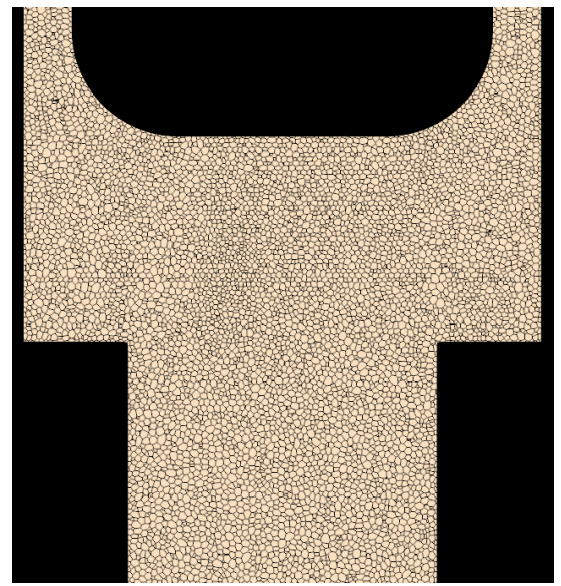

(f) $R_{A, \text { Curv }}=20 \mathrm{~mm}$

Figure A.1. Mesh structure in vicinity of transition region (Case-A). 
Rev. 1

Title:

Computational Evaluation on Effect of Edge-rounding in Duct with Cross-section varying from Circle to Annulus

ECAR No.:

5067

Rev. No.: 0

Project No.:

Date: TBD

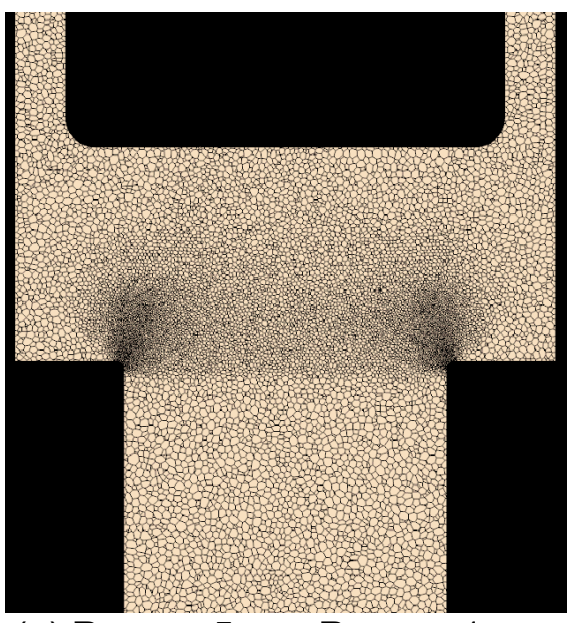

(a) $\mathrm{R}_{\mathrm{A}, \text { Curv }}=5 \mathrm{~mm}, \mathrm{R}_{\mathrm{C}, \text { Curv }}=1 \mathrm{~mm}$

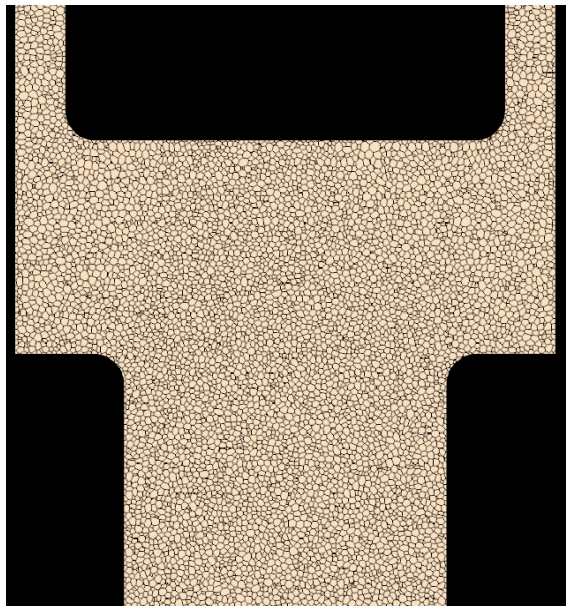

(c) $\mathrm{R}_{\mathrm{A}, \text { Curv }}=5 \mathrm{~mm}, \mathrm{R}_{\mathrm{C}, \text { Curv }}=5 \mathrm{~mm}$

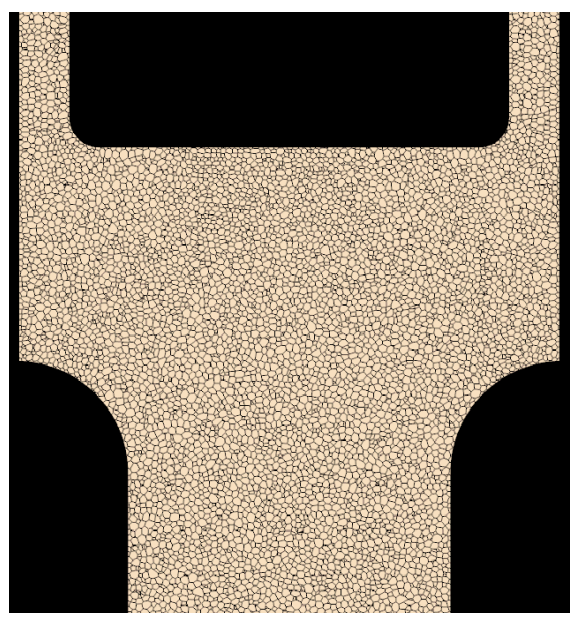

(e) $R_{A, C u r v}=5 \mathrm{~mm}, R_{C, \text { Curv }}=20 \mathrm{~mm}$

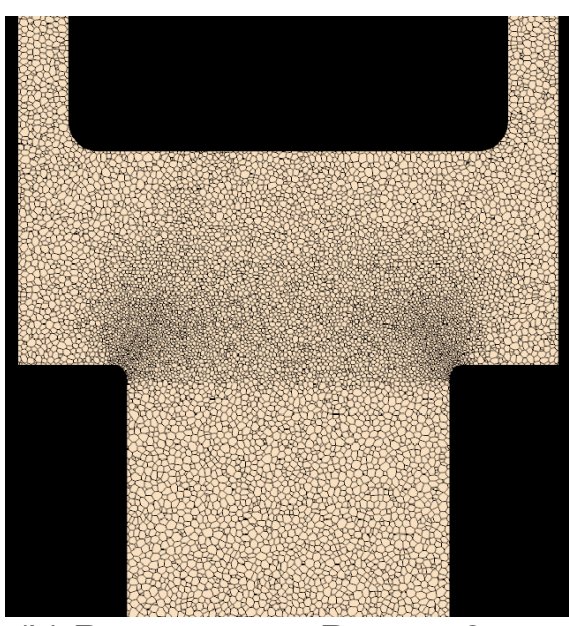

(b) $R_{A, C u r v}=5 \mathrm{~mm}, R_{C, \text { Curv }}=2 \mathrm{~mm}$

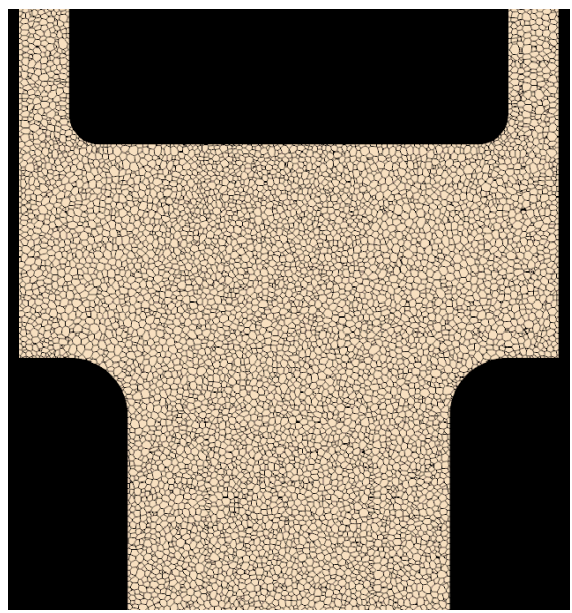

(d) $R_{A, \text { Curv }}=5 \mathrm{~mm}, R_{C, \text { Curv }}=10 \mathrm{~mm}$

Figure A.2. Mesh structure in vicinity of transition region (Case-B). 
Title:

Computational Evaluation on Effect of Edge-rounding in Duct with Cross-section varying from Circle to Annulus

ECAR No.:

5067

Rev. No.: 0

Project No.:

32833

Date: TBD

\section{Appendix B. THE STAR-CCM+ VELOCITY DISTRIBUTION RESULTS}

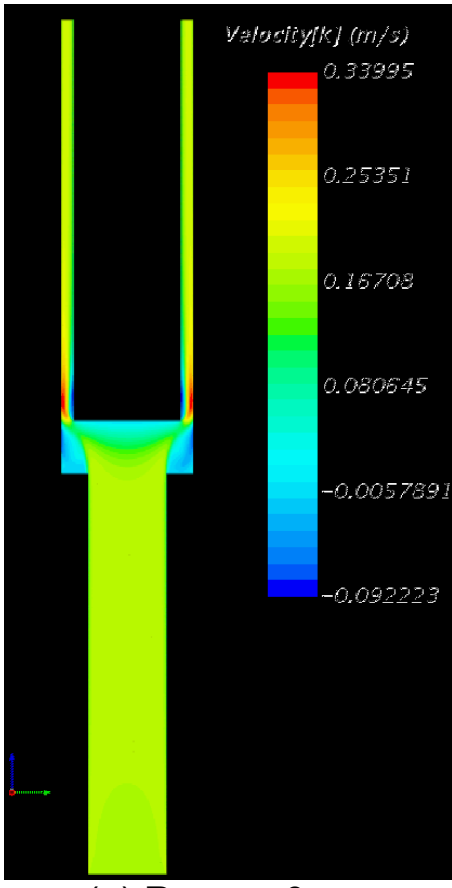

(a) $\mathrm{R}_{\mathrm{A}, \mathrm{Curv}}=0 \mathrm{~mm}$

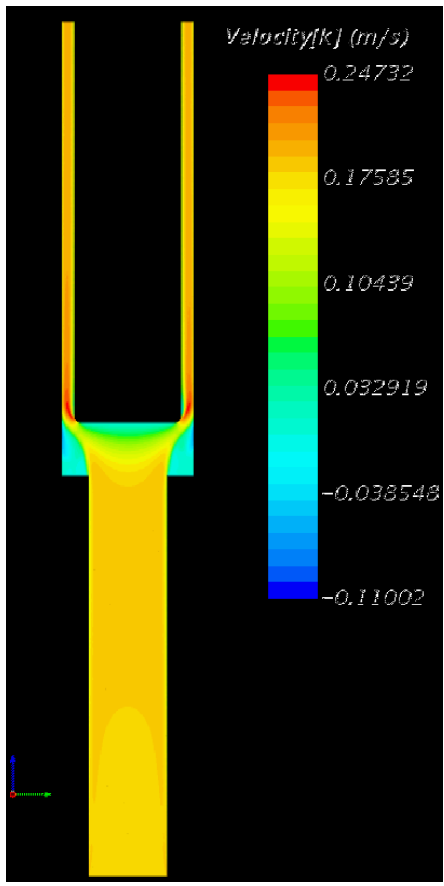

(d) $R_{\mathrm{A}, \text { Curv }}=5 \mathrm{~mm}$

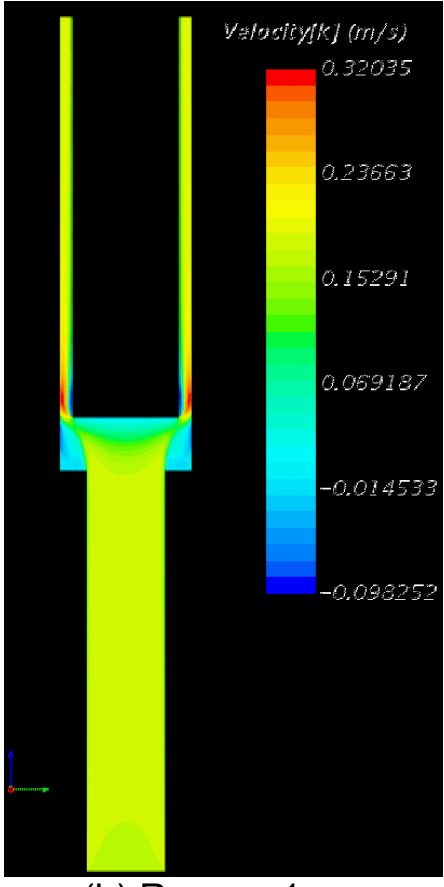

(b) $R_{A, \text { Curv }}=1 \mathrm{~mm}$

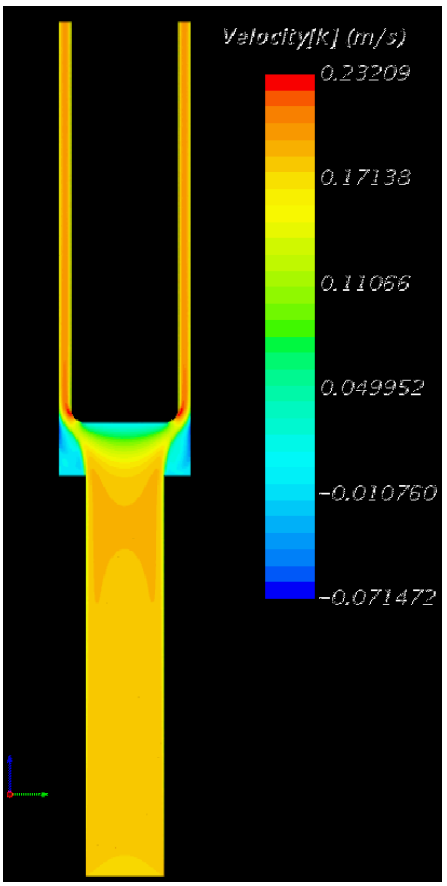

(e) $\mathrm{R}_{\mathrm{A}, \text { Curv }}=10 \mathrm{~mm}$

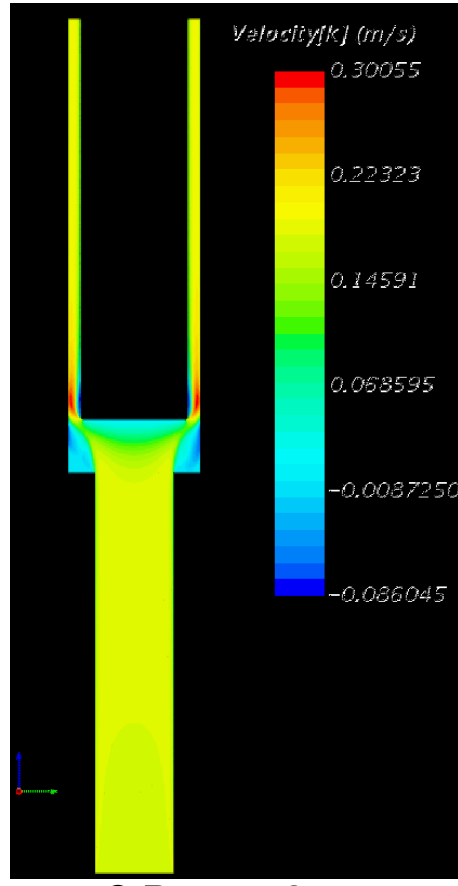

(C) $\mathrm{R}_{\mathrm{A}, \text { Curv }}=2 \mathrm{~mm}$

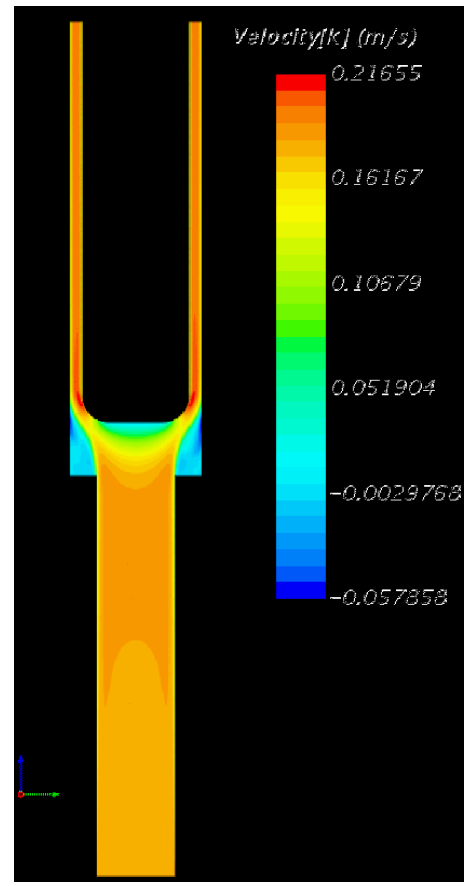

(f) $R_{A, C u r v}=20 \mathrm{~mm}$

Figure B.1. Velocity profiles on the mid-plane of the channel (Case-A, $R e_{D}=3 \times 10^{4}$ ). 
Rev. 1

Title: $\quad$ Computational Evaluation on Effect of Edge-rounding in Duct with Cross-section varying from Circle to Annulus

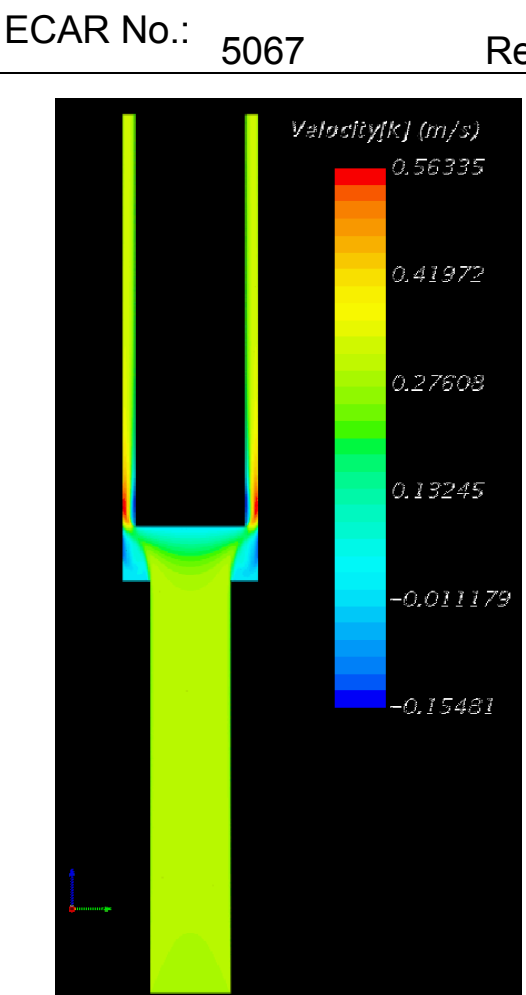

(a) $\mathrm{R}_{\mathrm{A}, \mathrm{Curv}}=0 \mathrm{~mm}$

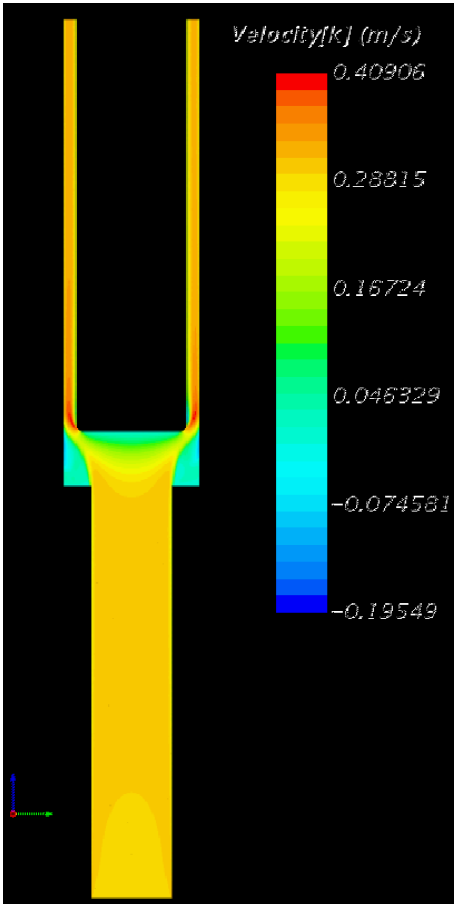

(d) $R_{A, \text { Curv }}=5 \mathrm{~mm}$

Rev. No.: 0

Project No.:

32833

Date: TBD

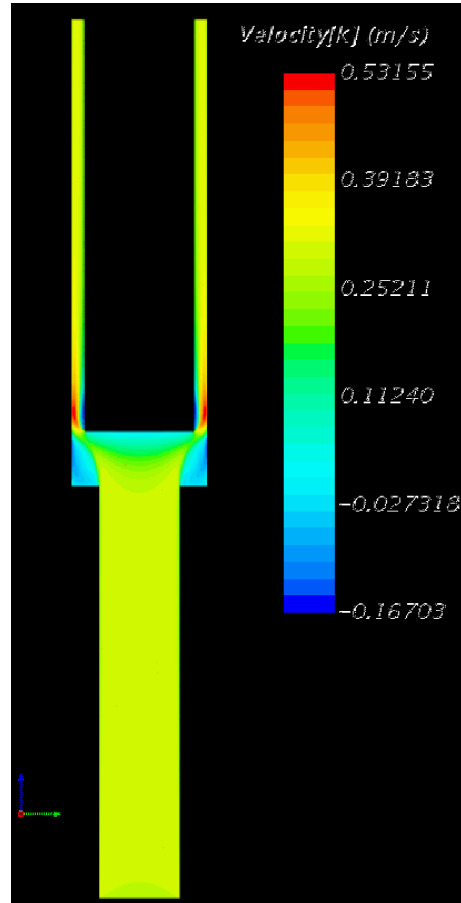

(b) $R_{A, \text { Curv }}=1 \mathrm{~mm}$

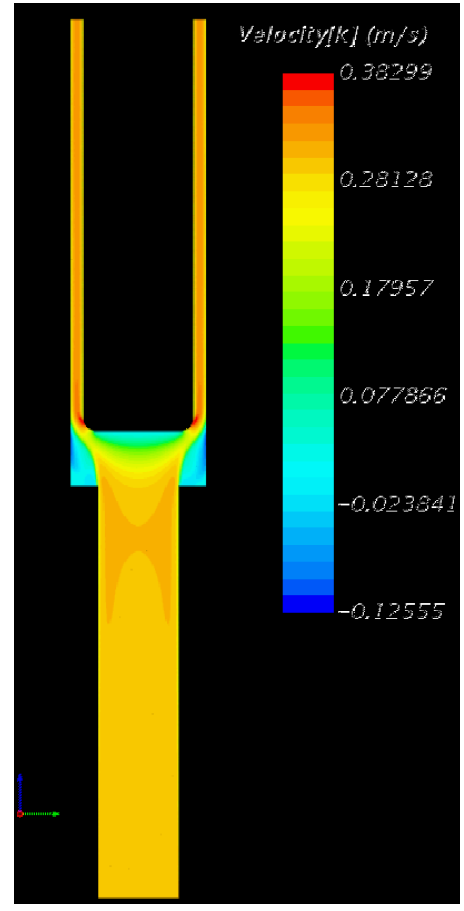

(e) $R_{A, \text { Curv }}=10 \mathrm{~mm}$

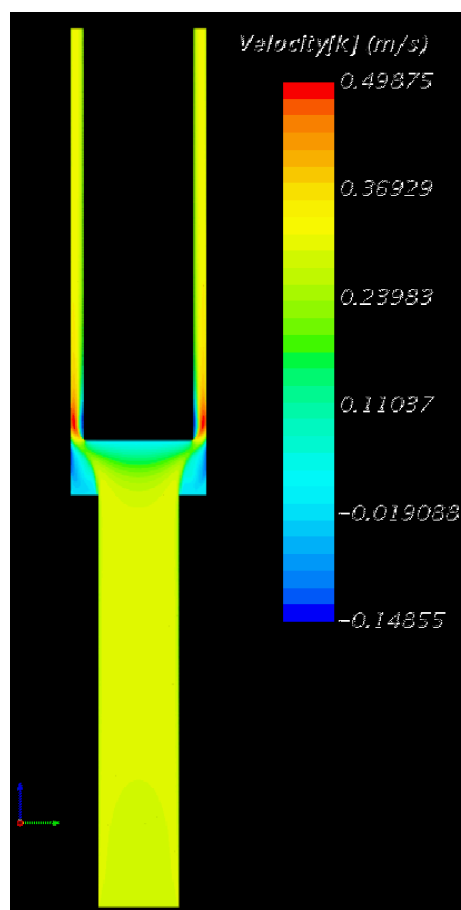

(C) $\mathrm{R}_{\mathrm{A}, \text { Curv }}=2 \mathrm{~mm}$

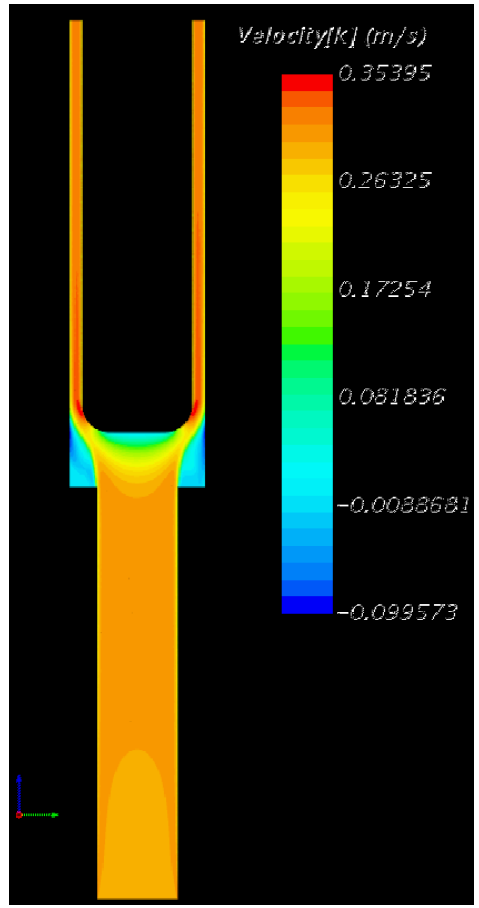

(f) $R_{A, \text { Curv }}=20 \mathrm{~mm}$

Figure B.2. Velocity profiles on the mid-plane of the channel (Case-A, $R e_{D}=5 \times 10^{4}$ ) 
Rev. 1

Title: $\quad$ Computational Evaluation on Effect of Edge-rounding in Duct with Cross-section varying from Circle to Annulus

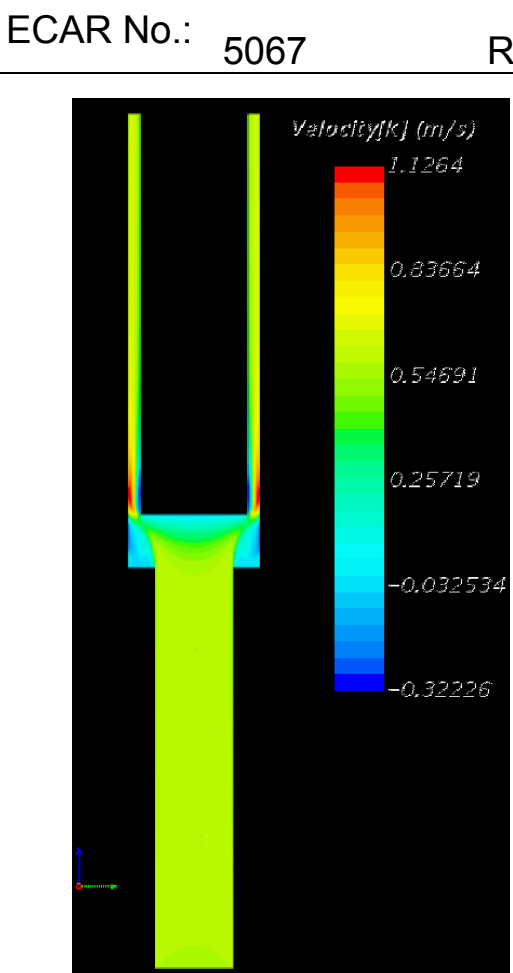

(a) $\mathrm{R}_{\mathrm{A}, \text { Curv }}=0 \mathrm{~mm}$

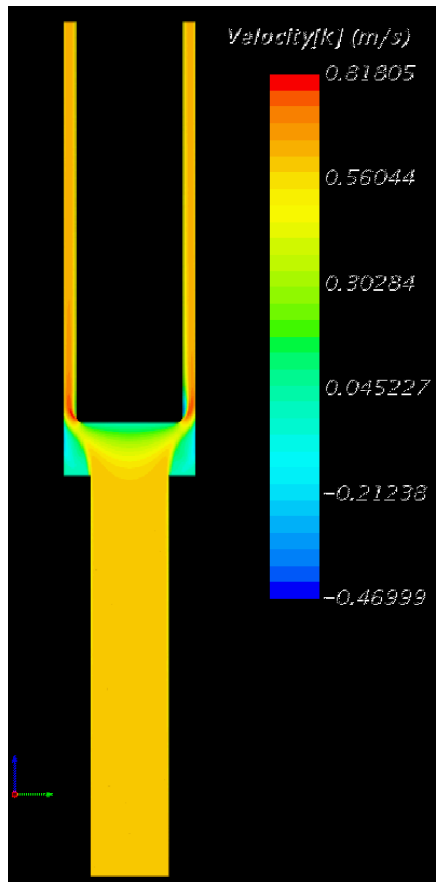

(d) $R_{A, \text { Curv }}=5 \mathrm{~mm}$

Rev. No.: 0

Project No.: 32833 Date: TBD

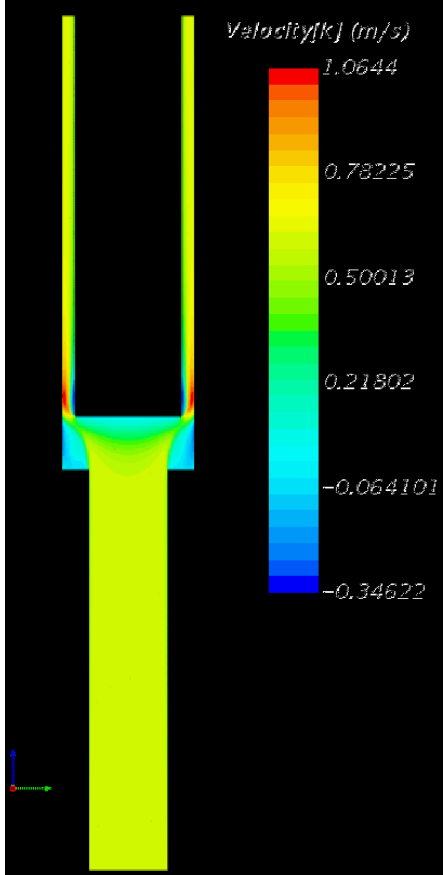

(b) $R_{\mathrm{A}, \mathrm{Curv}}=1 \mathrm{~mm}$

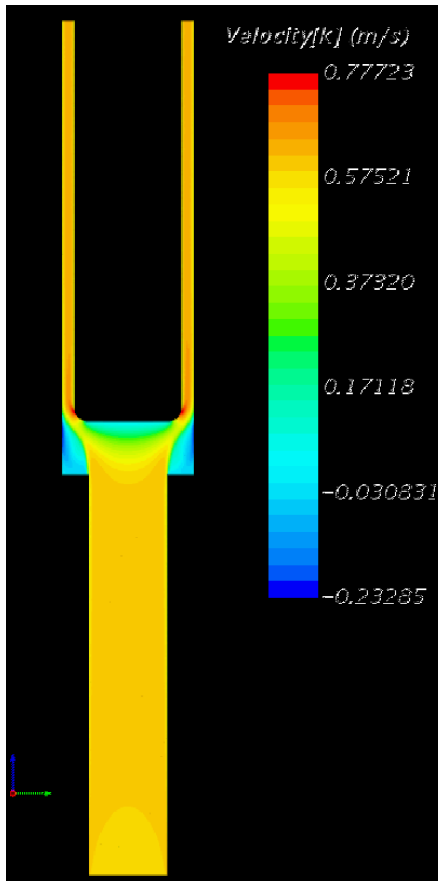

(e) $R_{\mathrm{A}, \text { Curv }}=10 \mathrm{~mm}$

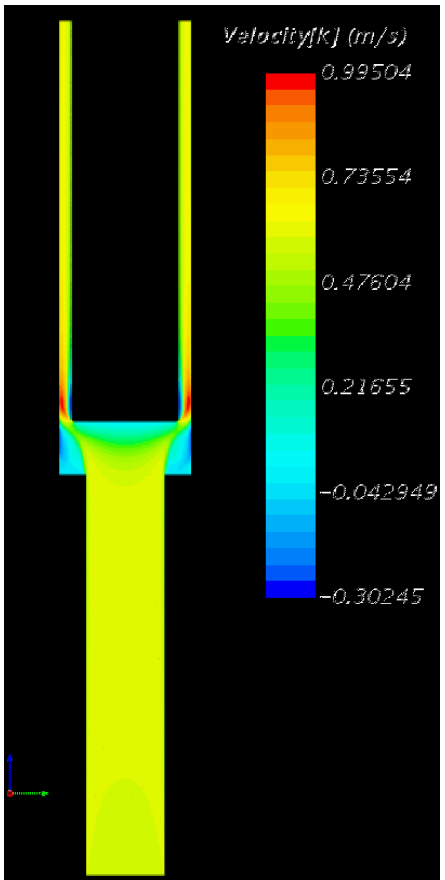

(C) $\mathrm{R}_{\mathrm{A}, \text { Curv }}=2 \mathrm{~mm}$

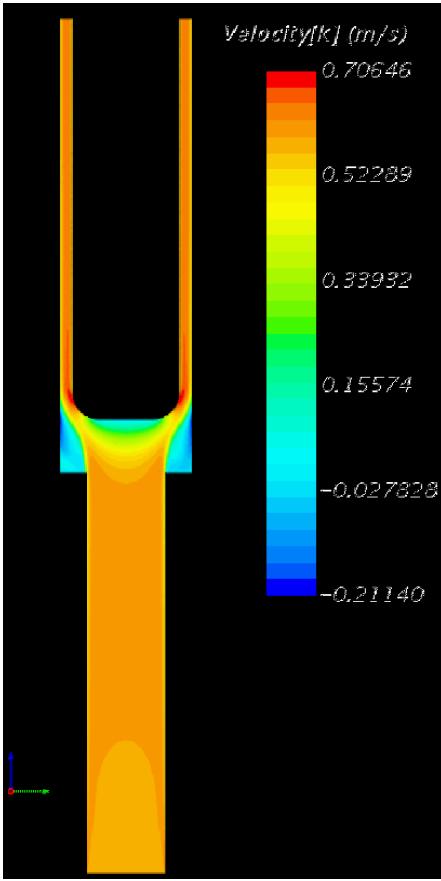

(f) $R_{A, \text { Curv }}=20 \mathrm{~mm}$

Figure B.3. Velocity profiles on the mid-plane of the channel (Case-A, $\operatorname{Re}_{D}=1 \times 10^{5}$ ). 
Rev. 1

Title: $\quad$ Computational Evaluation on Effect of Edge-rounding in Duct with Cross-section varying from Circle to Annulus

ECAR No:

5067

Rev. No.: 0

Project No.:

32833

Date: TBD
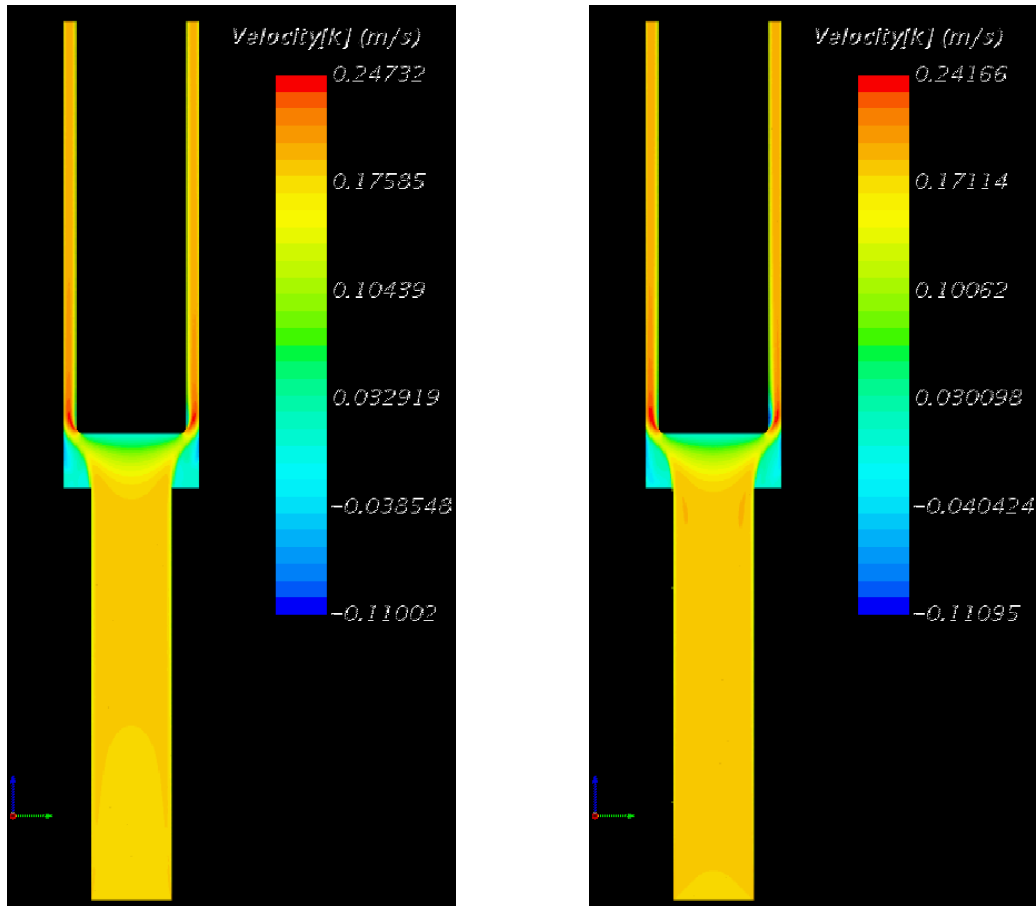

(b) $R_{\mathrm{c}, \text { Curv }}=1 \mathrm{~mm}$

(a) $R_{c, \text { Curv }}=0 \mathrm{~mm}$ (Case-A)

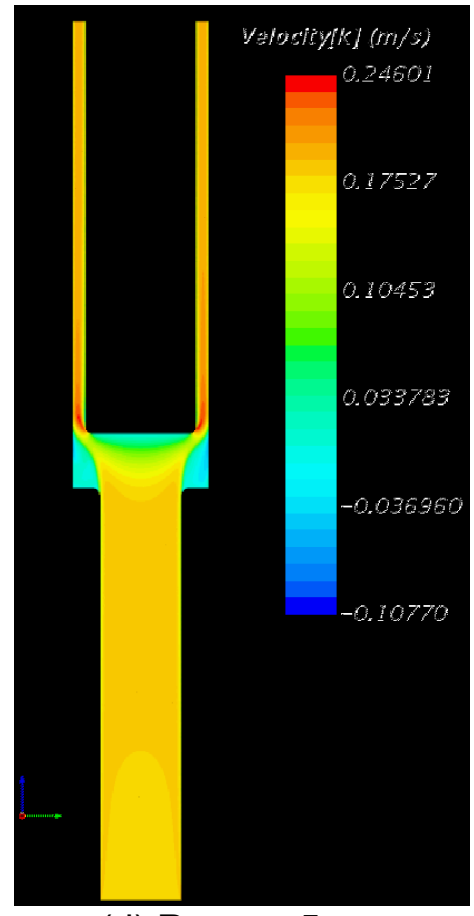

(d) $R_{\mathrm{C}, \text { Curv }}=5 \mathrm{~mm}$

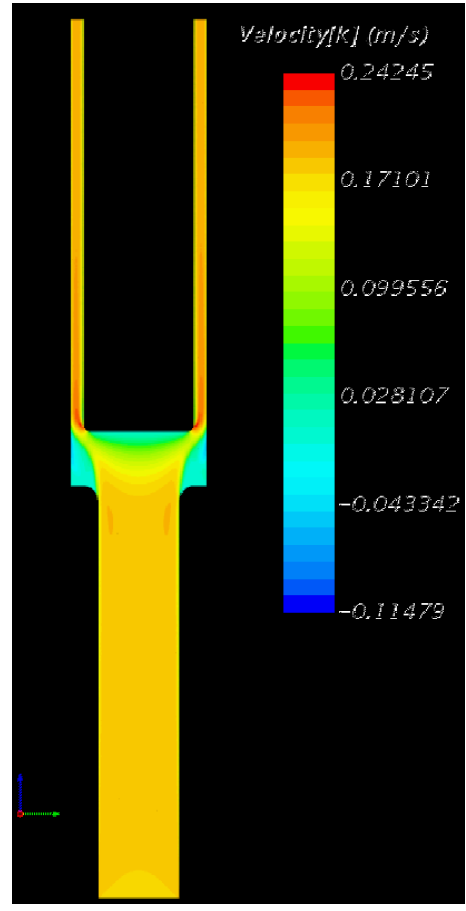

(e) $R_{c, \text { Curv }}=10 \mathrm{~mm}$

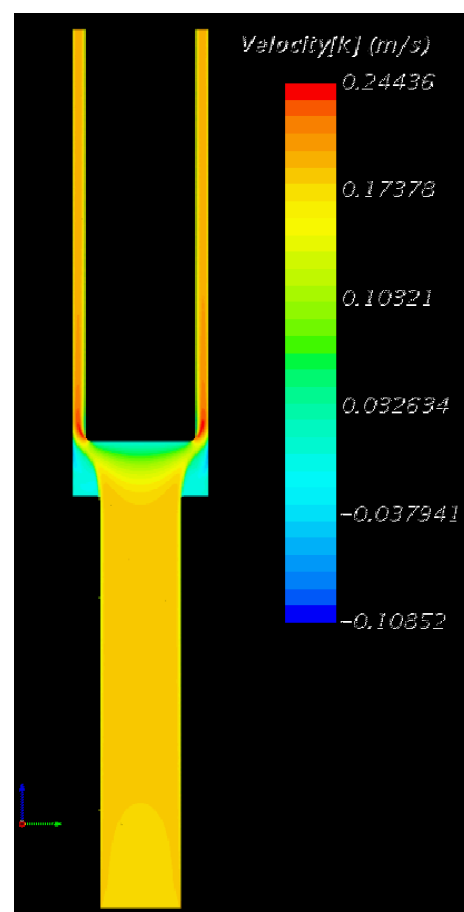

(C) $\mathrm{R}_{\mathrm{C}, \mathrm{Curv}}=2 \mathrm{~mm}$

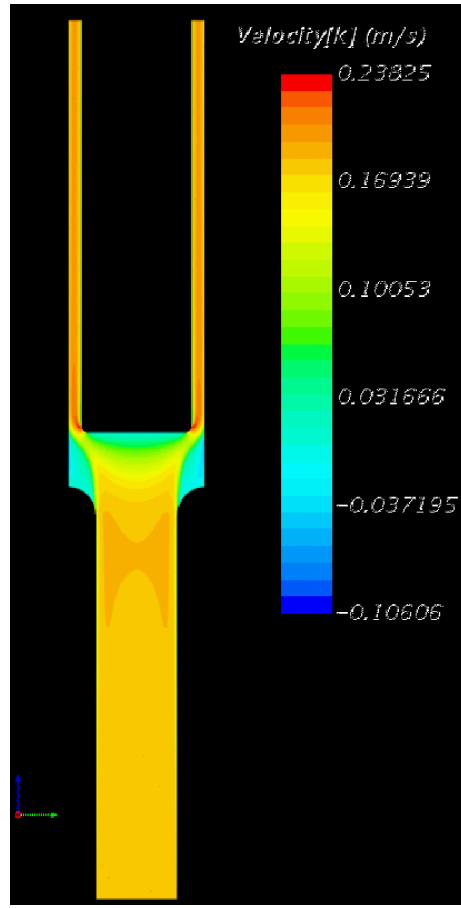

(f) $R_{\mathrm{C}, \text { Curv }}=20 \mathrm{~mm}$

Figure B.4. Velocity distributions on the mid-plane of the channel (Case-B, $R e_{D}=3 \times 10^{4}$ ). 
Rev. 1

Title: $\quad$ Computational Evaluation on Effect of Edge-rounding in Duct with Cross-section varying from Circle to Annulus

ECAR No:

5067

Rev. No.: 0

Project No.:

32833

Date: TBD
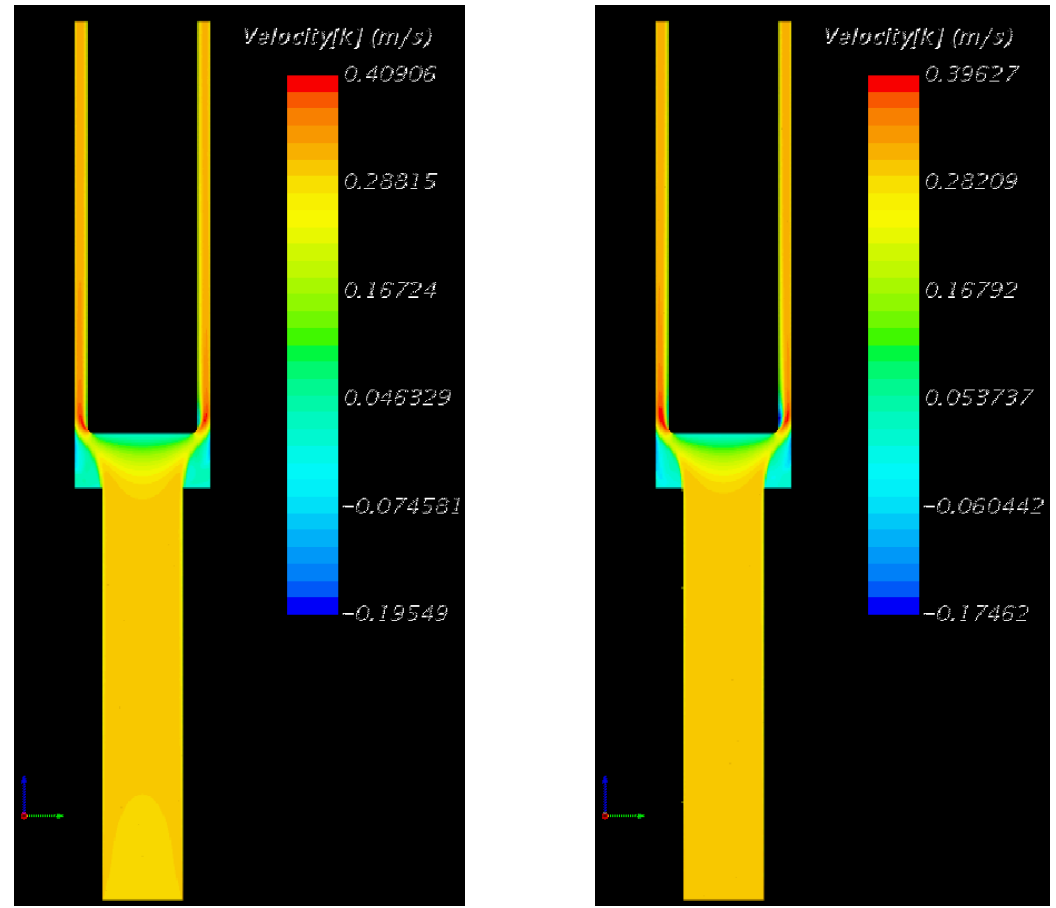

(b) $R_{\mathrm{c}, \text { Curv }}=1 \mathrm{~mm}$

(a) $R_{c, \text { Curv }}=0 \mathrm{~mm}$ (Case-A)

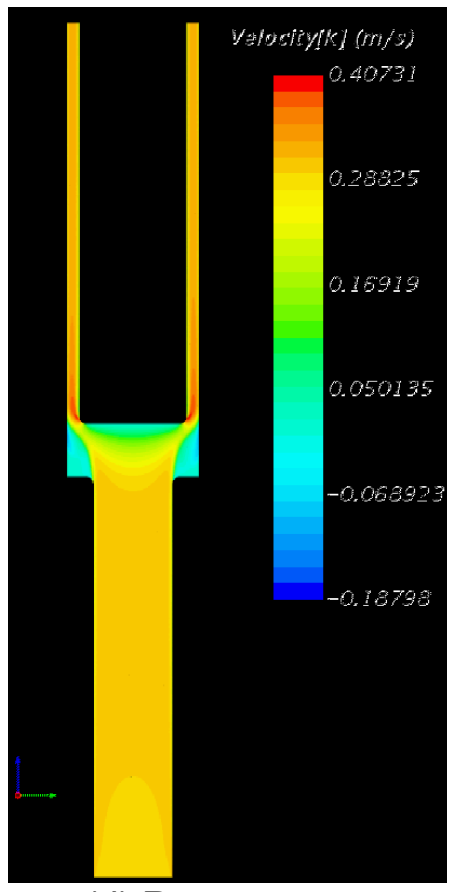

(d) $R_{\mathrm{C}, \text { Curv }}=5 \mathrm{~mm}$

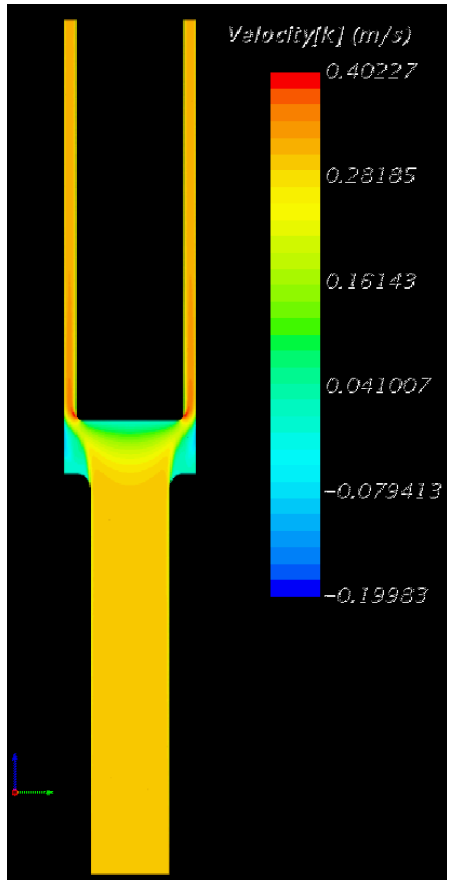

(e) $R_{c, \text { Curv }}=10 \mathrm{~mm}$

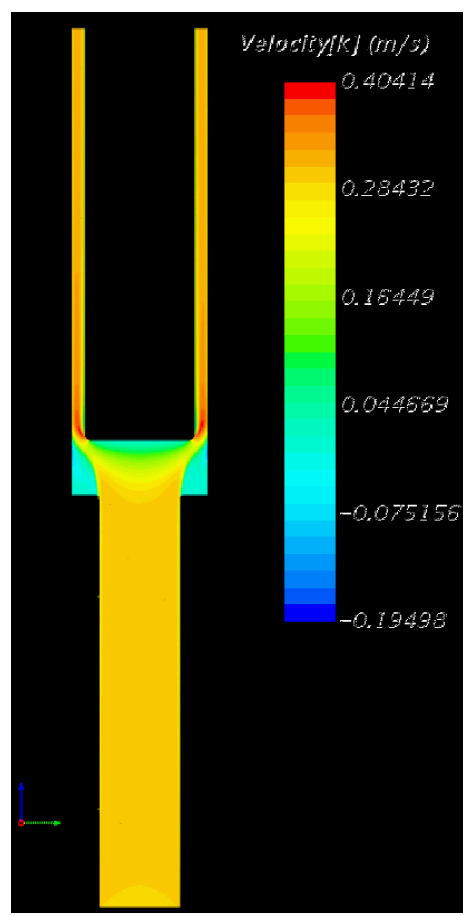

(C) $\mathrm{R}_{\mathrm{C}, \mathrm{Curv}}=2 \mathrm{~mm}$

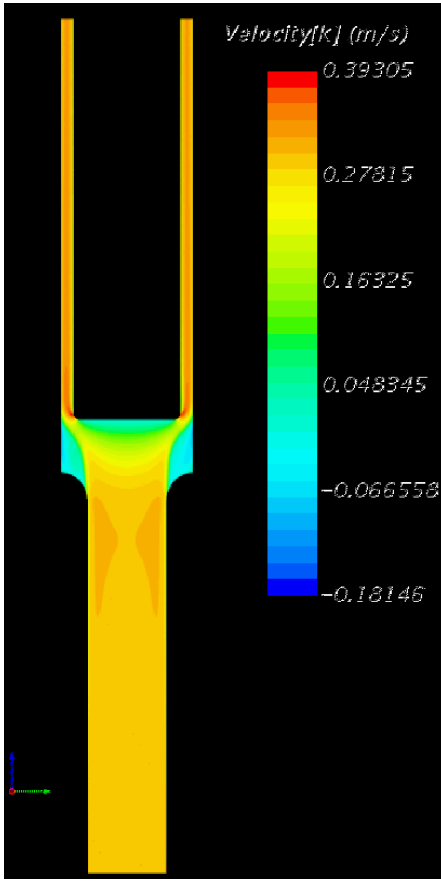

(f) $R_{C, C u r v}=20 \mathrm{~mm}$

Figure B.5. Velocity distributions on the mid-plane of the channel (Case-B, $R e_{D}=5 \times 10^{4}$ ) 
Title: $\quad$ Computational Evaluation on Effect of Edge-rounding in Duct with Cross-section varying from Circle to Annulus

ECAR No:

5067

Rev. No.: 0

Project No.:

32833

Date: TBD

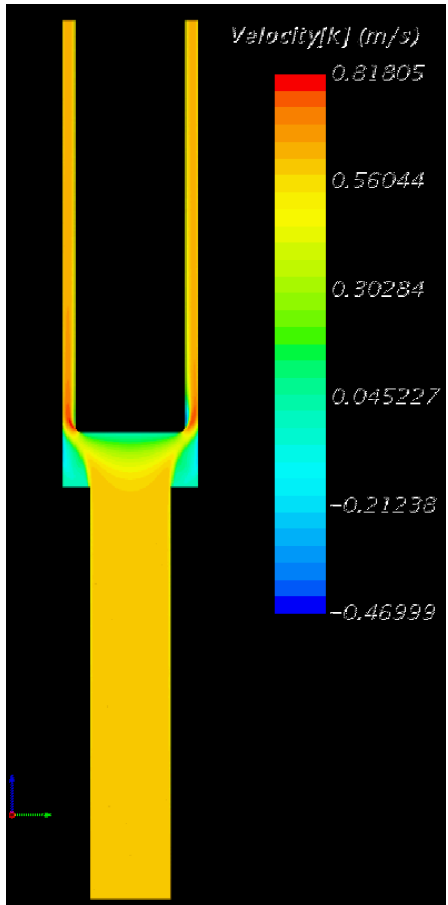

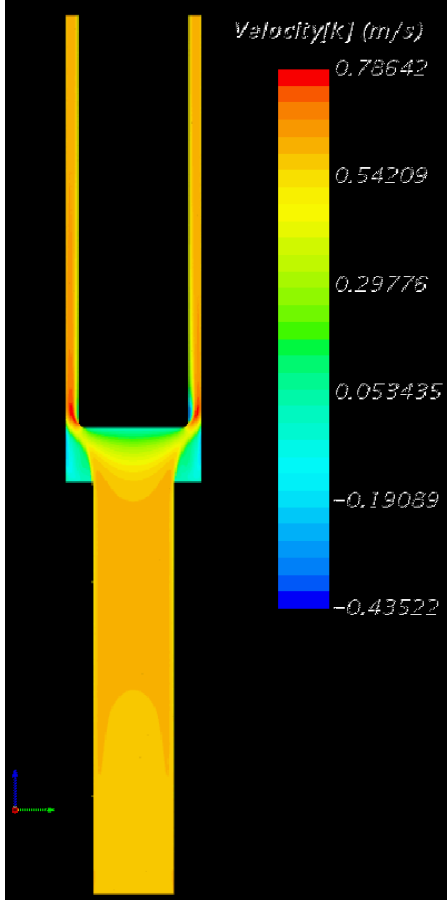

(b) $R_{\mathrm{c}, \text { Curv }}=1 \mathrm{~mm}$

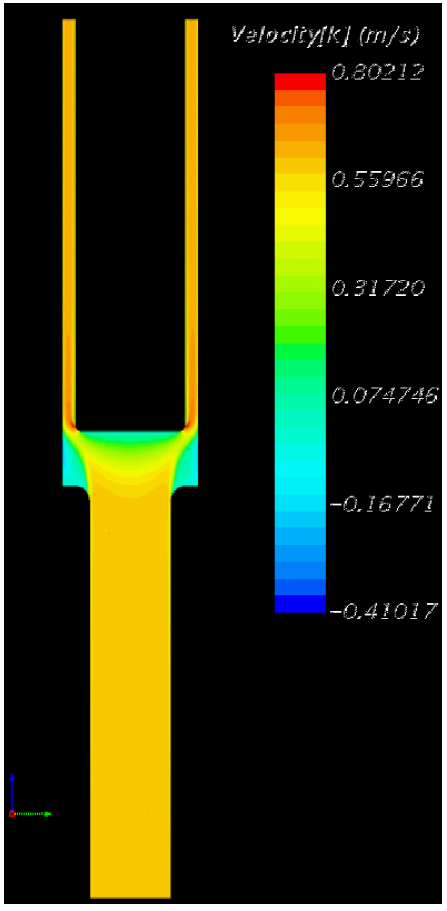

(e) $R_{\mathrm{c}, \text { Curv }}=10 \mathrm{~mm}$

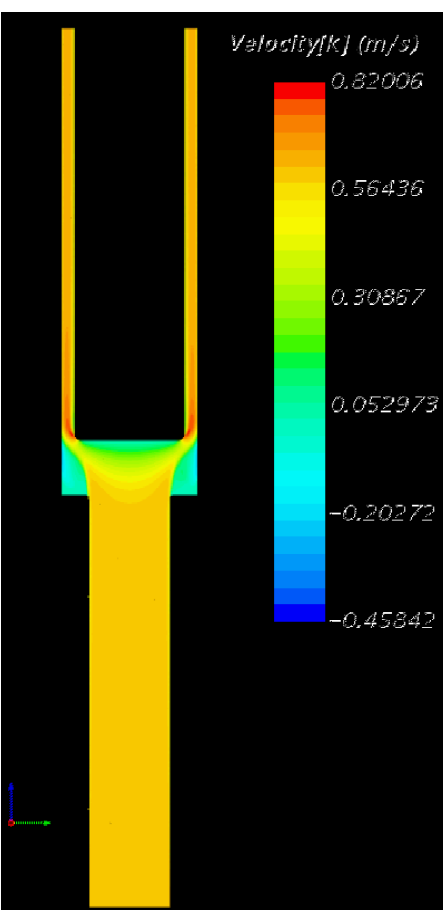

(C) $\mathrm{R}_{\mathrm{C}, \mathrm{Curv}}=2 \mathrm{~mm}$

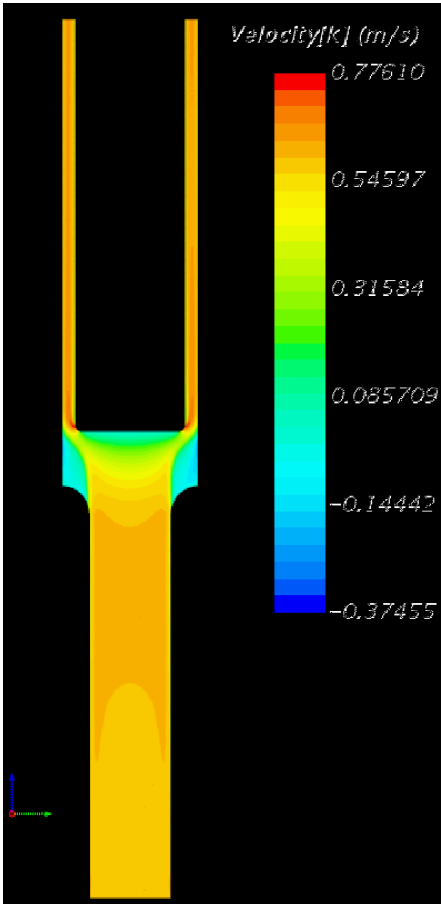

(f) $R_{\mathrm{C}, \text { Curv }}=20 \mathrm{~mm}$

Figure B.6. Velocity distributions on the mid-plane of the channel (Case- $\left.B, \operatorname{Re}_{D}=1 \times 10^{5}\right)$. 
Rev. 1

Title: $\quad$ Computational Evaluation on Effect of Edge-rounding in Duct with Cross-section varying from Circle to Annulus

ECAR No:

5067

Rev. No.: 0

Project No.:

32833

Date: TBD

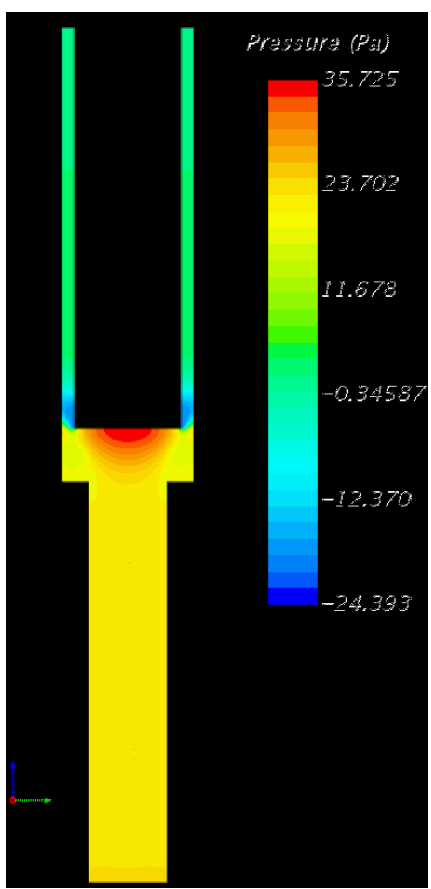

(a) $R_{A, C u r v}=0 m m$

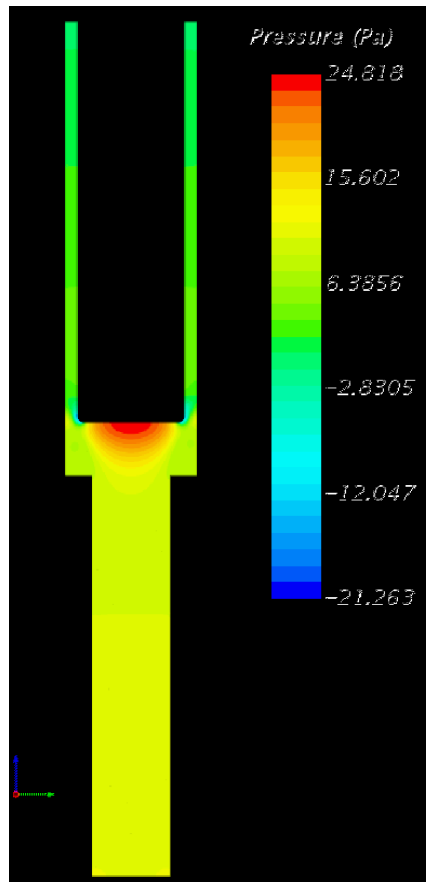

(d) $\mathrm{R}_{\mathrm{A}, \mathrm{Curv}}=5 \mathrm{~mm}$

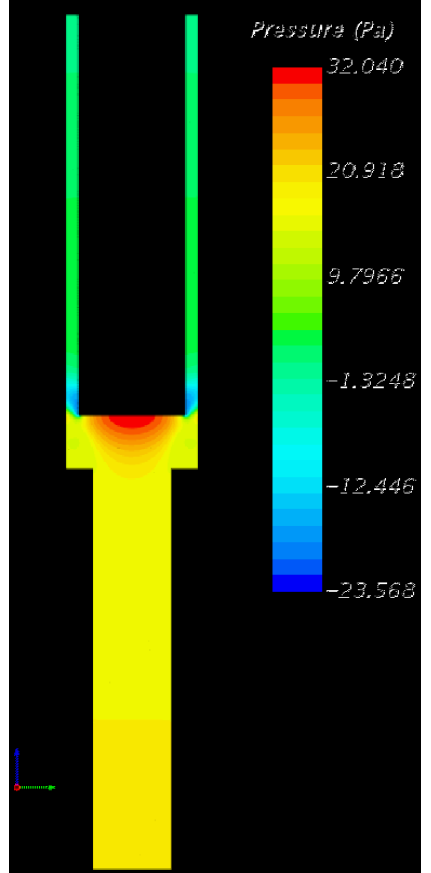

(b) $R_{\mathrm{A}, \text { Curv }}=1 \mathrm{~mm}$

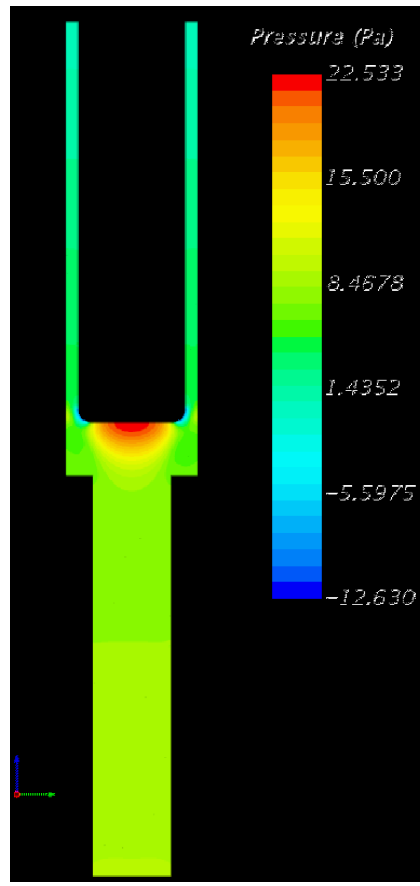

(e) $\mathrm{R}_{\mathrm{A}, \text { Curv }}=10 \mathrm{~mm}$

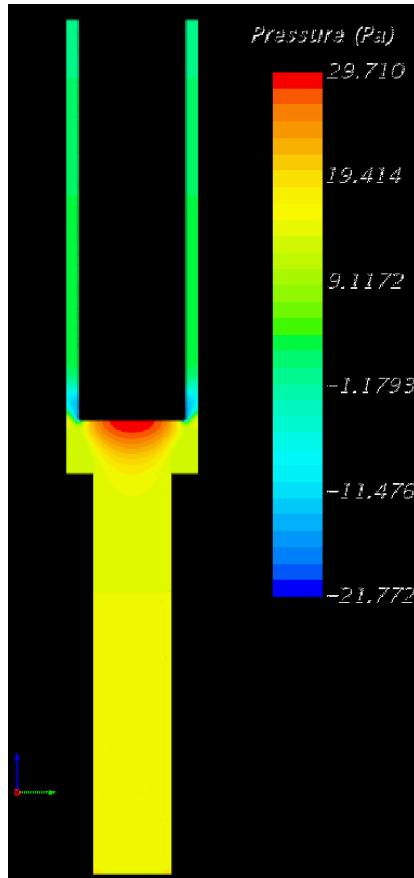

(C) $\mathrm{R}_{\mathrm{A}, \text { Curv }}=2 \mathrm{~mm}$

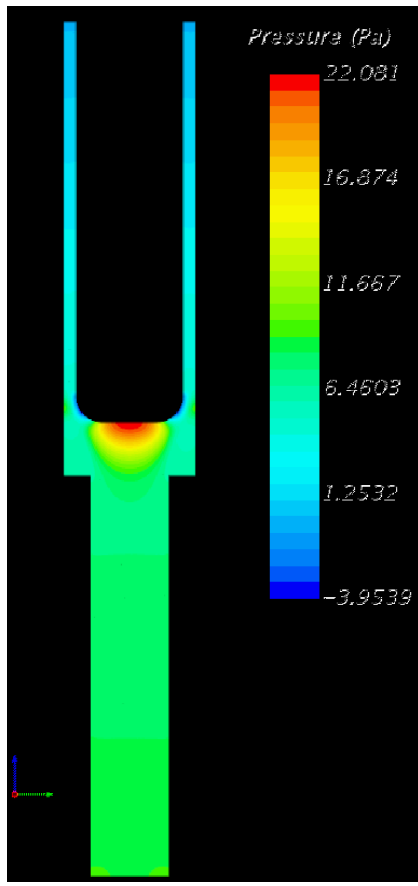

(f) $\mathrm{R}_{\mathrm{A}, \mathrm{Curv}}=20 \mathrm{~mm}$

Figure C.1. Pressure distributions on the mid-plane of the channel (Case-A, $R e_{D}=3 \times 10^{4}$ ). 
Title: $\quad$ Computational Evaluation on Effect of Edge-rounding in Duct with Cross-section varying from Circle to Annulus

ECAR No:

Project No.:

32833

Date: TBD

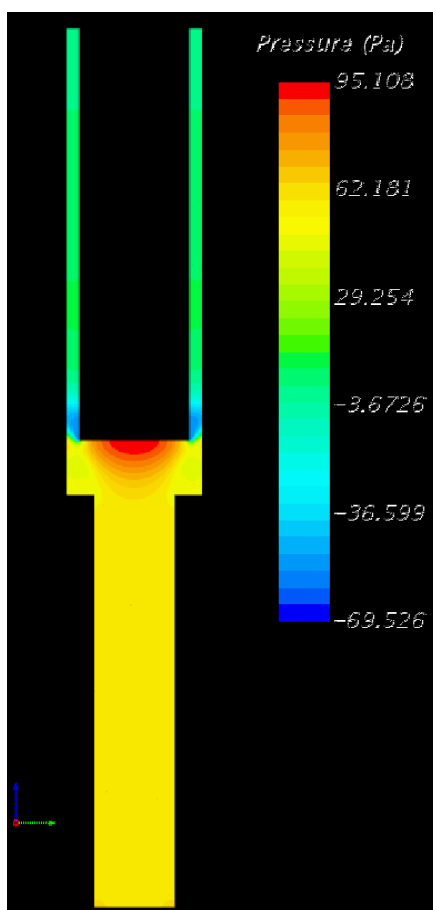

(a) $\mathrm{R}_{\mathrm{A}, \mathrm{Curv}}=0 \mathrm{~mm}$

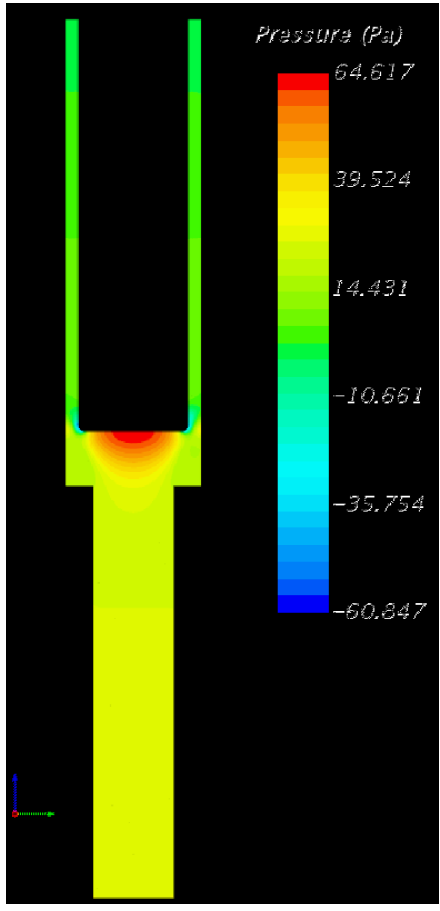

(d) $R_{A, C u r v}=5 \mathrm{~mm}$

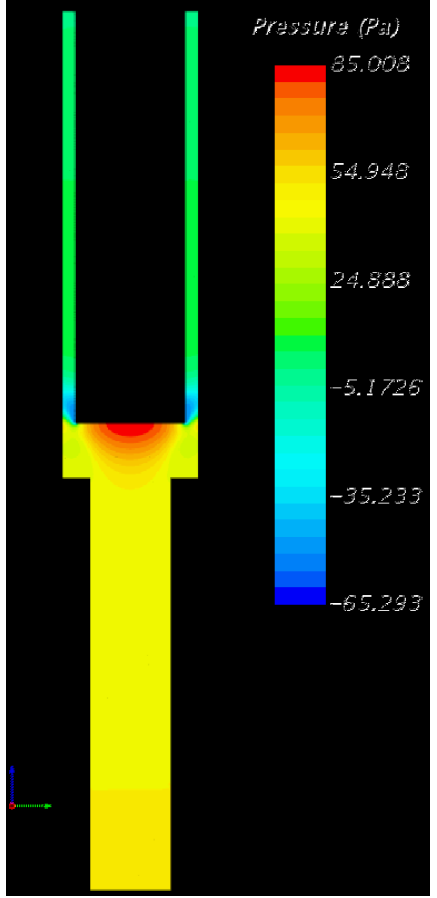

(b) $\mathrm{R}_{\mathrm{A}, \mathrm{Curv}}=1 \mathrm{~mm}$

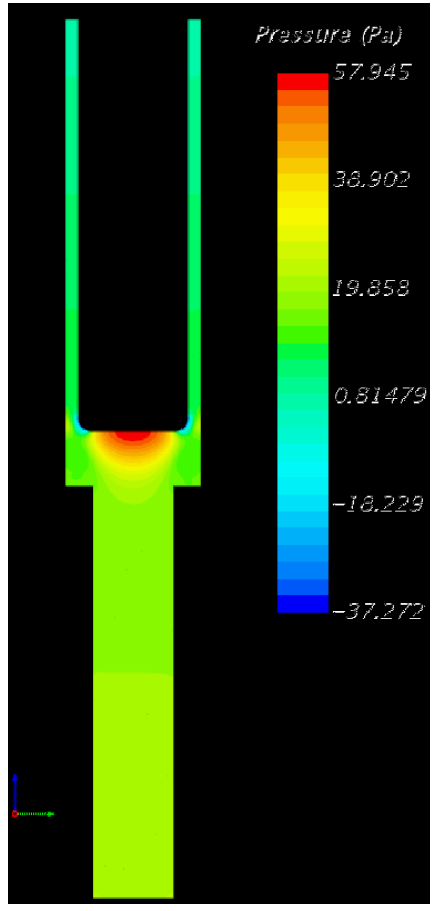

(e) $R_{\mathrm{A}, \text { Curv }}=10 \mathrm{~mm}$

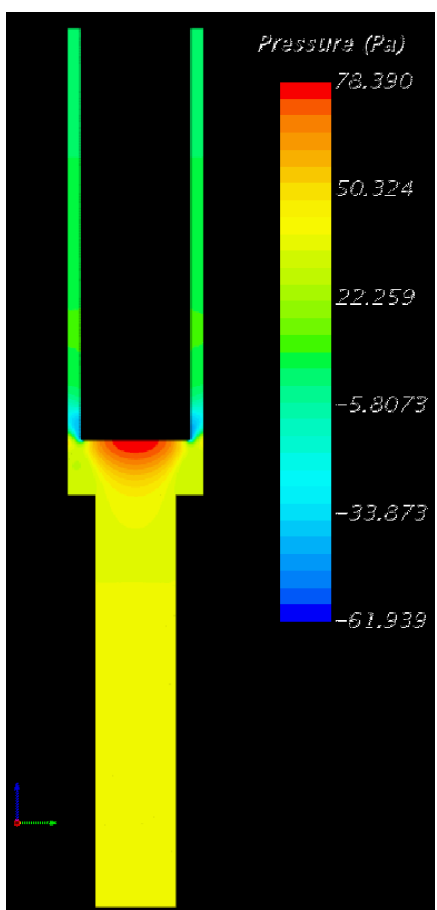

(C) $\mathrm{R}_{\mathrm{A}, \text { Curv }}=2 \mathrm{~mm}$

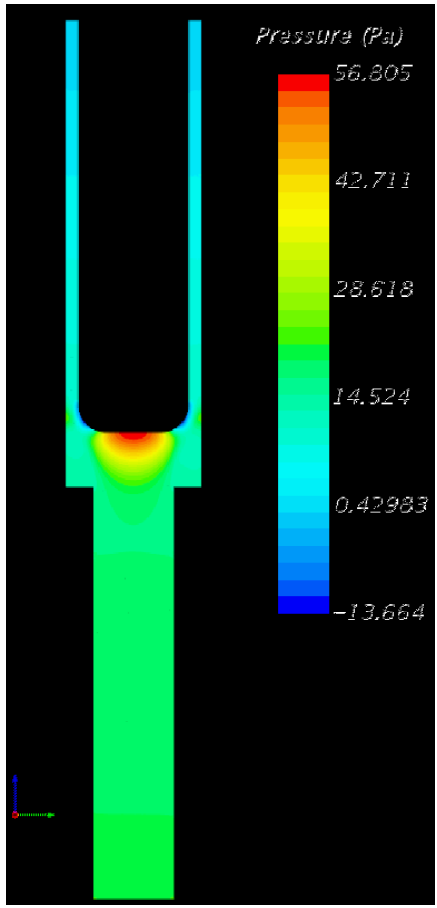

(f) $R_{A, \text { Curv }}=20 \mathrm{~mm}$

Figure C.2. Pressure distributions on the mid-plane of the channel (Case-A, $\operatorname{Re}_{D}=5 \times 10^{4}$ 
Title: $\quad$ Computational Evaluation on Effect of Edge-rounding in Duct with Cross-section varying from Circle to Annulus

ECAR No:

Project No.:

32833

Date: TBD

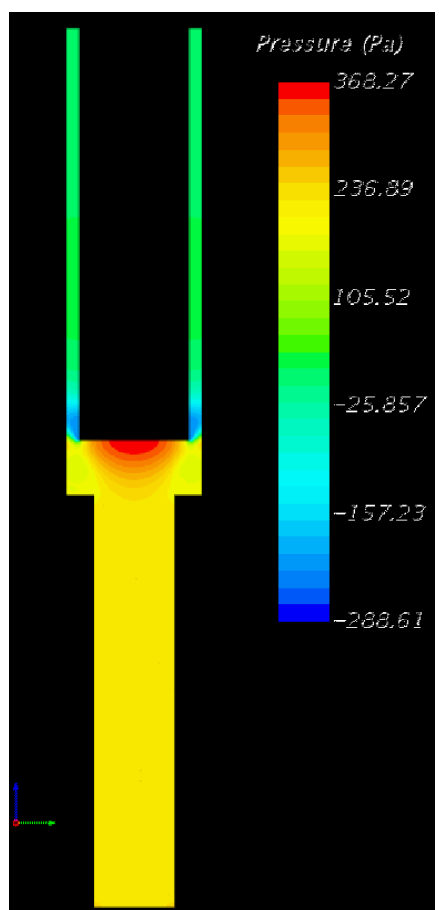

(a) $\mathrm{R}_{\mathrm{A}, \mathrm{Curv}}=0 \mathrm{~mm}$

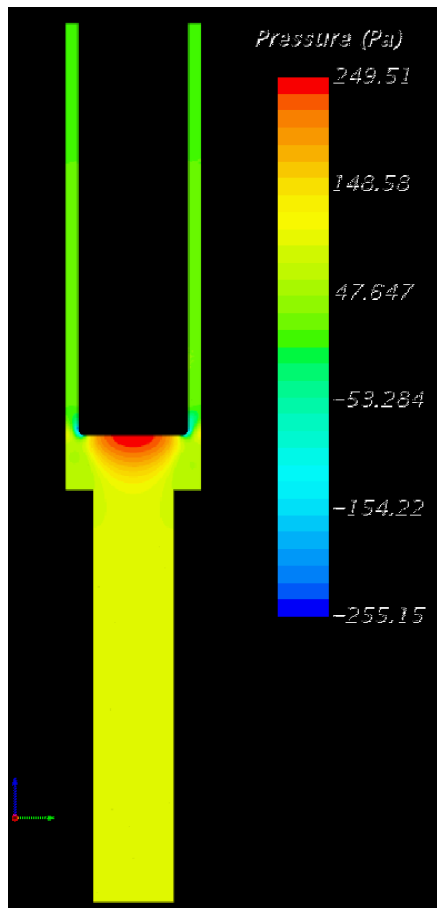

(d) $R_{A, C u r v}=5 \mathrm{~mm}$

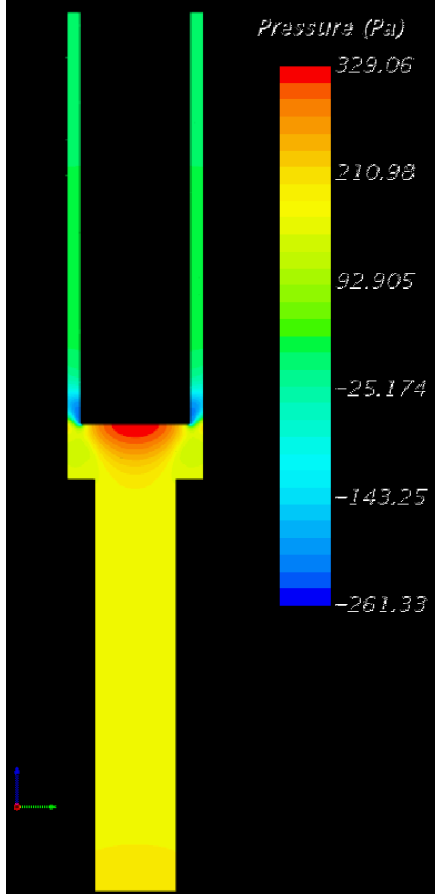

(b) $R_{A, \text { Curv }}=1 \mathrm{~mm}$

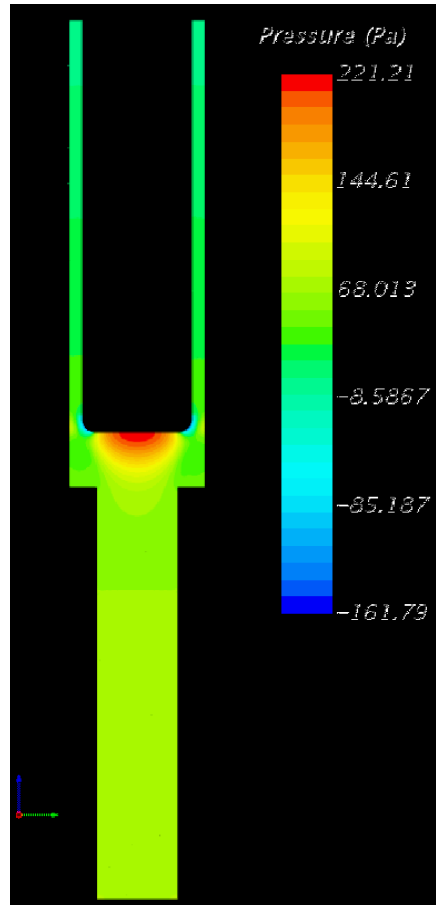

(e) $R_{\mathrm{A}, \text { Curv }}=10 \mathrm{~mm}$

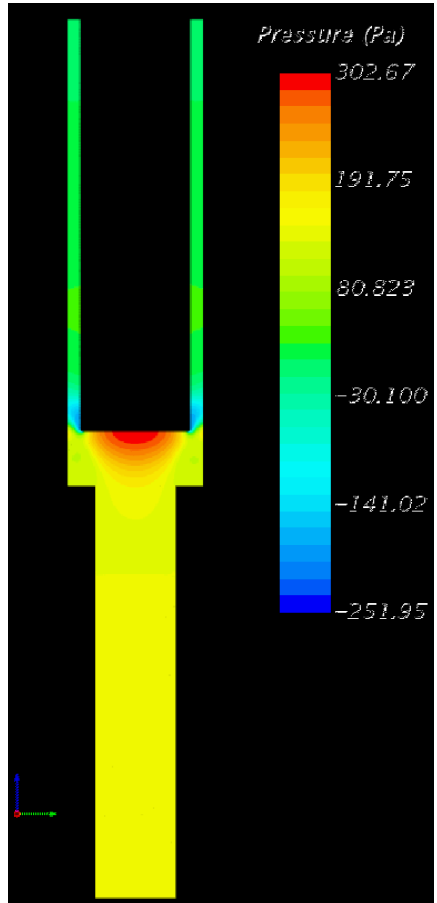

(C) $\mathrm{R}_{\mathrm{A}, \text { Curv }}=2 \mathrm{~mm}$

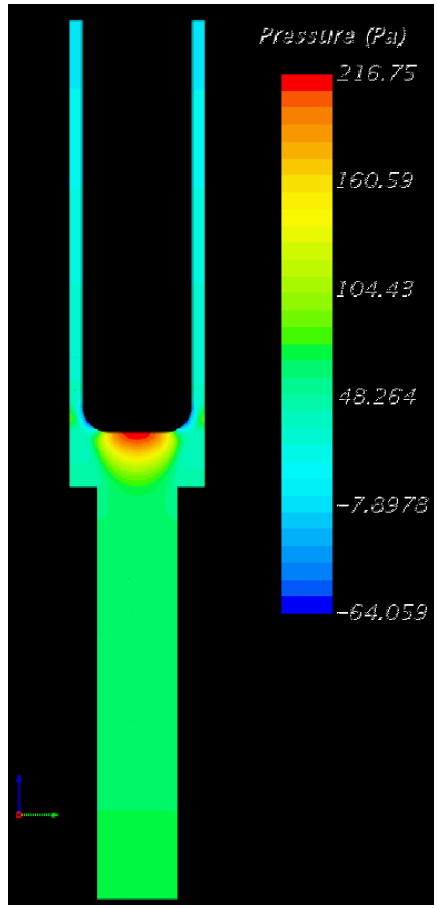

(f) $R_{A, \text { Curv }}=20 \mathrm{~mm}$

Figure C.3. Pressure distributions on the mid-plane of the channel (Case-A, $R e_{D}=1 \times 10^{5}$ ). 
Title: $\quad$ Computational Evaluation on Effect of Edge-rounding in Duct with Cross-section varying from Circle to Annulus

ECAR No:

5067

Rev. No.: 0

Project No.:

32833

Date: TBD

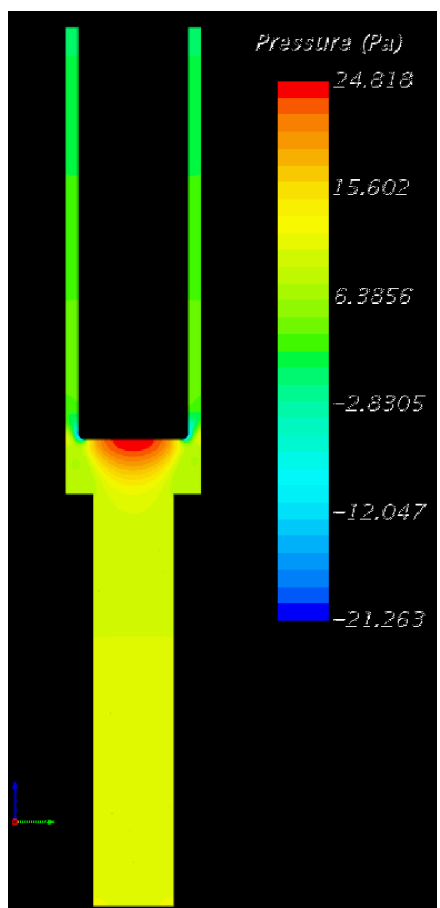

(a) $R_{c, \text { Curv }}=0 \mathrm{~mm}$ (Case-A)

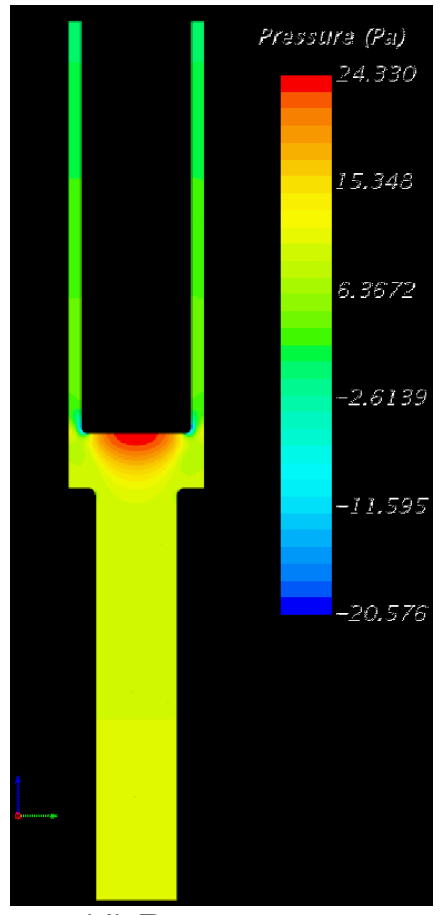

(d) $R_{\mathrm{C}, \text { Curv }}=5 \mathrm{~mm}$

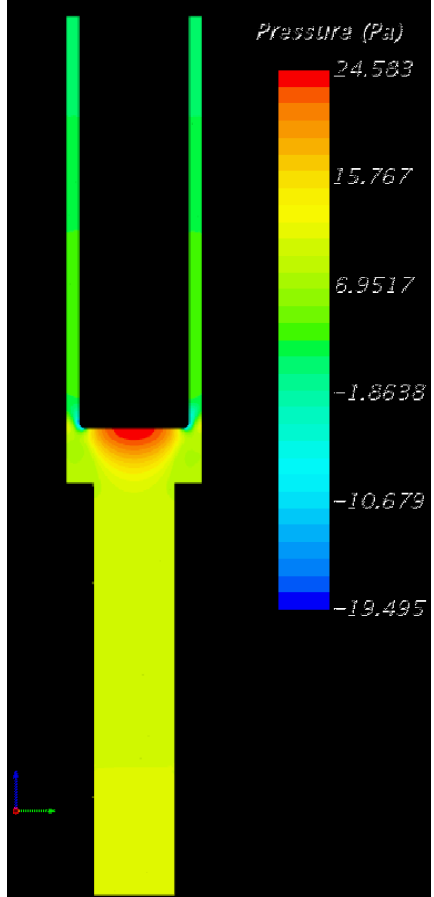

(b) $R_{\mathrm{C}, \text { Curv }}=1 \mathrm{~mm}$

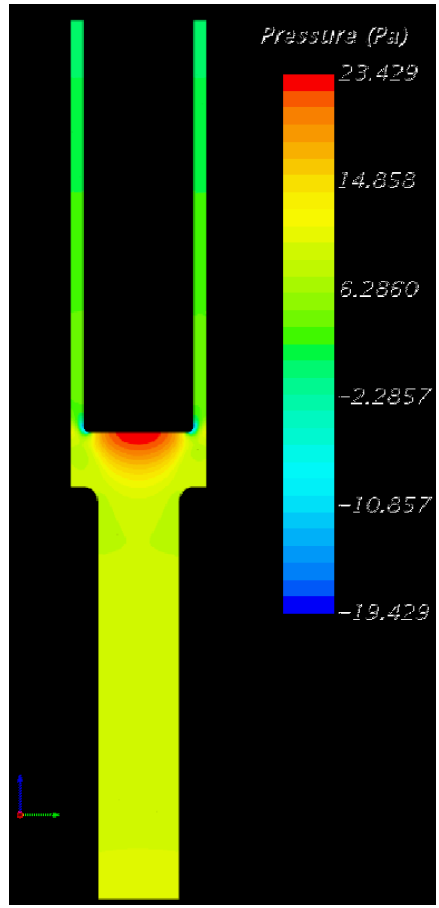

(e) $R_{\mathrm{c}, \text { Curv }}=10 \mathrm{~mm}$

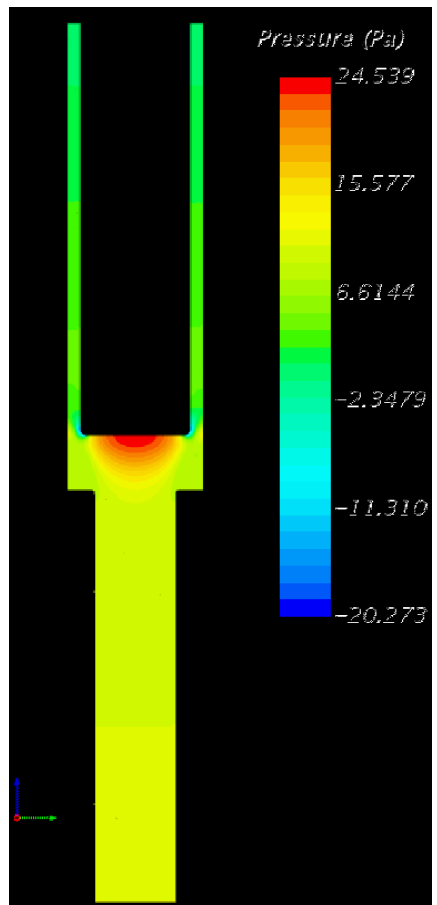

(C) $\mathrm{R}_{\mathrm{C}, \mathrm{Curv}}=2 \mathrm{~mm}$

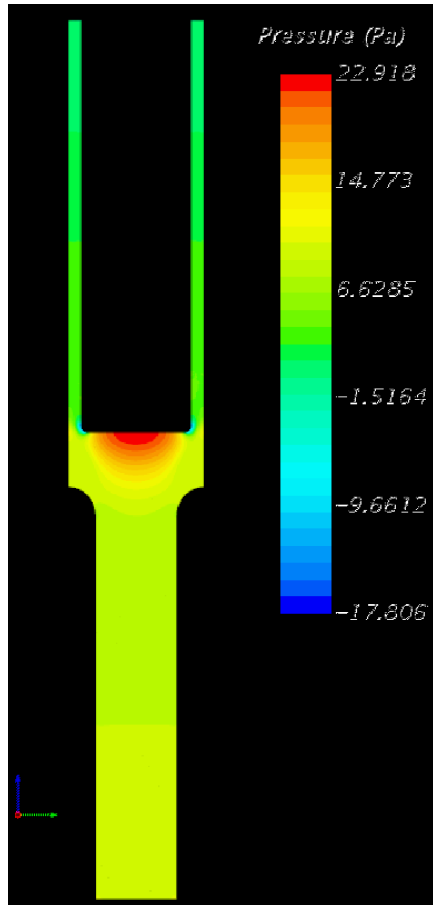

(f) $R_{\mathrm{C}, \text { Curv }}=20 \mathrm{~mm}$

Figure C.4. Pressure distributions on the mid-plane of the channel (Case-B, $R e_{D}=3 \times 10^{4}$ ). 
Title: $\quad$ Computational Evaluation on Effect of Edge-rounding in Duct with Cross-section varying from Circle to Annulus

ECAR No:

5067

Rev. No.: 0

Project No.:

32833

Date: TBD

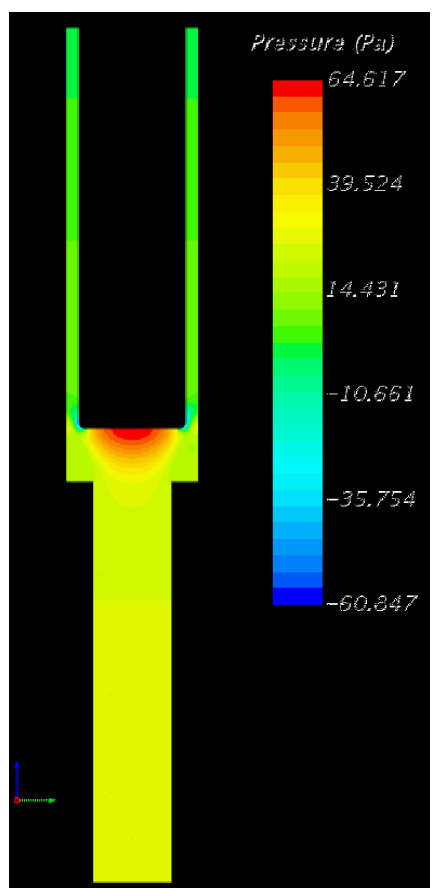

(a) $R_{c, \text { Curv }}=0 \mathrm{~mm}($ Case-A)

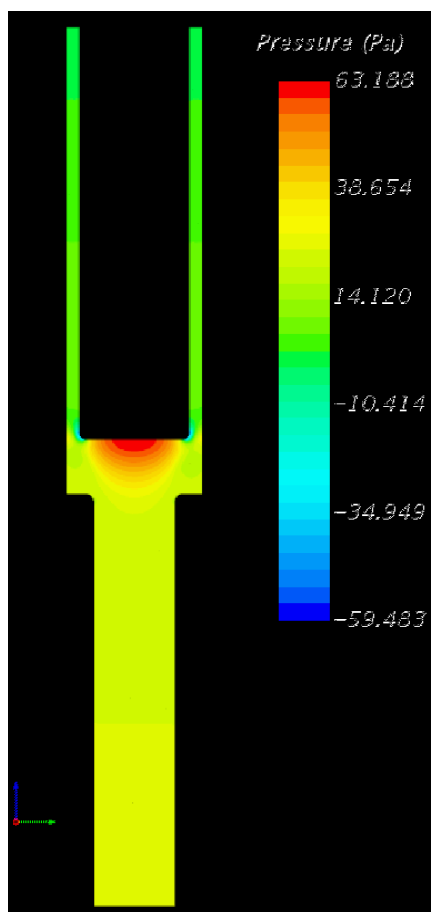

(d) $R_{\mathrm{C}, \text { Curv }}=5 \mathrm{~mm}$

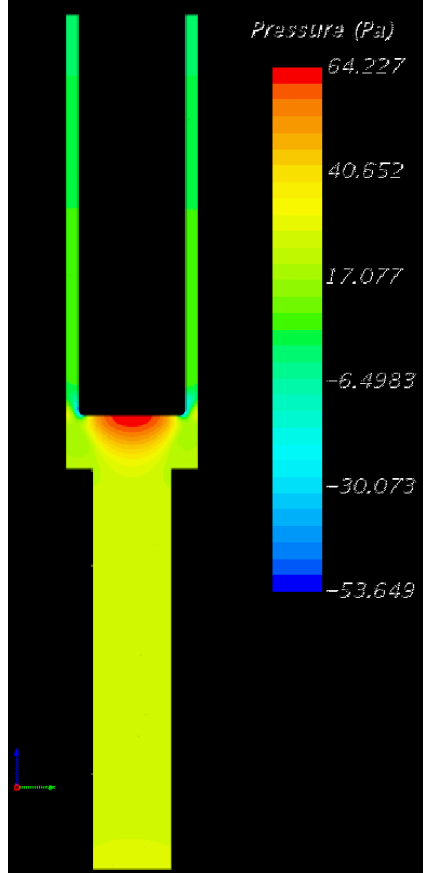

(b) $R_{\mathrm{c}, \text { Curv }}=1 \mathrm{~mm}$

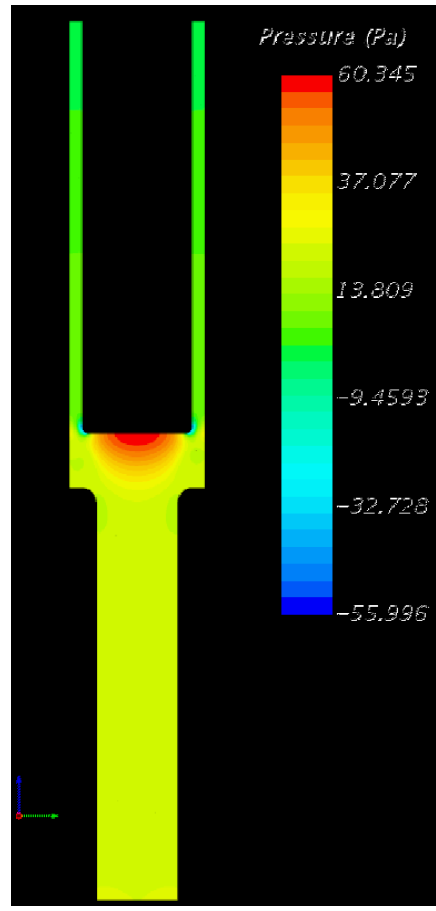

(e) $R_{c, \text { Curv }}=10 \mathrm{~mm}$

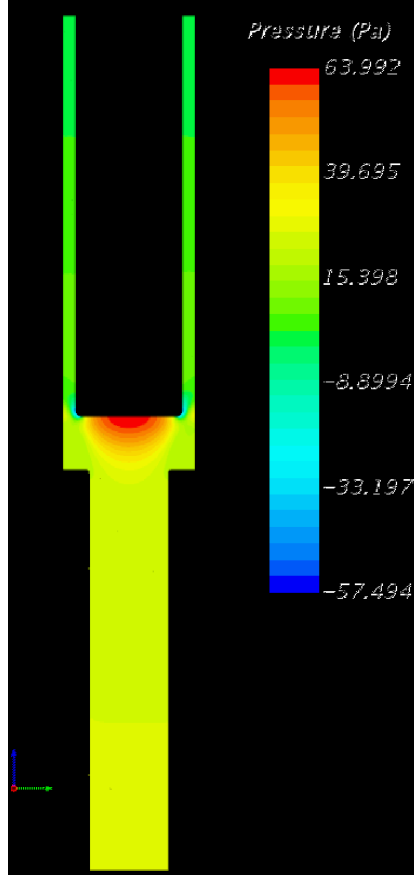

(c) $R_{C, \text { Curv }}=2 \mathrm{~mm}$

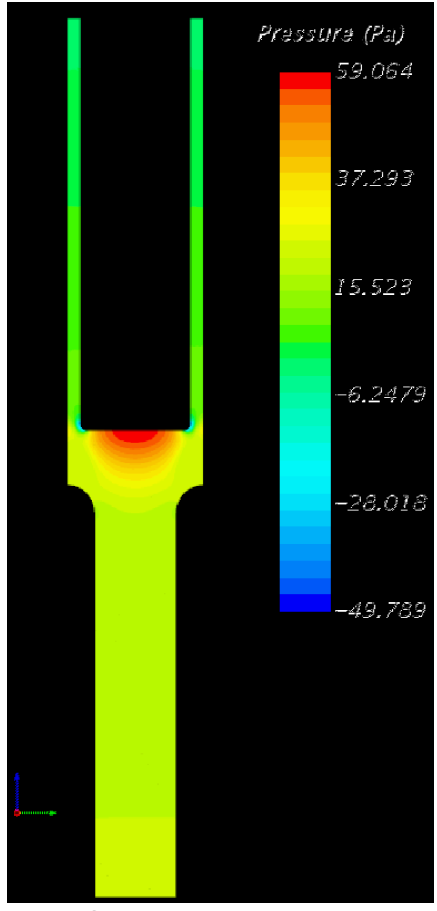

(f) $R_{\mathrm{C}, \text { Curv }}=20 \mathrm{~mm}$

Figure C.5. Pressure distributions on the mid-plane of the channel (Case-B, $R e_{D}=5 \times 10^{4}$ ) 
Title: $\quad$ Computational Evaluation on Effect of Edge-rounding in Duct with Cross-section varying from Circle to Annulus

ECAR No:

5067

Rev. No.: 0

Project No.:

32833

Date: TBD

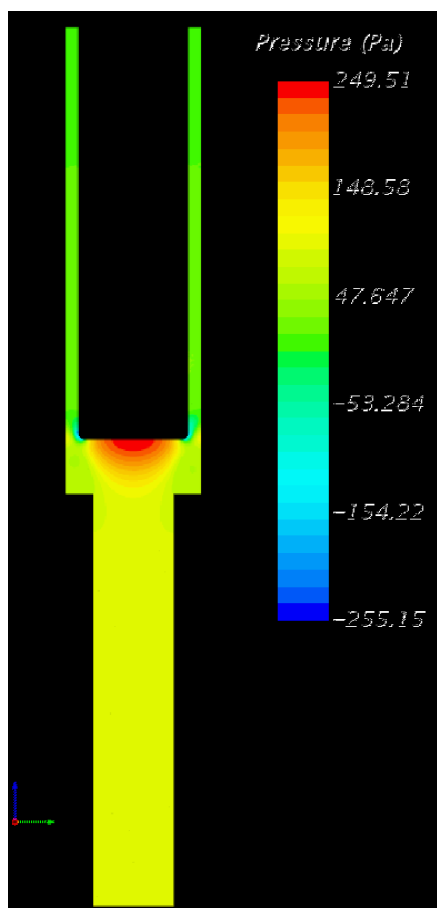

(a) $R_{c, \text { Curv }}=0 \mathrm{~mm}$ (Case-A)

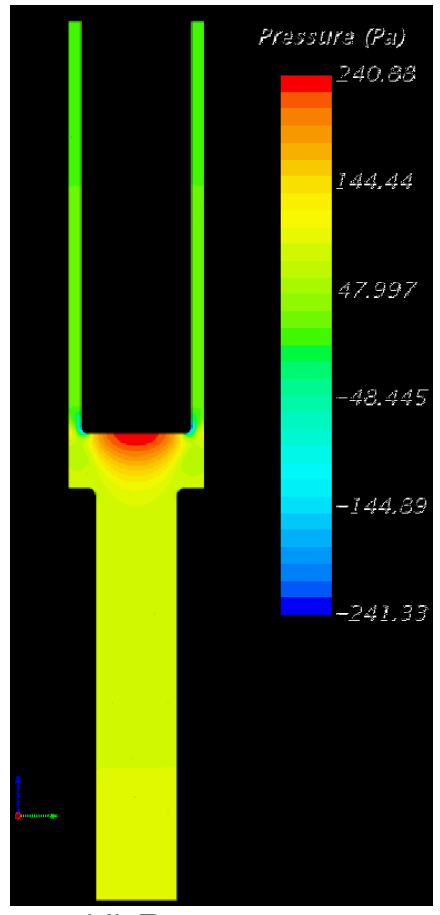

(d) $R_{\mathrm{C}, \text { Curv }}=5 \mathrm{~mm}$

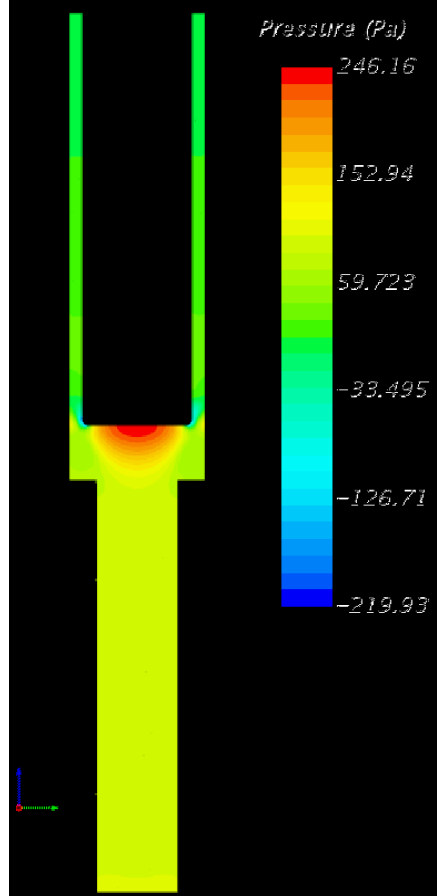

(b) $R_{\mathrm{c}, \text { Curv }}=1 \mathrm{~mm}$

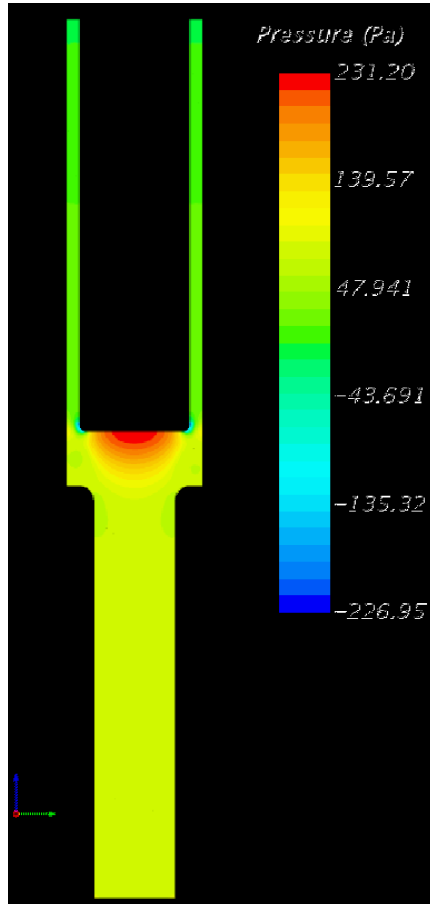

(e) $R_{\mathrm{c}, \text { Curv }}=10 \mathrm{~mm}$

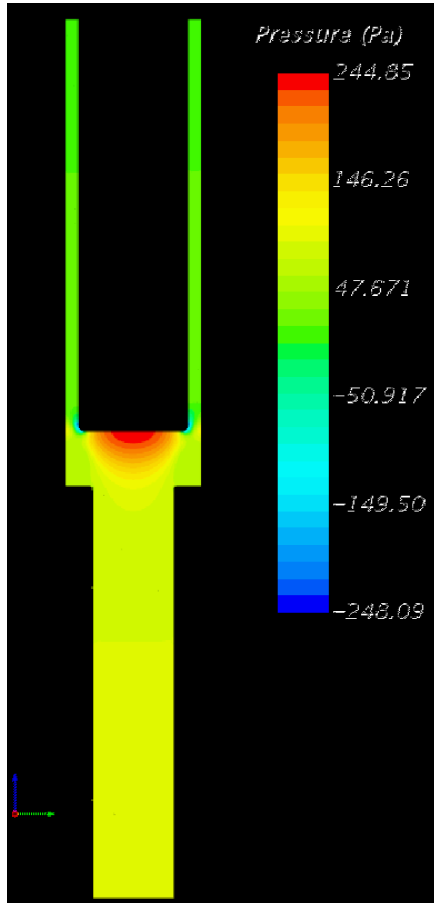

(c) $R_{C, \text { Curv }}=2 \mathrm{~mm}$

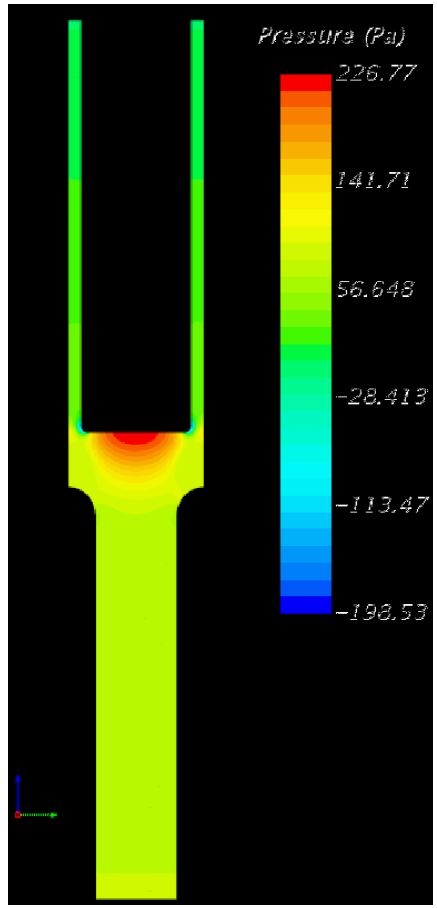

(f) $R_{\mathrm{C}, \mathrm{Curv}}=20 \mathrm{~mm}$

Figure C.6. Pressure distributions on the mid-plane of the channel (Case-B, $\left.R e_{D}=1 \times 10^{5}\right)$. 
TEM-326

$01 / 07 / 19$

Rev. 1

Title: $\quad$ Computational Evaluation on Effect of Edge-rounding in Duct with Cross-section varying from Circle to Annulus

ECAR No.

5067

Rev. No.: 0

Project No.: 32833

Date: TBD

\section{Appendix D. THE STAR-CCM+ PRESSURE DROP RESULTS}

Table D.1. CFD Results of Pressure Drop (Case-A)

\begin{tabular}{|c|r|r|r|r|r|r|r|}
\hline \multicolumn{1}{|l|}{ Case-A } & \multicolumn{7}{|c|}{ Pressure drop (Pa) } \\
\hline $\begin{array}{c}\text { Re number } \\
\mathrm{R}_{\mathrm{A}, \text { Curv }}(\mathrm{mm})\end{array}$ & $2.00 \mathrm{E}+04$ & $3.00 \mathrm{E}+04$ & $4.00 \mathrm{E}+04$ & $5.00 \mathrm{E}+04$ & $7.50 \mathrm{E}+04$ & $1.00 \mathrm{E}+05$ & $2.12 \mathrm{E}+06$ \\
\hline 0 & 10.22 & 21.21 & 36.18 & 55.54 & 121.76 & 212.16 & 88961.72 \\
\hline 1 & 8.54 & 17.52 & 29.70 & 45.49 & 99.48 & 173.06 & 54486.27 \\
\hline 2 & 7.51 & 15.19 & 25.57 & 38.91 & 84.99 & 146.72 & 46879.34 \\
\hline 5 & 5.34 & 10.36 & 16.98 & 25.40 & 54.36 & 94.16 & 24252.13 \\
\hline 10 & 4.37 & 8.07 & 12.78 & 18.69 & 39.55 & 65.92 & 20355.14 \\
\hline 20 & 4.12 & 7.63 & 11.95 & 17.54 & 36.93 & 61.28 & 19973.94 \\
\hline
\end{tabular}

Table D.2. CFD Results of Pressure Drop (Case-B)

\begin{tabular}{|c|c|c|c|c|c|c|c|}
\hline Case-B & \multicolumn{7}{|c|}{ Pressure drop $(\mathrm{Pa})$} \\
\hline $\begin{array}{l}\text { Re number } \\
R_{c, \text { Curv }}(\mathrm{mm}) \\
\end{array}$ & $2.00 E+04$ & $3.00 E+04$ & $4.00 E+04$ & $5.00 E+04$ & $7.50 \mathrm{E}+04$ & $1.00 E+05$ & $2.12 E+06$ \\
\hline 0 & 5.34 & 10.36 & 16.98 & 25.40 & 54.36 & 94.16 & 24252.13 \\
\hline 1 & 5.29 & 10.13 & 16.52 & 24.91 & 53.75 & 90.79 & 22735.15 \\
\hline 2 & 5.23 & 10.07 & 16.34 & 24.75 & 53.50 & 89.33 & 22277.10 \\
\hline 5 & 5.13 & 9.87 & 15.87 & 23.88 & 51.57 & 85.19 & 22005.33 \\
\hline 10 & 4.79 & 8.98 & 14.29 & 21.11 & 45.69 & 75.74 & 20717.10 \\
\hline 20 & 4.60 & 8.46 & 13.34 & 19.81 & 42.15 & 71.55 & 20188.43 \\
\hline
\end{tabular}


Title:

Computational Evaluation on Effect of Edge-rounding in Duct with Cross-section varying from Circle to Annulus

ECAR No::

5067

Rev. No.: 0

Project No.:

32833

Date: TBD

\section{Appendix E. NEK5000 AVERAGED VELOCITY AND PRESSURE} DISTRIBUTIONS

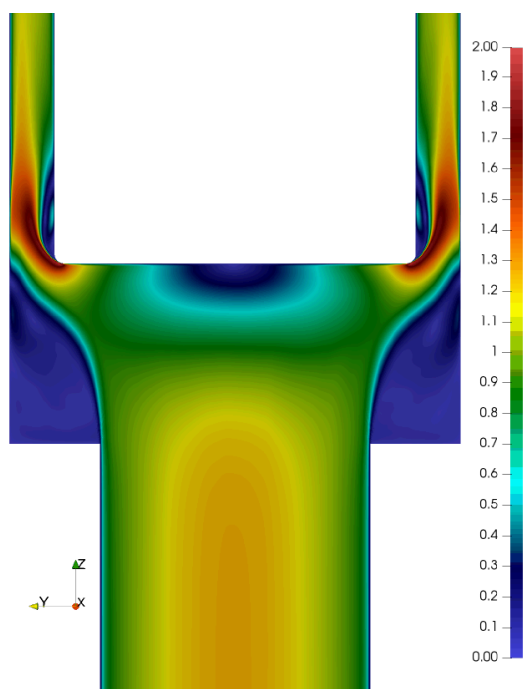

(a) $R_{c}=0 \mathrm{~mm}, \mathrm{R}_{\mathrm{a}}=2 \mathrm{~mm}$

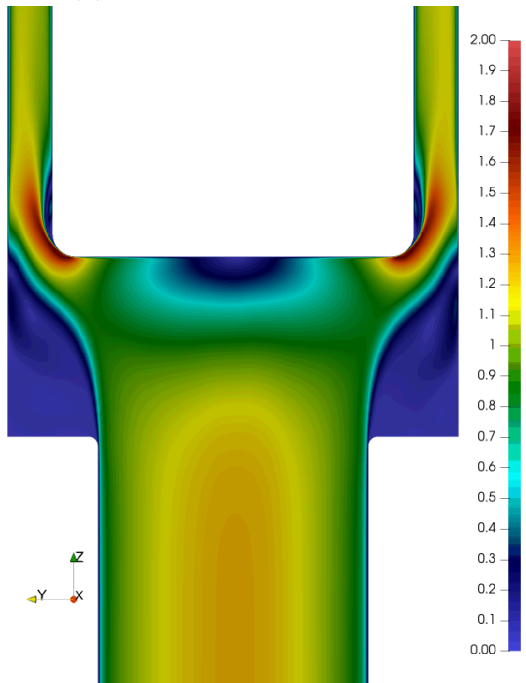

(d) $\mathrm{R}_{\mathrm{c}}=2 \mathrm{~mm}, \mathrm{R}_{\mathrm{a}}=5 \mathrm{~mm}$

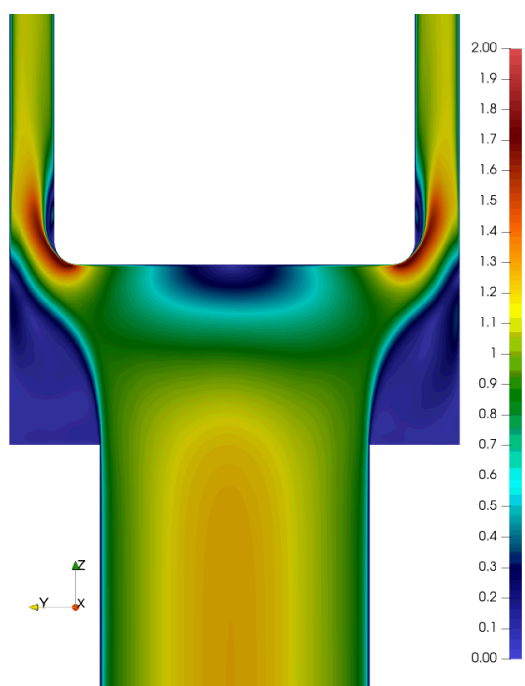

(b) $\mathrm{R}_{\mathrm{c}}=0 \mathrm{~mm}, \mathrm{R}_{\mathrm{a}}=5 \mathrm{~mm}$

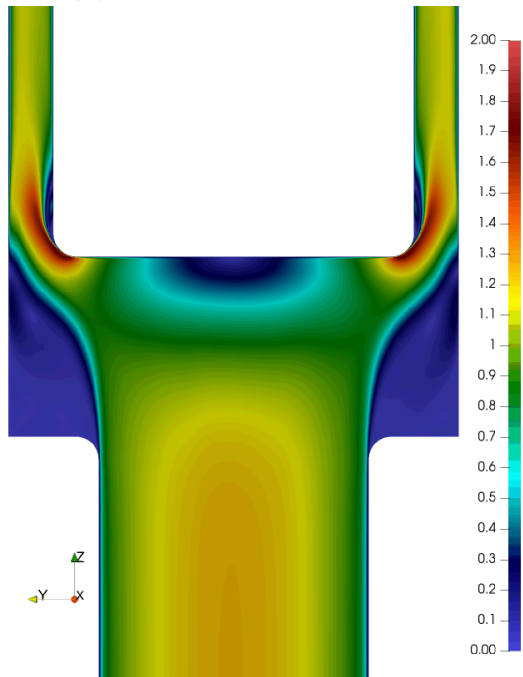

(e) $\mathrm{R}_{\mathrm{c}}=5 \mathrm{~mm}, \mathrm{R}_{\mathrm{a}}=5 \mathrm{~mm}$

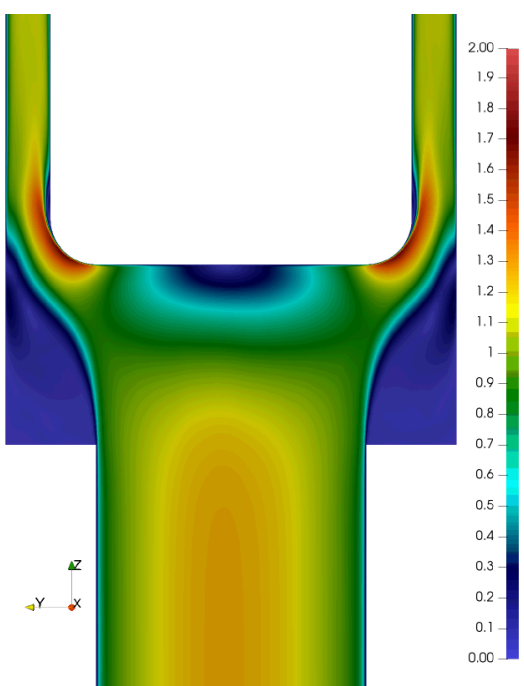

(c) $\mathrm{R}_{\mathrm{c}}=0 \mathrm{~mm}, \mathrm{R}_{\mathrm{a}}=10 \mathrm{~mm}$

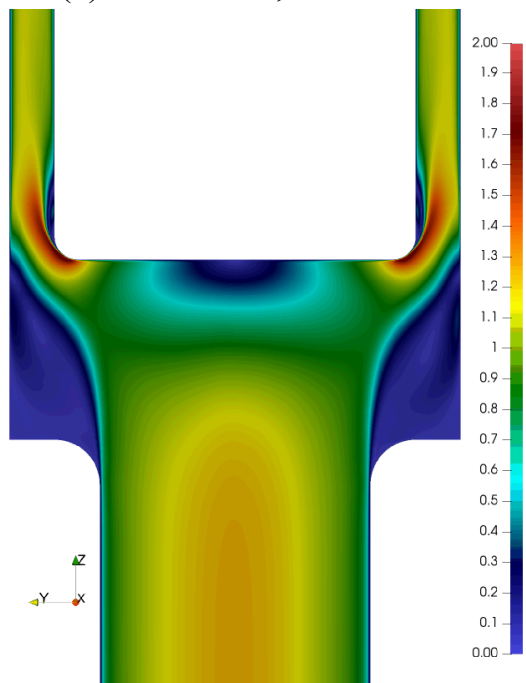

(f) $R_{c}=10 \mathrm{~mm}, R_{a}=5 \mathrm{~mm}$

Figure E.1. Time-averaged velocity magnitude distributions across a midplane slice through the transition region at $\mathrm{Re}=20,000$ for different edge radii. 
Title:

Computational Evaluation on Effect of Edge-rounding in Duct with Cross-section varying from Circle to Annulus

ECAR No.:

5067

Rev. No.: 0

Project No.:

32833

Date: TBD

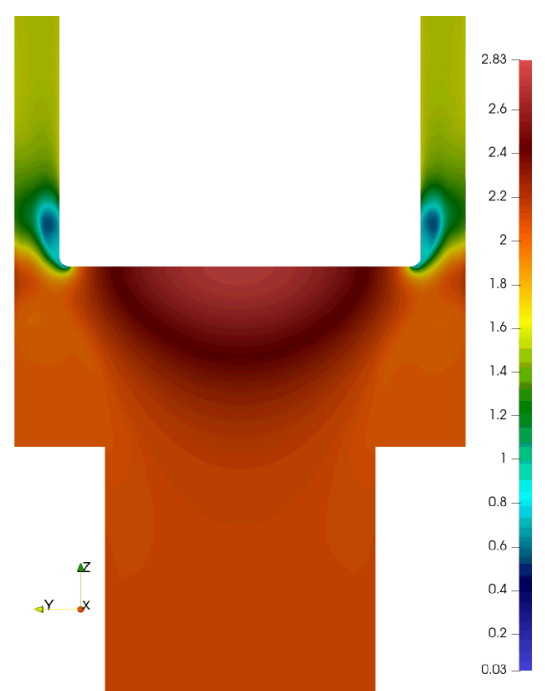

(a) $R_{c}=0 \mathrm{~mm}, R_{a}=2 \mathrm{~mm}$

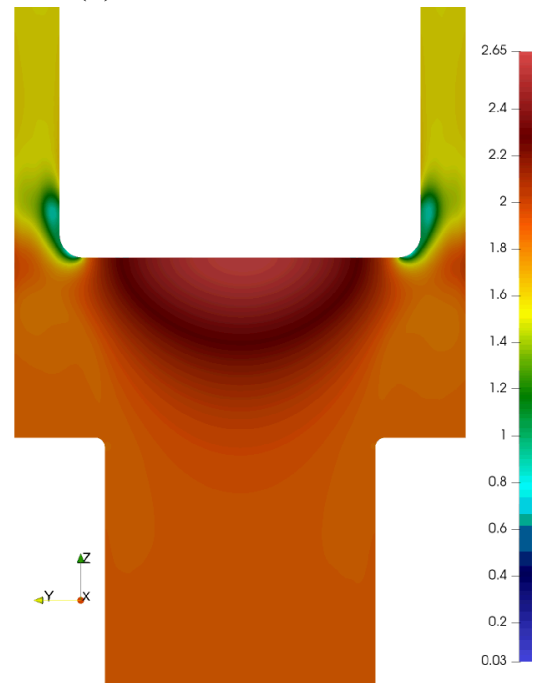

(d) $\mathrm{R}_{\mathrm{c}}=2 \mathrm{~mm}, \mathrm{R}_{\mathrm{a}}=5 \mathrm{~mm}$

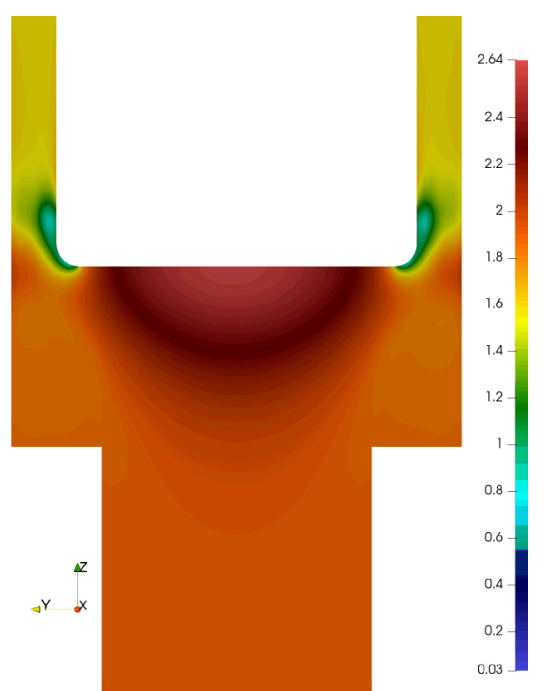

(b) $\mathrm{R}_{\mathrm{c}}=0 \mathrm{~mm}, \mathrm{R}_{\mathrm{a}}=5 \mathrm{~mm}$

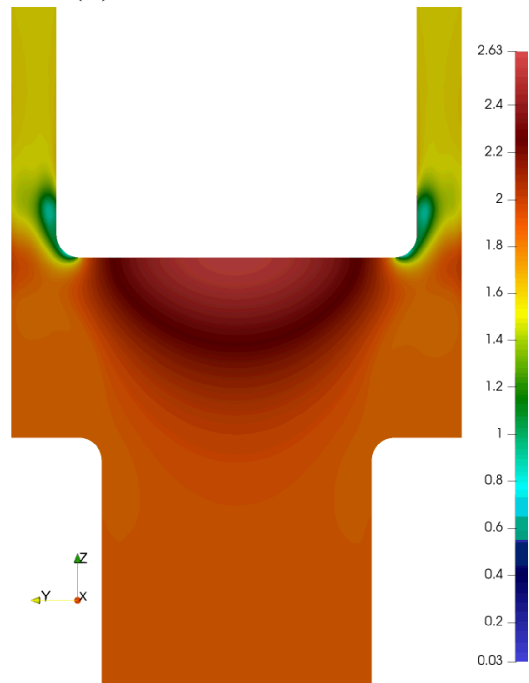

(e) $\mathrm{R}_{\mathrm{c}}=5 \mathrm{~mm}, \mathrm{R}_{\mathrm{a}}=5 \mathrm{~mm}$

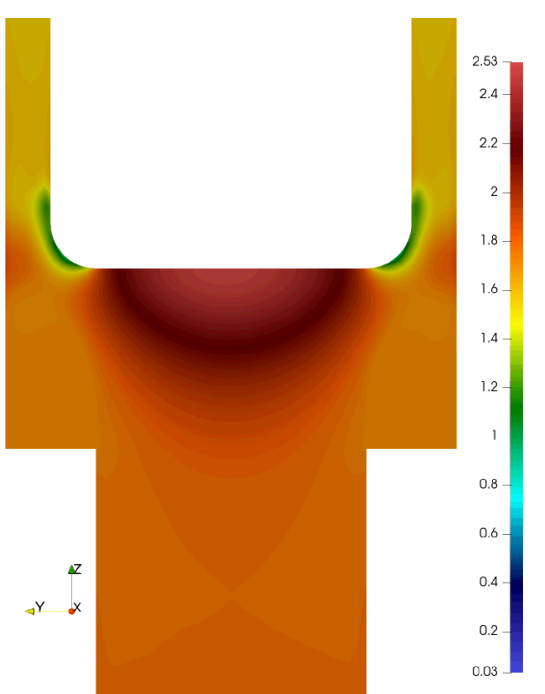

(c) $\mathrm{R}_{\mathrm{c}}=0 \mathrm{~mm}, \mathrm{R}_{\mathrm{a}}=10 \mathrm{~mm}$

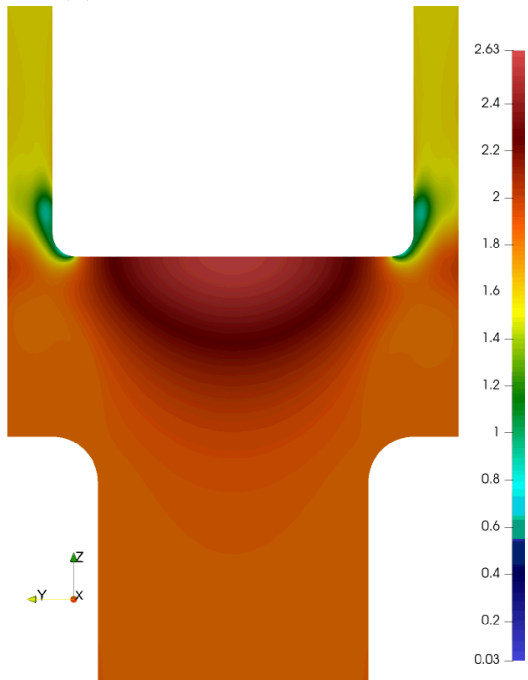

(f) $R_{c}=10 \mathrm{~mm}, R_{a}=5 \mathrm{~mm}$

Figure E.2. Time-averaged pressure distributions across a midplane slice through the transition region at $\mathrm{Re}=20,000$ for different edge radii. 